\title{
Fire Modeling of the Heiss \\ Dampf Reaktor Containment
}

Manuseript Completed: August 1995

Date Published: September 1995

Prepared by

V. F. Nicolette

Sandla National Laboratories

Albuquerque, NM 87185-10835

K.T. Yang

University of Notre Dame

Notre Darae, IN 46556

W. Gleaves, NRC Project Manager

\author{
Prepared for \\ Division of Engineering Technology \\ Office of Nuclear Regulatory Research \\ US. Nuclear Regulatory Commission \\ Washington, DC 20555-0001 \\ NRC Joh Code L1330
}




\section{MiREG/CR-6017 has been reproduced}

frol the best avallable copy. 


\section{DISCLAIMER}

This report was prepared as an account of work sponsored by an agency of the United States Government. Neither the United States Government nor any agency thereof, nor any of their employees, make any warranty, express or implied, or assumes any legal liabitity or responsibility for the accuracy, completeness, or usefulness of any information, apparatus, product, or process disclosed, or represents that its use would not infringe privately owned rights. Reference herein to any specific commercial product, process, or service by trade name, trademark, manufacturer, or otherwise does not necessarily constitute or imply its endorsement, recommendation, or favoring by the United States Government or any agency thereof. The views and opinions of authors expressed herein do not necessarily state or reflect those of the United States Government or any agency thereot. 


\section{DISCLAIMER}

Portions of this document may be illegible in electronic image products. Images are produced from the best available original document. 


\section{Abstrect}

This report sumarizes Sandia National Laboxatories' particlpation in the fire modeling activities for the German Heiss Dampf Reaktor (HDR) containment building, under the sponsorship of the United states Nuclear Regulatory corutission. The purpose of this report is twofold: 1) to stumarize Sandia's participation in the HDR fire modeling efforts, and 2) to sumberize the results of the international fire modeling community involved in modeling the HDR fire tests.

Calculacions were conducted for an HOR ail flre test using the COMPBR zone model, and the University of Notre Dame fire field model. COMPRR had difficulty stmulating the fixe envixontant beyond the first 4 minutes following ignition due to lnstabilities resulting from high wall, ceiling, and hot gas layer termeratures. The Notre Dane fire model results indicate reasonable (and, in some cases, excallent) agreement with the experimental data. Discrepancies between calculation and experiment are explainable in terms of leakage around the doorway of the fire room.

Calculations were also conducted for an HDR cable Eire test using the COMPBRN model. Results were obtained fot the first 9 minutes of the fire (up to the point at which the door to the Eire room was opened in the text). The strengths of compBRw are seen to be its ability to model the transient ignition and burnsing of cable tray fires in preElashover conpartments.

Aaditional comuents on the state of fire modeling and trends in the international fire modeling comunity are also included. It is noted that although the trend internationally in firte modeling is toward the development of the more complex fire field models. each type of Ifire model bas something to contribute to the understanding of fires in nuclear power plants. 


\section{Table of Contents}

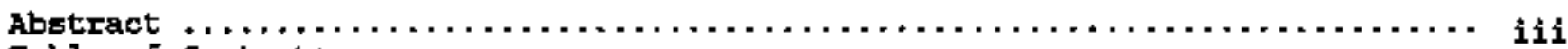

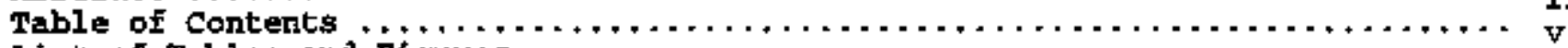

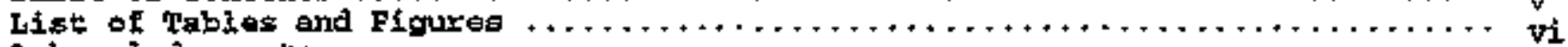

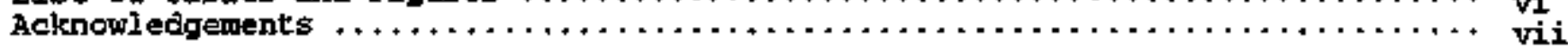

Executive strmaty $\ldots \ldots \ldots \ldots \ldots \ldots \ldots \ldots \ldots \ldots \ldots \ldots \ldots \ldots \ldots \ldots \ldots \ldots \ldots \ldots \ldots \ldots$

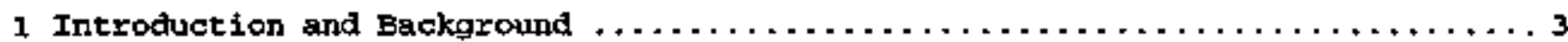

$1.1 \mathrm{HDR}$ Fire Experiments $\ldots \ldots \ldots \ldots+\ldots \ldots \ldots \ldots \ldots \ldots+\ldots \ldots \ldots \ldots \ldots \ldots \ldots$

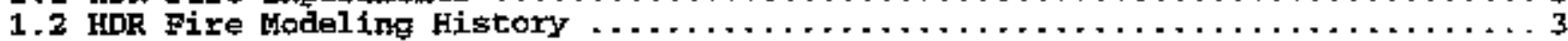

1.3 Sandia's Role in HDR Fire Tests $\ldots \ldots \ldots+\ldots \ldots \ldots \ldots+\ldots \ldots \ldots \ldots \ldots \ldots \ldots \ldots \ldots$

1,4 Brief Overview of pire Hodeling of Nuelear power plants $\ldots \ldots \ldots \ldots \ldots \ldots \ldots \ldots$.

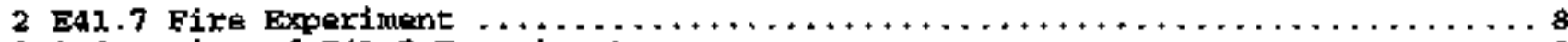

2.1 overview of E41.7 Experiment $\ldots \ldots \ldots \ldots \ldots \ldots \ldots \ldots \ldots \ldots \ldots \ldots \ldots, \ldots \ldots \ldots$

2.2 E41.7 zone Sodel Calculations Using COMPBEN $\ldots \ldots \ldots \ldots \ldots \ldots \ldots \ldots \ldots \ldots \ldots \ldots \ldots+8$

2.2.1 E41.7 COAPBRM Asstmptions and Input $\ldots \ldots \ldots \ldots \ldots \ldots \ldots \ldots \ldots \ldots \ldots \ldots \ldots \ldots$

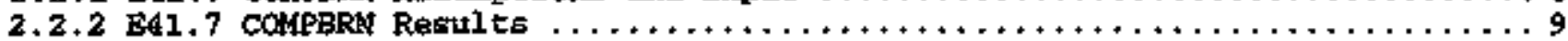

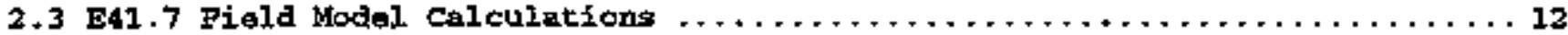

2.3.1 FA1.7 Field Model Assuroptions and Input $\ldots \ldots \ldots \ldots \ldots \ldots \ldots \ldots \ldots \ldots \ldots \ldots \ldots \ldots 13$

2.3 .2 E4t.7 Field Model Results $\ldots \ldots \ldots \ldots \ldots \ldots \ldots \ldots \ldots \ldots \ldots \ldots \ldots+\ldots \ldots \ldots \ldots \ldots 14$

3 E42 2 Fire Experiment $\ldots \ldots \ldots \ldots \ldots+\ldots+\ldots+\ldots \ldots \ldots+\ldots \ldots \ldots \ldots+\ldots+\ldots \ldots \ldots \ldots \ldots \ldots 18$

3.1 overview of E42.2 Experiment $\ldots \ldots \ldots \ldots \ldots \ldots \ldots \ldots \ldots \ldots \ldots \ldots \ldots \ldots \ldots \ldots \ldots+\ldots \ldots \ldots$

3,2 E42.2 zone Model Calculations Using COMPBEN $\ldots+\ldots \ldots \ldots \ldots+\ldots+\ldots \ldots \ldots \ldots \ldots 18$

3.2.1 E4Z.2 COMPBRH Astumgtions and Input $\ldots \ldots \ldots \ldots \ldots \ldots \ldots \ldots \ldots \ldots \ldots+\ldots \ldots+\ldots+18$

3.2 .2 E42.2 CotpgRN Results $\ldots \ldots \ldots \ldots \ldots \ldots \ldots \ldots \ldots \ldots \ldots \ldots \ldots \ldots \ldots \ldots+\ldots+\ldots \ldots 19$

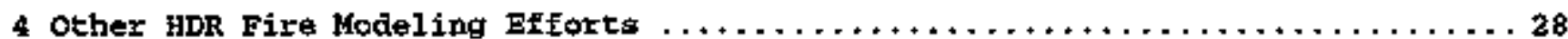

4.1 E41.7 participants $\ldots \ldots \ldots \ldots \ldots \ldots \ldots \ldots \ldots \ldots \ldots \ldots \ldots \ldots \ldots \ldots \ldots \ldots \ldots+\ldots \ldots+28$

4.2 E41.7 Calculations by other Participants $\ldots \ldots \ldots \ldots \ldots \ldots \ldots \ldots+\ldots \ldots \ldots \ldots \ldots 29$

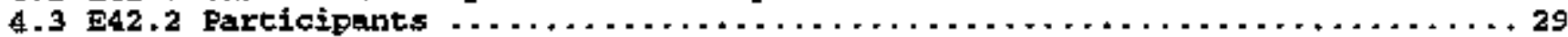

4.4 E42.2 Calculations by other Participants $\ldots \ldots \ldots \ldots \ldots \ldots \ldots \ldots \ldots \ldots \ldots \ldots 31$

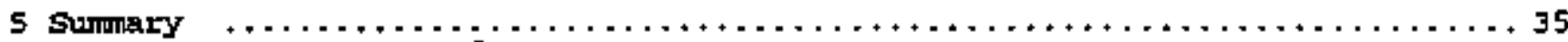

$5.1 \$ 41.7$ Lessons tearned $\ldots \ldots \ldots \ldots \ldots \ldots \ldots \ldots \ldots \ldots \ldots \ldots \ldots \ldots \ldots \ldots \ldots+\ldots \ldots \ldots 35$

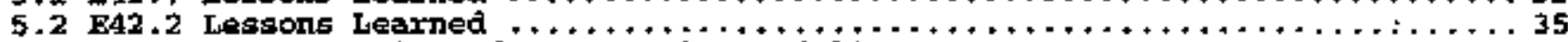

5.3 General observations from toR Fire todeling $\ldots \ldots \ldots \ldots \ldots \ldots \ldots \ldots \ldots \ldots \ldots \ldots 36$

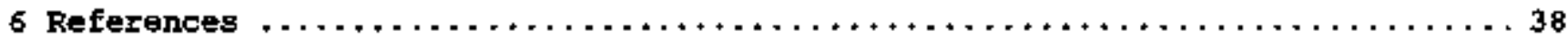

Appendix A: Brief Description of Fire Models Used by Other HDR Participants +.. A-1

Appendix B: University of Notre Dame Field Model Calculations for $\mathrm{HDR}$ teat $\mathrm{E41.7} \ldots \ldots+\ldots \ldots \ldots \ldots \ldots \ldots \ldots \ldots \ldots \ldots \ldots \ldots \ldots \ldots \ldots \ldots, \mathrm{B}-1$

Appendix $c$ : Univerzity of Notre Dame Field Model Calculations for $\operatorname{HDR}$ test $\mathrm{BA1} .5 \ldots \ldots \ldots \ldots \ldots \ldots \ldots \ldots \ldots \ldots \ldots \ldots \ldots \ldots \ldots \ldots, \ldots \ldots \ldots$ 


\section{List of Tables}

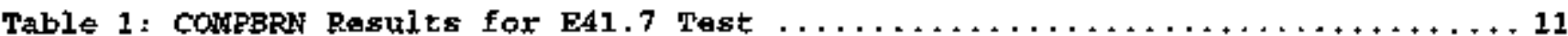

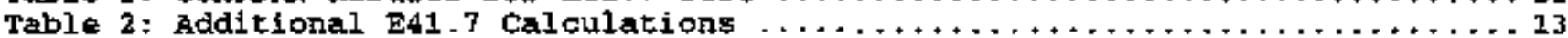

Table 3: Cable Tray Ignition/Temperature $\ldots \ldots \ldots \ldots \ldots \ldots+\ldots+\ldots \ldots \ldots \ldots+\ldots \ldots \ldots+\ldots \ldots 25$

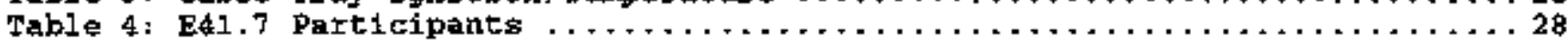

Table 5: HDR E42.2 Calculation Participants

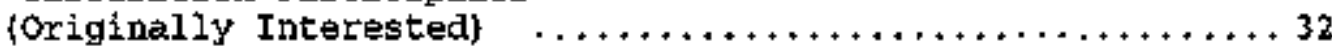

Table 6: Fire Hodels for ISP $\ldots \ldots \ldots \ldots \ldots+\ldots \ldots \ldots \ldots \ldots \ldots$

\section{List of Figures}

Flgure 1: The Hor contginment Building $\ldots \ldots \ldots \ldots \ldots \ldots \ldots$

Flgure 2: zone Fire todel Example . . . . . . . . . . . . . . . . . . . . . .

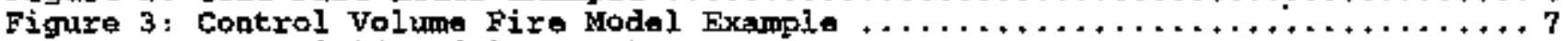

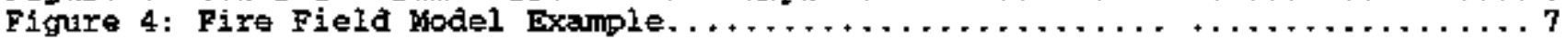

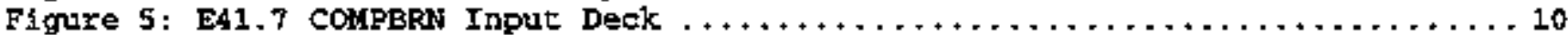

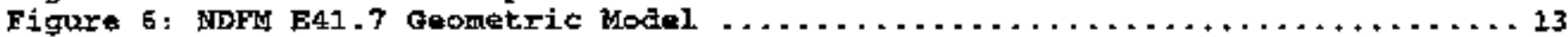

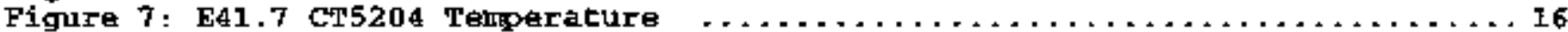

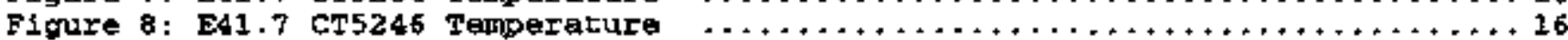

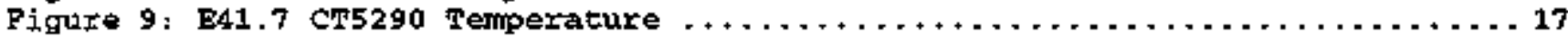

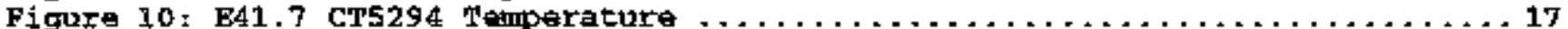

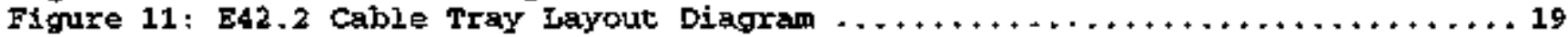

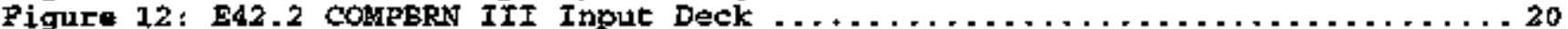

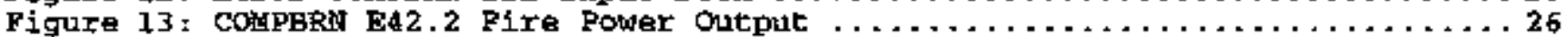

Figure 14: CoMPBRH E42.2 Fire Total Energy output ................... 26

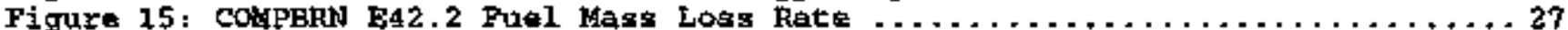

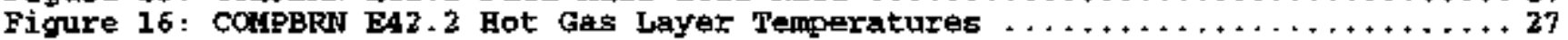

Figure 17; E41.7 Comparison of Hodels to Exgeriment $\ldots \ldots \ldots \ldots \ldots \ldots \ldots \ldots \ldots \ldots \ldots \ldots \ldots$

Figure 18: E42.2 Comparison of Lodels to Experiment $\ldots \ldots \ldots \ldots \ldots \ldots \ldots$ 


\section{Acknowledgements}

The authore wish to thank Steve Nowlen, of sandia National Laboratories for maneging this project.

This work has been funded entirely by the Urited states Nuclear Regulatery Commission (USNRC) under FIN L1330. The authars are especially greteful to Bill Fartmer (USNRC, Iet.), who provided much support and enthusiasu for this international cooperative program.

The Gempan nuclear safety research institutions were very gracious in permitting and encouraging us to join. in this unique opportunity. 'vielen dank' to Herr $\mathbf{K}$. Muller (KEK), Herr tiemersdort (GRS), and Hert $\mathrm{L}$. Wolf (Battelle, Frankfurt), and a,1 of their colleagues. A special thank you goes to Herr $\mathbf{K}$. Moller (XfR) for arranging all of the meetings and coordinating the many researehers acound the world involved in this project.

The authors would like to take this opportunity to thank the many fire modeling resparchers involved in this effort for thelr interest and helpfuI discussions related to fire modeling of the HDR containment.

The authors gratefully acknowledge the efforts of graduate students $\mathrm{Q}$. Xia and $\mathrm{H}$. J. Huang at the University of Notre Dame for performing the field model calculations referred to herein. 


\section{Exrecutive Summary}

The Heiss Dampf Reaktor (HDR) is a decomissioned oxpezinental nuclear reactor in the Federal Republic of Germany. The German nucleax reactor sefety authority, Gesellschaft für anlagen und Reaktorsicherheit (GRS), has recognized the unficue opportunity that the HDR containment represents for reactor safety research, and has conducted a series of large-scale fire tests in the HDR containment.

The HDR fire tests are the only fire tests that heve been conducted inside an actual nuclear reactor containment builaing. As a result, there has been mush interest in using fire models to simulate these fire tests within the international mucleax reactor safety comanuity. Many different countries have participated over the past 5 yesrs in a cooperative effort to model these tests using the iatest fire models available.

Sandia National Laboxatorieg (Sandia) has served as technical consultants to the Dnited stetes druclear Regulatory Conmission (USNRC) concerning the HDR fire tests. The puzpose of this report is twofoldi i) to summarize Sandia's participation in the HDR fire modeling efforts, and 2) to swimatize the results of the international fire modeling community involved in modeling the HDR fire teats.

As part of sandia's support of the HDR fire modeling activities, a fire zone model (COUPEaW and a fire fleld model (the Notre Dame Fire Modol, or NDFM) have been used to simulate some of the HDR tests. HDR test E4I.7 was a large oil pool fire test in a small room in the contalmment. The E41.7 COMIPBN calculations could not be obtained beyond 4-7 minutes into the fire (depending on the input parameters) due to instablijties in the COWPBRN code. The calculations becorne unstable due to the large radiative heat fluxes that are calculated to exist. These results indicate that COUPBR cannot stodel very large fires in suall rooms it was not developed for fires of this type).
The E41.7 test Notre Dane Fire Model calculations demonetrate the capabilities of a fire field model. The fire heat relesse rate used for the field model calculations was based on ComPBR results. All of the temperatures obtained in the calculations conpared reasonably well with experimental data. For some of the data locations, the agreement is excellent. D1screpencies between the calculated and measured temperatures are explainable in texms of leakage around the doorway of the fire room. Such good agreement of the NDFM calculations with data was sornewhat surprising in view of the fact that only $y$ few calculations were performed with the model, and that the heat release estimates were obtained using the coMPsent code.

The resurlts of the other 841.7 participants indlcate that the level of agreement of the different model results with the test mesurements is a strong function of location in the containnent. Even within the fire room itself, only two of the models were consistenty within $250 \mathrm{C}$ of the measured gas temperatures. This poor agrement was heavily influenced by the fact thet the fire room was virtually a fireball, which most fire models are not dosigned to model. In general, the agreenent became worse (and the disparity wider) as rooms farther removed from the fire room were examined.

HDR test E42.2 was selected as an international standard probletn (2SP). This tost intolved a cable tray fire that sprand from tray to tray. The E42,2 CONPBRN results dermonstrate that COMPBEN can yield reasonable results for small to medsum-sized fires. Note that results were only obtained early in the fire, before the doox to the fire room was ogened. The strengthe of COMPBRN are seen to be its abilitty to model the transient iomition and burning of cable tray fires in a pre-flashover compartment.

Agreement of the COHPBNN E42.2 results with experimental data is reasoneble, but hot gas layer temperatures and cable 
tray mass loss rates are sionificantly underpredicted during the initial stages of the fire. The timing and sequence of cable tray ignition were well-predicted with the exception of the very early rtages of the fire. Unforturately, the COMPRRN results were very sensitive to the user's cholce of 1nput parameters.

The results of the other E42.2 participants indlcate similar (or worse) descrepancies with the experimental date. The need for better models of the cable insulation burning and gharring was seen to be $x$ major rosenech need by all of the participarts.

Fire modeling contintues to grow and derelop in maturity. However, compared to wany other areas of science, it is stiml relatively immature. Its development has been hindered by the complexity and tight coupling of the non-linear phenomena involved. In many respects, there is still somewhat of an art to making accurate fire modeling calculations. Experience with a particular fire model is exsential to determine its weak areas and potential pitfalis. Many models require the input of parameters which are not well known, and to which the results are very sensitive, unfortunately.

Just a few years ago, fire modeling efforts were dominated by zons models and control volume models. With advances in computers and computational flutia Aynamics (CFD), many of the fire modeling efforts world wide are moving in the direction of field model developutent. It is not expected that fire fiold models will replace the other types of ftre models, but rather will serve to complement the suite of fire analysis tools available for fire safety analyses.

Validation of fire modols remalns an important isgue. The HDR comparisons have demonstrated that fire moala perform poorly when used outside of the tealm for which they were designed and validated. Thus, validation of the models against more tixe data representative of fires in nuclear power plints is nesded.

In concluaion, the HDR fire, tests and modeling efforts bave contributed a wealth of information regarding actual fires in nuclear power plant. containments, and the strengths and weaknesses of present day fire models for simulating these fires.

Based on the experiencis with the for Eire modeling efforta, fiste models can potentially contribute to improved fire safety of nucleax power plants; when they are used withth theit reslm of apglicablitty. Defining this realm of applicability, and the sansitivities inherent in today's fire models, is a task that remeins to be comileted. 


\section{Introduction and Background}

\subsection{HDR Fire Eqperiment.}

The Heiss Dampf Reaktor (HDR) is a decommissionea experimental nuclear reactor in the Federal Republic of Germany. Since the HDR reactor has been decormaissioned, the containment building is available for nuclear reactor safety studies. The German nuclear reactor safety authority (Gesellschaft für Anlagen und Reaktors Icherheit, or GRS) has recognized the unique opportunity that the HDR containment represents for reactor safety research, and has conducted t series of large-scale tests in the HDR containment building. To date. seismic tests, hydrogen transport tests, blowdom tests, and fire tests have all been conducted jnside the HDR containment buflaing.

The HDR test profirams have been conducted by the nuclear research center Rernforschungszentrum in Karlsruhe, Germany (or (RfK) . Both the GRS and Battello-Frankfurt heve provided oversight and tranagement functions for the tests. The $\operatorname{EDR}_{\text {R }}$ itself is located in the tow of Kahl, just outside of frenkfurt.

The goal of the HDR tests has been to generate large-scale experimental data for seismic, hydrogen transport, blowdown, and fire phenomena ingide an actual nuclear reactor containment. This tost data can then be used to evaluate the state-of-the-art in modeling techniques and tools for these phenctuena. Areas of uncertaincy in present modeling technicnies can then be sdentified, and future research directed toward reducing these uncertalnties.

Since the focus of this report is on the FDR fire tests (and the application of fire modeling tools to these tests), only the HDR fire tests and modeling fforts will be discussed in this report.

\subsection{HDR Fire Modeling His- tory}

The HDR fire tests represent a unique contribution to the existing large-scale fire test database. These tests are the only fire tests that have been conducted inside an actual nuclear reactor contalnment building. As a result, there has been much interest in these tests within the international nuclear reactor safety companitity.

Because of this interest, KfX organized fire modeling efforts among any countries that wore interested in participating. Wany different countries have participated over the past 5 years in a cooperative effort to model thespe tests using the latest fixe models availeble.

These E1re modeling efforts ustally have sevaral steges associated with them: 1) a pre-test calculation, 2) a blind posttest calculation (before most of the experimental results are released, but including the experinentally measured moss loss rate), and 3) an open post-test calculation (in which all of the experimental results have been previously released for comparison). Also, one international standard problem (ISP) has been formulated for one of the fire tests.

The HDR containment bulding is relatively small in comparison to United states (U.3.) power generat.ing reactors. The containment is $20 \mathrm{~m}$ in ditameter by 60 m high. The inside surface area is about $10,000 \mathrm{~m} 2$, with a volurue of $11,000 \mathrm{m3}$. As shown in Figure 1 , it is also highly colupartmentalized, without many of the large open zoons present in U.S. power reactors. 


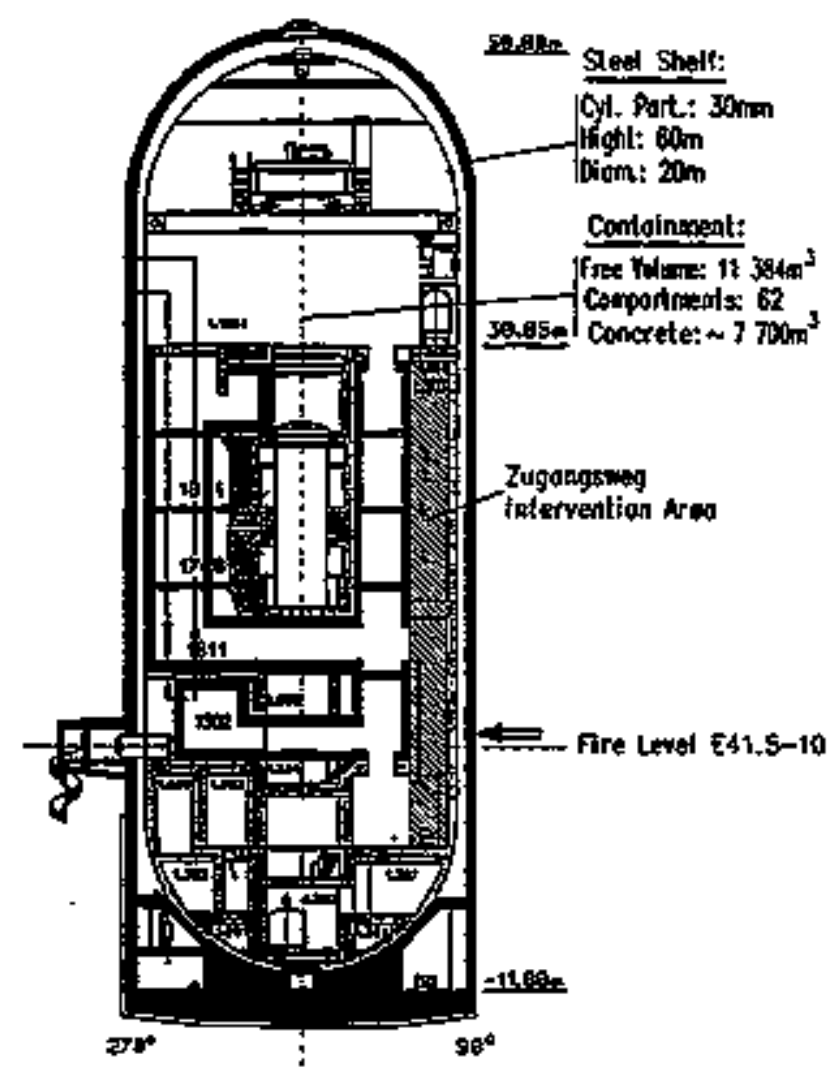

Figure 1 ; the HDR contatment Bu11ding

\subsection{Sandia's Role in FIDR Fire Tests}

Sandia has bẹn involved in the HDR fire test program ajuce $1990 \mathrm{as}$ techn1cal consultants to the United States Nuclear
Regulatory Commission (USNRC). The formal USNRC name for this program was the HDR/KfK Cooperetive Fire Research EfEort.

The objectives of this program were as follows: 1) to follow the progress of the fire tegting efforts being conducted by the Germans in the HDR tast facility, 2) to provide technical support for the development of tegt plans by the German researchers, 3) to participate it the international fire model assessuent Efforts baing coorojnated in conjunction with these tests, and \&) to comulunicato the results of the German fire tests and the international fire modeling activities to the USWRC.

As the above objectives indicate, sandia has been invo3ved in the HDR tosts in both fire modeling and-test support roles. However, the focus of this report is on the HDR fire modeling efforts (as opposed to the test support efforts . The Sandia test support efforts for the HDR are discussed in a separate report (Nowlen, 2993).

The purpose of this report is twofold: 1) to sumbarize Sandia's participation in the HDR fire modeling efforts, and is to sumparize the results of the international fire modeling compunity for the HDR fire tests. While there were some HDR fire modeling efforts by the international community before samala's involvement in this program (namely, the EAI +1 teat calculations), these will not be alscussed herein. Rather, this report wil focus on the last two HDR fire tests for which fire rodeling calculations have been performed in the international coumunity (including sandia). These two HDR tests have been given the names EAl.7 and 342.2 .

\subsection{Brief Overview of Fire Modeling of Muclear Power Blants}

In this section, a brief overview of tire modeling of nuclear power plents will be given. The intent is to familiarize the reader with some of the terms used later on in the report. A more detailof 
discussion can be found in Nicolette and Nowlen (1991).

Fire modeis are useful for predicting the consequences of a fire inside a nuclear power plant. They can be used to

determine how large a fire will grow, and what equipment might be dameged in a titre. The $X$ can also be used to aszess evacuation procedures and 1nhabitab111ty of the control room. As such, they might potentially be used to provide a basis for licensing and regulatory decisionmaking, and are often coupled into a fire rssk assessment as part of the suite of evaluetion tools.

The value of fire madeling can be seen from the above aiscussion. The questions then ariser How good (accurate) are these fire models? that types of fire models are best? What is the state-of-the-art in fire toodeling, and in what direction is the international fire modeling community moving?

It is with these gaestions in mind that the top fire modeling studies were conducted. Fire science is relatively young compared to other fields of science. The complexity of the fire onvizonment (involving the interaction of combustion, fluid mechanics, heat transfex, and turbulence) has hindered progress in the development of accurate models. The non-linearity of the

phenomena involved has al so made progress slow. In spite of these impodiments, a number of fire rodels have been developed over the years which can be applied to the analyeis of nuclear power plant. Eires.

Genorally spoaking, there are three besic types of fire models : zone models, hybrid (control volume) nodels, and fleld models, in increasing order of complexity. Zone models (e.g., COMPBRN, CRAST, BRI2) are the simplest fire models, and typically divide the fire room tnto tour reglons: flame, plume, hot gas layer, and ambijent (Figure 2). Somo zone models also allow for the inclusion of secondary targets and combustible fuel elements. They are relatively easy to use, and require little cotoputer (CPJ) t.me. Their main disadvantages are that: 1) many of them are limitad to the calculation of only one room, 2) they are besed on experimental deta and correlations to a great extent, which limits their applicabilisty to fires for which data exists, and 3) they generally only provide spatially-aperaged results for each region of interest $(e . g$.

temperatures are averaged throughout the hot gas layer).

A hybrid (or control volume) fire model (e.g., GOTHIC/FATHOAs) is more sophisticated than a zone model, and all lows for many rooms or compartments to be interconnected. Additionally, a given room can be subdivided to the level of interest. The control volume approach is shown in Figure 3 . In the control volume model approach, mesi, heat and tomentum transfer occur between the compartments via pipelines or pathways. Their main advantage is that they can handle complex peometries easily. They are also very well suited to tnelude systams models of complex phenomene found inside reactor containments (such as water sprays, or fan coolers).

The main dibadrantages of the hybrid model approach are: 1) the pathway flow coefficients from room to room (ar compartment to coropattment) imast bo specified, 2) they generally only provide spatiaily-averaged results, and 3 ) the CPU requirements can be very large.

Fire fieia models (e.g. NDFA, KAMELEON Pire, CFDS-FLOW3D) ere generally the most complex models available (although hybrid models with many different systems models incorporated may surpass them). Field models gain their nante from the fact that they solve the governing differential equations for mass, heat, and momentum transport throughout the entire field (at discrete locations, or nodes). A typical field model

calculational grid is show in Figure 4.

The main advantages of field models are: 1) they provide very detailed information bout the fire environment, 2) of al1 the models, they have the fewest assumptions built into them, and 3) they are not limited to the moteling of fires for which experimental data exists. This last point implies that field models can be used to predict fires for which no 


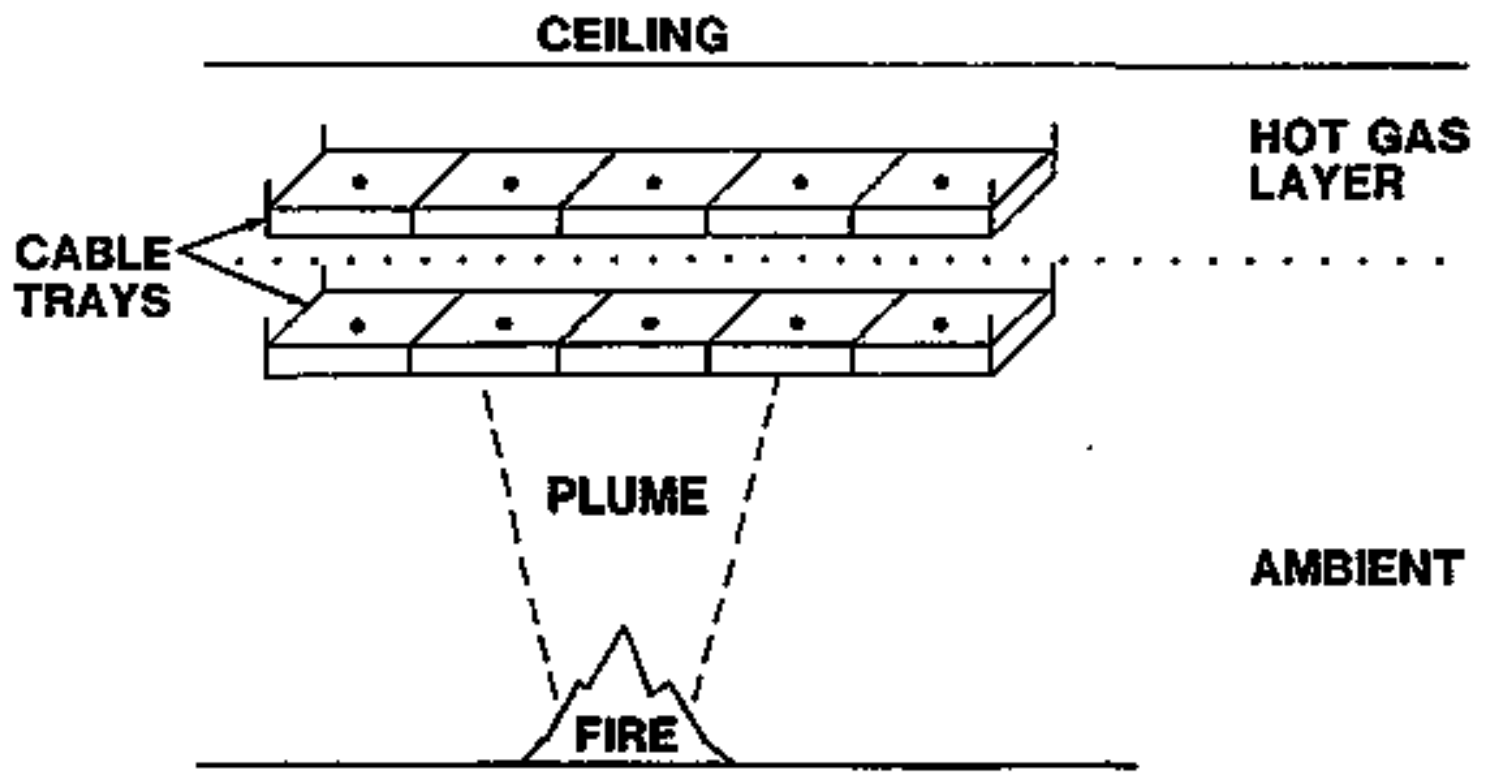

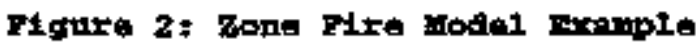

repregentative experimental data exists, because field models tre besed on a "first-principles" approach that solves the Eundamental governing ecutations. with very few essumotions.

There are generally three major disadvantages to fire field models. First, they require very extensive cPO $t$ ime to perform a calculation (although this restriction is diminishing as computer speeds and storage increase). several hours of CPU time on a CRAT XMP computer would not be uncommon with a field model. Second, the input requirements can be more complex for a field model, because the usex must specify a detailed numerical grid for the calculations. Finird, field models generally lack the extensive validation of the other types of fire rodels. This last point is mainly tue to the inmaturity of field modeling relative to the other models, and to the general difficulty of obtaining the detailed fiela data needed for the validation.

The above discussion is not meant to single out one type of model that should be usced exclusive of the others. Bach of the different types of models has a role to piay in nuclear power plant fire modeling. The type of model employed to solve a particular problern should be based on the information that is required Fron the model, as well as the scenario the model is applied to. If detailed information is reguired for a flre which is greatly different than those represented in the experimental data base, if field model is the best choice. If a very iarge number of fire scenariog must be investigated feuch as for a fire risk axsessineit $\}$, and a sufficient experimental database exists for fizes of this type, a zone modeI is the best seleation. Finally, 立 multi-roosu transport and cosplex geonetries are important considerations, a hybrid control volume model may be the best of all three.

Unfortunately, with all of the different types of fire models there is a strong sensitivity to the input paraneters and/ or grid selected by the user. Fire model resilt ts are, therefore, a function of the knowledge and experience base of the user regarding filre nodeling in general, and also with the specific model being appited. In this light, fire model results mist always be interpreted in view of the experience of the person who generated them, as well as with regard to the model that profuced thenl. 
TO ZONE 68

FREROOW

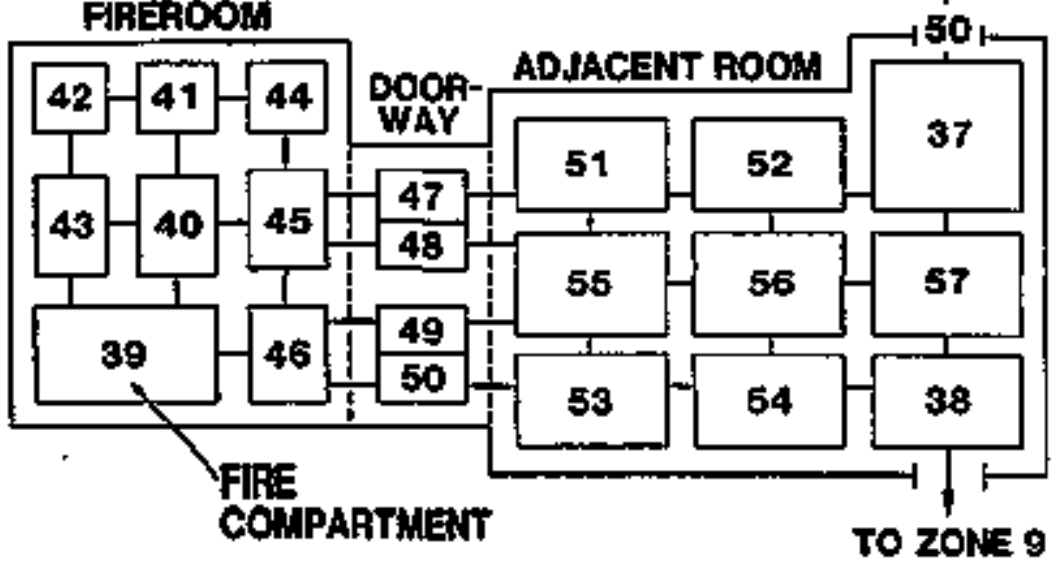

PIguxe $3 t$ Control Volume F1ze Hodel Examplo

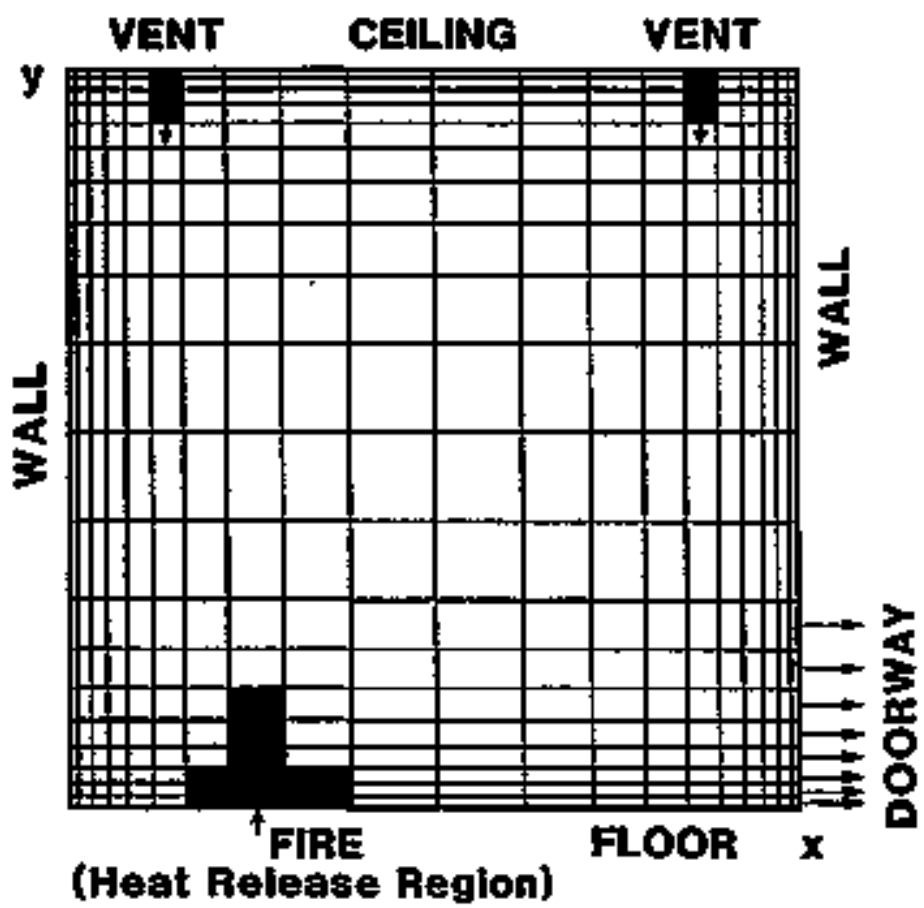

F1gure 4: Fire Fleld model Exaple 


\section{E41.7 Fire Experiment}

\subsection{Overview of $\mathrm{E} 41.7$ Exper- iment.}

The detalis of the E41.7 test spectifation are contained in the problem specification report (Waller and Mex, 1991). Test E41.7 was an oll pool fire test with high forced ventilation at the 1500 level of the HDR conteinuent building. The ventilation rate for the fir room was specified as 30 air changes per hout (ACH) for the eirat 15 minttes of the test. Inuxing this time period, the doors to the fire roold were closed. After 15 minutes, the doors were opened and the ventilation rate was reduced to $10 \mathrm{ACH}$. The focus herein is only on the first 15 ginutes.

The fire room has a volume of $100 \mathrm{~m}^{3}$ (approximate ceiling helght of $4.7 \mathrm{~m}$. and floor area of $22 \mathrm{~m}^{2}$ ). The floor and side walls are made of concrete. The side walls are protected with Alaiflex mats (2.5 cra thick). The ceiling is protected with Promatec (5.0 cul thick) . The material properties for these materials can be found in the problem specification report (Maller and Max, 1991).

The fuel was burned in a $2 \mathrm{~m} x$ Im pen located near the center of the fire roon. The inttial fuel loading was 40 isters of shell solT oil. This fuel has a density of $0.756 \mathrm{~kg} / \mathrm{l}$ and a calorific value of $42,500 \mathrm{~kJ} / \mathrm{kg}$. When the initial fuel load was consumed, oil wes supplied at a rate of $0.12 \mathrm{~kg} / \mathrm{s}$ for the duration of the test.

\subsection{E41.7 Zone kodel Calcu- lations Using COMPBRN}

The gotl of the E41.7 coupBRy calculations mas two-fold: 1) parform blind post-test calculations with CoNpBkit to gentrate result for later comparison to the test data, and 2) Based on the COMPBRH results, estimate the heat release rate for this test for use in the Notre Dane Pire Model calculations being performed by the University of Notre Dame. Because no heat. release rate information was given in the problen specification, it had to be calculated as part of the results.

A modified version of the coMPBRN III fire model (Ho, et al., 19a5) was applied to the E41.7 test. This version (Nicolette, ot. al., 1989) was madified for the USNRCsponsored Fire Risk Scoping study (IAmbrifht, et al., 1989).

COMPBRN III it a zone fire model that models the growth and consecisences of a fire in a single roora. It has been useg in several muclear power plant fire risk assessment efforts to assess the fire vilnerability of safety-related equipment fsee for excmple, Lambright and Bohn, 1989a and 1989b). CoupBR II was selected for this study because of Sandia' $s$ extensive experience in applying it to nuclear powet plant fire scenarjos.

\subsubsection{E41.7 COHPBRy Assumptions and Input}

Because COAPBRW IIt is a zone model, it will output valuos for parameters of interest that are spatially-averaged over a Fegion of the fire compartment. For this experiment, tho results of interest are the hot gas layer temperetures as a function of time, the fire heat release rate, and the length of tijue recruired for the initial pool of oll to be constrmed. First, some preliminary calculations mast be performed to getermine appropriate input prrameters.

The ventilation rate of $30 \mathrm{ACH}$ corresponds to $0.85 \mathrm{~m}^{3} / \mathrm{s}$ into the fire room. The amount of fuel initially is $30.2 \mathrm{~kg}$. For conduction into the walls, floor, and ceiling, the composite layers are converted into an equivalent thickness of Alsiflex by ratioing the thermal diffusivities of the materials (inclualing concretel. Thus, the walls are

represented by $27.5 \mathrm{~cm}$ of Alsiflex, the celling by $10.5 \mathrm{~cm}$ of Alsiflex, and the 
Test: E41.7

floor by 62.5 ctin of Alsiflex. The thermal diffusivity of all surfaces was varied over the range $1.5-2.0 \mathrm{E}-6 \mathrm{~m}^{2} / \mathrm{s}$. The absorptivity of al? surfaces wes varied Irom 0.7-0.9 with Iittle impact on the results.

COMPBRN requites the user to input burning parameters that describe the fuel and the fire. For these calculations, the assumption is made that the soLT oil behaves similarly to kerosene futl. An efficiency of 70-80\% is assumed for the burning process (1.e., 70 of the oll that is vaporized undergoes complete combustionj. Half of the energy released in the combustion process is essumed to be in the forza of thermal radiation (since these flames are sooty). A surface-controlled burning rate of 0.039 $\mathrm{kg} / \mathrm{m}^{2} \mathrm{~s}$ is used based on Information in the SFPE (Society of Fire Protection Englneers, 1988) handbook. This burning rate is considered to have a heat flux augpnentation factor of $1.3 \mathrm{E}-6 \mathrm{~kg} / \mathrm{m}^{2}-\mathrm{J}$. which is related to the inverse of the latent heat of vaporization $10.77 \mathrm{~kJ} / \mathrm{g}$ ). An initial temperature of $\mathbf{3 0 0} \mathrm{K}$ is assumed for all surfaces.

OnIy the case with a surface emissivity of 0.7 , an efficiency of 70\%, and a thermal diffusivity of $2.0 \mathrm{E}-6 \mathrm{~m}^{2} / \mathrm{s}$ will be discussed. These input parameters are belteved to be the most reasonable for the cases that were rum. The input deck is shown in Ptgare 5 .

\subsection{COLPERN Results}

COMPBRH calculations were performed for the ranges of parameters apecified above. The size of the calculated fire (on the order of megawatts (HW) is very large relative to the volume of the fire room. This agres with the observation during the test that most of the room was filled with flomes (i.e., a filrebeil).

consequently, the surfaces of the fire zoom hat up to very high temperatures very quifekly in the simulations.

As a rosult of these high wall and ceiling temperatures, the COMPBRN calculations become unstable within 4 7 suinutes fxom the beginning of the fire. This is due to the manner in which COMPBR models the radiative heat ingut into a surface. The fact that thermal radiation is a highly nonlinear process ivarying as the fourth power of absolute temporature) exacexbates this instability. Thirefore, the ealculations could not be carried out for long times.

The ConpBrs results are shown in Table 1 for the first 4 minutes of the calculation, along with some experimental results. The COMPBRHcalculated mass loss rate agrees guite well with the measurted values over the Eirst 2 minutes. The COMPBEN-calculated values are 1 ower by about 208. Kote that there is some aiscrepancy in the test data time equal to zexo. It is not clear why the test deta shows $0.11 \mathrm{~kg} / \mathrm{s}$ as the mass loss rate before igmition occurs. At 3 minutes, CoMPBRN talculates a mass loss rate of $0.1535 \mathrm{~kg} / \mathrm{s}$. This is about Sos larger than the measured value. The reason for this result is two-fold. First, COHPBR calculates that the hot gras layer results in substantial heat fluxes back to the pool of fuel, which results in more vaporization and more combustion. Second, CoAPBRA assumes that the air entrained by the fire is not diminished in oxygen concentration. In the actual test, some depletion of the oxygen may have been occurring, as evidenced by the monotonic decrease in the measured mass loss rate. By 4 minutes, COHPBR predicts that the fire has become linited by the amount of oxygen available (ventilation controlled burning). It no longer burns at a rate solely dependent on the amount of fuel surface area (surface controlled burning). The mass loss rate drops substentially at this time as a result.

The Initial pool fire is calculated to be approximately 2.8 KW in size. This calculated fire size agrees well (within 208) with the size predtcted by using equations and parameters out of the SFPE handbook. The coMPBRN calculated initial pool fite size is 208 larger than that obtained from the SFPE correlation because thermal radiation back to the pool surface augments the amount of fuel vaporized compared to the free-pool fire correlations.

During the initial pool fire burning. COMPBR calcolates that the surrounding surfaces heat up quickly and provide 
N.YOB, NTIME, DELT

1560.

NSM, NCOM, NPUEL,NNCOM,NPLOT, IROOM,INTG

$\begin{array}{lllllll}6 & 0 & 3 & 0 & 1 & 1 & 0\end{array}$

HDR E41.7 TEST (FIRST IS MINUTES)

SMX SMY, SMZ SLNG, SWID, SDEP SOLL POOL FIRE ( $2 \times 1 \mathrm{~m} 2)$ SM 1

$\begin{array}{llllll}1.3 & 1.4 & 6 & 2 & 1 . & 1\end{array}$

SMASS,SPOR,SLOSS,NFCLIORNT, IOIRECIITYP SEND OLL POOL FLRE

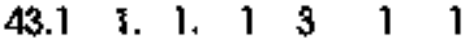

SMX SMY, SHAZ SLNG, SWID, SDEP SCEILING SM \#2

2.332 .334 .674 .664 .66 .105

SMASS.SPOR,SLOSS,NFCL.ORNT,IDIREC,IFYY SEND CEIUNS

1. 1.1 . 13013

SMX \$MY, \$WZ \$LNG, \$WID, SDEP \$WALل I, Y-Z X=O \$M \#3

0. 2.332 .344 .674 .66 .275

SMASS,SPORSLOSS, NFCLIORNT,IDIREC,IFTVP SEND WAL 1

j. 1.1 .1113

SMX, SMY, SMZ SLNG, SWID, SDEP SWAL $2 Y-Z, X-4.66 \mathrm{M}$ SM \#4

4.662 .332 .344 .674 .66 .275

SMASS,SPOR, 1 OSS,NFCLIORNT,IDIREC,IFTYP \$END WAU 2 .

1. 1.1 .11 1 33

SMX SMY, SWZ, SLNG, SWID, SDEP SWAL 3, X-Z, Y=0 SM:5

2.33 0. $2.344 .67 \quad 4.66 .275$

SMASS,SPOR SLOSS,NFCLIORNT,IDIREC, IFTYP SEND WAL 3

1. 1. 1.11233

SMX SMY, SMZ SLNG, SWID, SDEP \$WA I $4, X-Z, Y=4.66$ SM

$2.334 .662 .344 .674 .66 \quad .275$

SMAS5,SPOR,SLOSS,NFCL,IORNI,IDIREC,IFTYP SEND WALL 4

1. 1. I. 122 3 3

PIL, JPIL IPFUEL PMASS

1 I 1,01

IFUEL DENS, SPHT

$1,41.21 \quad 756.2 * 130$. 3*1000.

THK HEAT EFF

$.1,2 * 0.2 \quad 4.25 E 7,2 * 1 . \quad 7.2 * 0,1$

HGTP FDAM FIGTS

$573.2 * 2000.573 .2 * 2000$. 573..2*2000.

BRATV BRATSO BRATSI

.025.2*0. .039.2\%O. 1.3E-6,200.

GAMMA FABSRP REFL

$3 * 5 \quad 3 * 1.4 \quad 3 * 1$

RIEMP FCF HROOM CALTEM

300. 23. 10.0 .

IPOOL ESIGN, EPGN, EDAMG, QCRIS, QCRIP, QCRITD

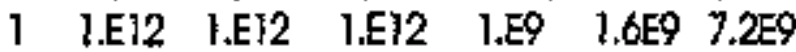

SEE: $N=L, J, K, L$

NSEE: $N V=L, J, K L$

ROOM DATA: DCFIN,DCFOUT,DHGT,DWID,FC,FH GABSRP,HCELLFLCF,VFV $\begin{array}{llllllllll}1.0 & 0.7 & 0 . & 0.0 .1 & 0.3 & 10 . & 0.0 .95\end{array}$

P1gure S: F41.7 COMPBRN Input Deck 
gubstantial radiative feedback to the fuel pool. Consecuently, the fire heat release rate elimbs very quickly between 2 and 4 minutes. After 3 minutes, the heat release rate is calculated to be 4.6 Ww. By 4 minutes, COMPBRN predicts that the Ifire has beooine limited by the amount of oxycon available. The COMPBRNcalculated heat xelease rate thep arops to just under $1 \mathrm{kth}$.

As shown in Table 1 , the COMPBRHcalculated hot gas layer (HeL) temperatures rise to a high level very early in the calculation. This result is influenced by the guasi-steady nature of COMPERN. COHPBRH alwaye calculates the HoL terpperature by assmoing that the HGL has reached a steady-state. Obviously, this assumetion will be in error during the first few minutes of a fire, when the HOL is developing rapidly. Prom the 2 minute mark and afterward, the calculated HGI temperatures are within $250 \mathrm{~K}$ of the themocouple data. This is reasonable in view of the quasi-steady nature of COHPBRH. Sy the 3 minute mark, the HOL cemperatures have roached $1135 \mathrm{~K}$. Thes* very high temperatures result in very large radiative heat fluxes back to the fuel pool, and to the walls and ceiling. As a result, the coMPBRN model becomes unstable after the 4 minute mark and does not produce a solution.

It should be noted that thermocouples provide an experimental indication of local gas temperacures, and not the actual gas temparatures. Thermocouples are essentially heat flux sensors, and are influenced by the radiative heat transfer in a fire. Therefore, the degzen to which theringcouple data reflect local gas temperatures is a strong function of the radiation environment that they are used in. KER estimated the experimental error associated with the thermocouple data to be less than 5\%. This error estinate 18 typical for the other data taken by KfK, except velocity (108).

In order to bettex guantify when the fire switches to the ventilation controlled burning mode (1.0.., whs it closer to 3 mirutes or to 4 minutes?), some additional calculations were performed. The COMPBRN celculations do not predict what happens between 3 minutes and 4 minutes due to the guasi-steady nature of the code.

Pour guantities were calculated: 1) the energy that could be released if all of the atrailable oxygen were consumed (Joules), 2) the amount of fuel (kg) corresponding to that energy (assuming a 706 efficiency), 3) the energy released (Joules) based on the COMPBRN calculations, and 4) the amount of fuel (kg) corresponding to the coupsRy energy release (again assuming a 70 용 efflatency). The first calculated quantity assumes that $3,000 \mathrm{~kJ}$ of energy are released per kilogram of air

Toble 1: CONTBRN Results for B4t.7 Test

\begin{tabular}{|c|c|c|c|c|c|}
\hline $\begin{array}{c}\text { Thue } \\
\text { (minntes) }\end{array}$ & $\begin{array}{c}\text { Calculated } \\
\text { Mass Loss } \\
\text { Rote (kods) }\end{array}$ & $\begin{array}{c}\text { Measured* } \\
\text { Mass Lass } \\
\text { Rate (kg/s) }\end{array}$ & $\begin{array}{c}\text { Calculated } \\
\text { Fire HRR } \\
\text { (MW) }\end{array}$ & $\begin{array}{c}\text { Calculated } \\
\text { HGL Temp } \\
\text { (K) }\end{array}$ & $\begin{array}{c}\text { Measured HGL } \\
\text { Temop (K) } \\
\text { CT5204 }\end{array}$ \\
\hline \hline 0 & 0 & .11 & 0 & 300 & 293 \\
\hline 1 & .09 & .11 & 2.8 & 815 & 450 \\
\hline 2 & .09 & .11 & 2.8 & 962 & 750 \\
\hline 3 & .1535 & .10 & 4.6 & 1135 & 873 \\
\hline 4 & .03 & .10 & 0.9 & 1138 & 925 \\
\hline
\end{tabular}

Measired with a load cell on the par 
Test E41.7

combusted, and that all of the ait 1s available to participate in the combustion process. This is probably a reasonable assumption since the fire room gases are relatively well mixed, and HGL tetmperatures are very high. For the third quantity calculated, the fire was assumed to stay constant at $4.6 \mathrm{wW}$ for the time pertod between 3 and 4 minutes.

The results of the calculations are shown In Table 2. It was found that at 4 minutes, the amount of fuel consumed was equal to the initial fuel loading in the fire room $(30 \mathrm{~kg})$. It can also be seen frotu Table 2 that virtually all of the available oxygen in the room has been consuned right at 4 minutes. Bessed on these results, the additional oll fuel flow $(0.12 \mathrm{~kg} / \mathrm{s})$ is predicted to begin at 4 minuteg after fire initiation.

A fuel consumption rate of $0.12 \mathrm{~kg} / \mathrm{s}$ corresponds to a very large fire $15.1 \mathrm{~kW}$, if 1008 efficient). Since the fire has become ventilation controlled following 4 minutes, the heat relaase rate will be limited by the available oxygen. The method COMPRR uses to calculate ventilation-controlled burning rates is not straightforward, and depends heavily on the user's input of a ventiletioncontrolled burning constant. Therefore, the following procedure is used to estimate the ventilation-controlled burning rate.

Additiongl oxggen enters the fire room in the form of fresh air at a rate of $30 \mathrm{ACH}$. Again assuning an energy release of 3,000 $\mathrm{kJ}$ per $\mathrm{kg}$ of air, and assuging that all of the avatisble oxygen is consumed, this would limit the fire to a size of $2.6 \mathrm{~kW}$ for all later times funtil the doors to the fire room are eventually opened or the ventilation rate is changed) -

However, because of the

very large radigtive foedback, all of the added fuel is probably vaporized. The burning efficiency of this ventilationcontrolled fire is thus 2.6/5.1 - 508.

The above calculations can be summarized as follows. COMPBR calculates that the Fire size grows from about $2.8 \mathrm{MW}$ turing the first $2-3$ minutes to $4.6 \mathrm{MW}$ during the 3-4 minute time frame. By 4 minutes, the initial fuel has been consumed as well as most of the initial oxygen supply. Measured rass loss rates are in rensonable agreement during the first 2 minutes of the test, but derriate significantly thereafter. The hot gas layer temperatures are calculeted to exceed $1100 \mathrm{~K}$, as compared to approximately $900 \mathrm{~K}$ measured. calculations could not be obtained beyond 4-7 minutes into the fire (depending on the ingut parameters) due to instabilities in the coMPBRN code. In this time frame, the hot ges layer temperature and the surface temperatures become very high. The calculations becone unstable due to the large radiative heat fluxes that are calculated to exist.

These resulte indicate some of COHPBR III's limitations. The COMPBis code is guasi-steady in nature, and cannot be expected to exactly describe the early stages of transient fires. Also, the coxrelations and models upon thich COMPERI is based do not generaliy appiy for fires that are this large in size. While those results demongtrate some of the imitations of the COMPER code, it should be remembered that COMPBRN was not designed to calculate large fires in small rooms.

\subsection{EA1.7 Field Model Calcu- lations}

Along with the COMPBRN zone model calculations, field model calculations were also performed for the E41.7 tegt. The model used is the University of Matre Diene Fire Hodel (NDFM), developed by Professor R. T. Yang and collegaues. This fire mode? is a rexearch tool that has been under development since the mid$1970 s$, wd has been used to simulate many different fires (see for example, Liu and Yang, 1978). The calculations discussed herein were performed by Professor Yang and his colleagues at the University of Notre Daine. Other field models could have been used (e.g.), the KaMELEON Pire model), but the MDFM was selected due to the authors ' fargiliarity with it. 


\subsubsection{E41.7 Fiela Hode1 Assump- tions and Input}

The geometric model of the HDR fire room used in the NDFH E41.7 calculations 15 sketched in Figure 6. Note that the fire room consiste of a largar room (in which there was a pool of fuel) and a smaller room (alcove) that was directly attached. The alcove had doors on the enâ of it that led to the rest of the containment, but these doors were assumed to be closed. For the model, the ventilation air was incraduced inta the fire room through a scquare hole at the actual location of the ventilation inlet in the HDR Fire room. This is near the origin in Figure 6 . The ventilation rate was maintained at a constant value of $0.85 \mathrm{~m} 3 / \mathrm{s}$.

The calculation domain was divided into cubical cells measuring 0.273 m on each stde. The unlform grid used was $28 \times 24 \times 19$ cells (IxJ)<R). A transient 1-D conduction model for the walls (emissivity=0,9) was included. The coefficient of hat.

transfer at the exterior wall and ceiling surfaces of the fire room (to the

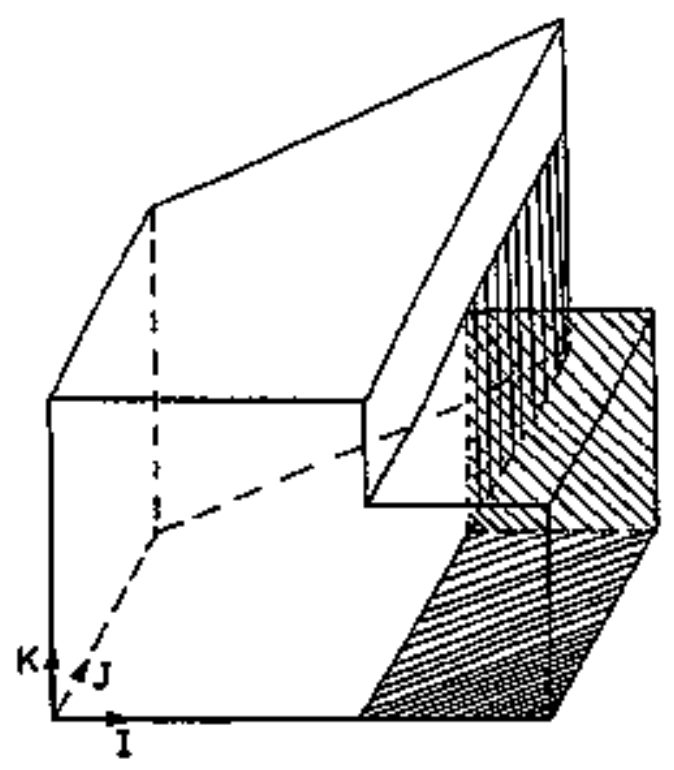

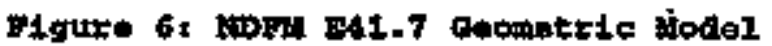

Table 2: Additional EAI.7 Caloulations

\begin{tabular}{|c|c|c|c|c|}
\hline $\begin{array}{c}\text { Tine } \\
\text { (minutes) }\end{array}$ & $\begin{array}{c}\text { Comblative } \\
\text { energy release } \\
\text { hased on availahle } \\
\text { air (MU) }\end{array}$ & $\begin{array}{l}\text { Fuel burned } \\
\text { based on avallable } \\
\text { aif, assuming } \\
70 \% \text { efircieucy } \\
\text { (kg) }\end{array}$ & $\begin{array}{l}\text { Compulathe } \\
\text { energy release } \\
\text { based on } \\
\text { coMPBRN fire } \\
\text { sloes (MJ) }\end{array}$ & $\begin{array}{l}\text { Fuel burned } \\
\text { based on } \\
\text { COMPBRN, } \\
\text { assuring } 70 \% \\
\text { efficiency } \\
\text { (ks) }\end{array}$ \\
\hline 0 & 300 & 10 & 0 & 0 \\
\hline $0-1$ & 453 & 15 & 166 & 6.6 \\
\hline $1-2$ & $\infty 06$ & 20 & 335 & 11 \\
\hline $2-3$ & 759 & 26 & 611 & 21 \\
\hline $3-4$ & 912 & 31 & 888 & $30 *$ \\
\hline
\end{tabular}

- hittol fuel loading was $30.2 \mathrm{~kg}$. 
arubient) was assumed to be $85 \mathrm{~W} / \mathrm{mak}$. The fraction of flame energy radiated away from the flame was asaumed to be 0.9 . other physical propertiss were based on those given in the design specification report (tholler and Max, 1991).

The NDFM does not have a contsustion model. Therefore, the user miust input a heat release rate, and specify a 'Elame volume' over which the energy is distributed. As a result, the model should not be expected to closely predict the temperatures in the flome volutae. since they are heavily tied to the assumptions on the size of the Elame volumee.

For the NDFH Calculations of test E41.7, the heat release rate (HRR), in megawatte (WWi), ass assumed to vary with time (t) according to the following relationship: HRR $=1.9525 t$, for $0<t<2$ minutes,

$$
\text { HRR }=1.17 t+1.30 \text {, for } 2<t<4
$$
ininutes

This particular form of the relationship was based on the COMPERN results, and was used to provide a smoath ramp-up of the FRR to reduce any problems with instabilities in the model.

\subsubsection{E41.7 Field Hode1 Regnit:}

The Notre Dame field model results for E41.7 will be sumarized briefly here. Detajls of the calculations can be found in the report attached as Appendix B.

The E41.7 calculations with the NDFM were performed on an IRI RISC 6000 machine. The time steps used were between 0.05 and 0.001 seconds. The total estimated cPu tine required to model 4 minutes of the fire was about 50 hours. Decause of the large CPU time requirements, only a single set of calculations was performed with the NDPM for the EA2.2 test. As a result, there was no 'adjustment of parameters' used to obtain the following results. However, sone calculations with the NDFM had been previously performed on another HDR test (E4\}.5: natural

ventilation) to deteran an an appropriate grid and time step. These calculttions are discussed in the report attached as Appondix $C$.
To begin the NDWh calculations, the model was run with the ventiletion turned on. but with no fire load (zero HRR) until a steady-atate flow was achieved in the room. Then the fire was assured to start (time equal to zero in the plots). calculations were only carried out until 4 minutes was reached, since the CoMPBRN results were being used to provide a basis for estimating the HRR for the NDFN calculations.

With a field model such as the NDFr, the HGL is descrtbed by many nodes. A rough description of the physical location of each point of interest is given below. A more detailed description can be found in the problem spepcification report (Haller and Max, 1991).

Thermocouple number 5204 (CT5204) was located directly above the fuel pool, just below the coling. The calculated restilte for this thermocouple are in very good agreement with the measured values, as shown in Figure 7. The flight

difference in the shape of the caiculated and measured curves could be due to a difference in the rate of heat release used for the calculations, as compared to the test. This agreement is very good, considering the uncertainty in the HRR values and profiles uged in the NDFM eslculations. As mentioned previously. the error associated with the experimental data is expected to be less than 58.

Thermocouple number 5246 (CTS246) Has located year the closed doors in the alcove, in the vicinity of the ceiling. Figure indicates reasonable agreement between the calculated and measured gas temperatures at this location, with the calculated results underpredicting the test data by about $100 \mathrm{C}$. The trends in the two curves are very similar, although the calculated temperatures rise more slowly. A possible reason for this discrepaney is that some outflow may have occurred in the test in the vicinity of the doors, whereas the calculations asstune a perfectly leak-tight boundary. Leakage around the doors in the test would have resulted in a larger flow of hot gases into this otherwise 'dead' corner, thereby increasing the locel gas temperature. There was anecdotal 
information that leakage did indeed occur around the doors in the experisunt.

Thermocouples 5290 and 5294 were focated close to the junction of the talin roosa and alcove. Cr5z90 was very elose to the floor, and cr5294 wes very close to the celiling. For CT5290 (floor), there is excellent agreement during the Eirst 2.5 minutes of the test, as shown in Figure 9. Both the NDFM calculations and the test measurements indicate that the HGL has not descended to this location yet. However, by the 3 minute park the NDFH results indicate that the HGt has indeed descended almost to the floor, while the tact results indicate otherwise. If there is some cold air infilcration near the base of the doors, a fresh supply of cold air would be drawn into the fire room right over CP5290, thus keeping it close to amblent temperature. Howerer, the calculations assime zero infiltration around the closed doors, which allows the HCI, to descend more guickly. This is one possible explanation of the discrepancy between the calculated and measured results during the $3-4$ minute time Erame +

Thermocouple 5294 was located directly above CT5290, but very near the celling. Excallent ggreament between the calculated and the measured HGt temperatures can be seen in pigure 10. The calculated tamperatures are within approximately $25 \mathrm{c}$ of the measured values over the 4 minute time period, reaching a maxisum value of about $550 \mathrm{c}$.

In general, the NBFH results show very good agreement with the measured temperatures. Discrepancies between the calculations and the measurements are explainable in terms of gas leakage around the doors. Since only one calculation was performed with the NDFM for test $\mathbf{4} 41.7$ (1.)., there was no finetuning of the HRR or other input parameters), such good agreement was somewhet of a surprise in view of the uncerteinty in HRR. 
Test E41.7

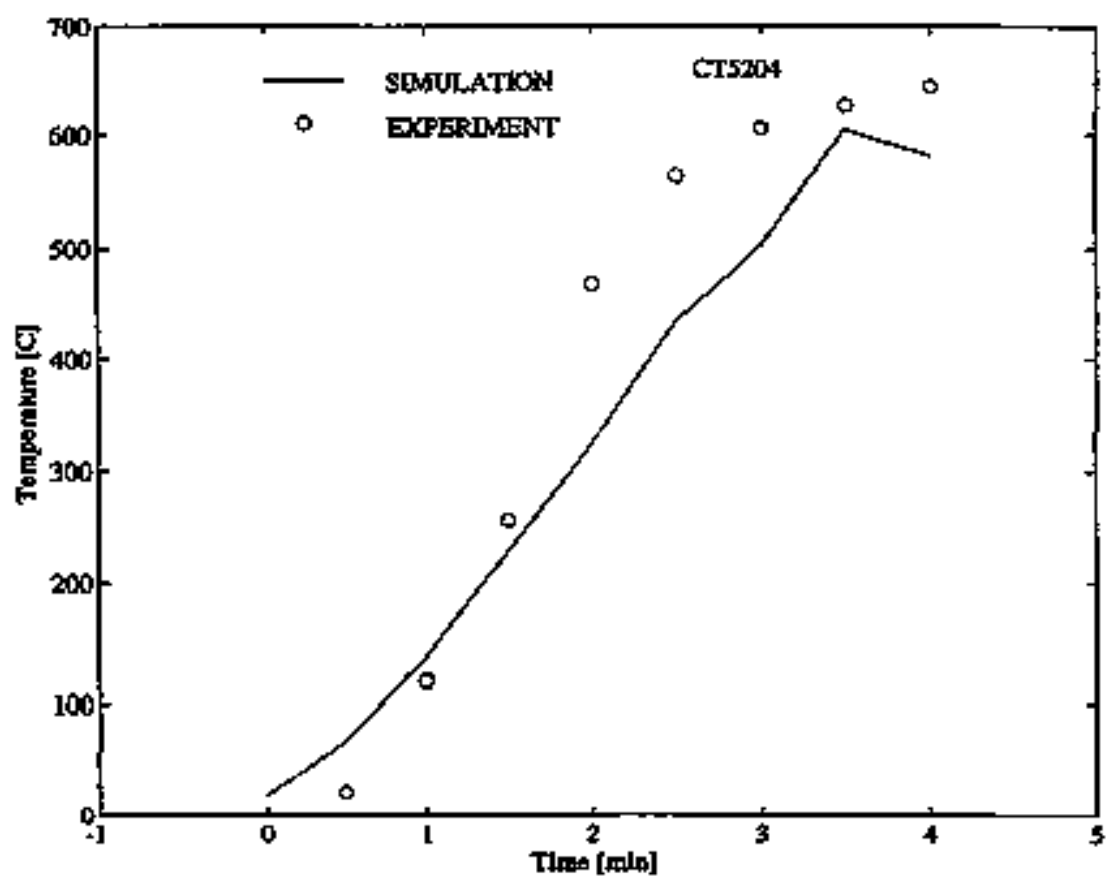

B1gure 7: B41.7 Cr5204 Temperature (BolldeIDFu, ClrclenData)

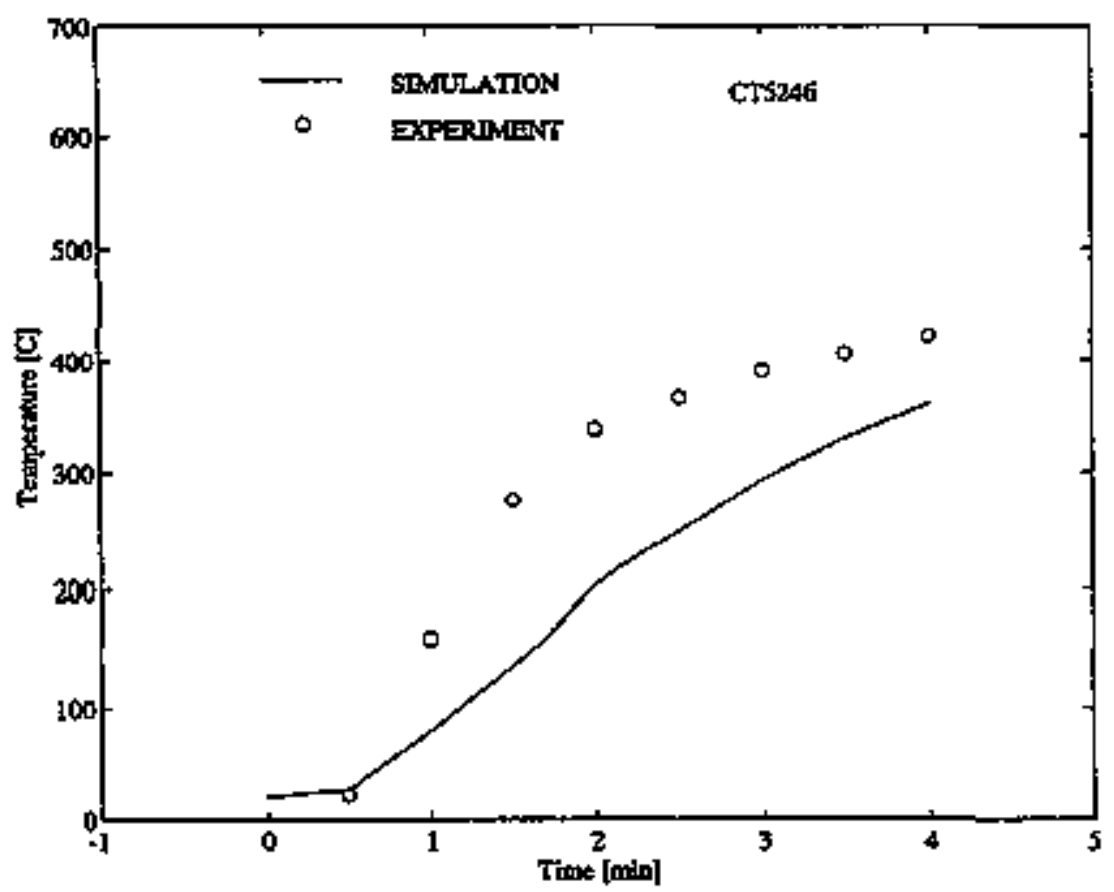

Figure B : BA1.7 CH5246 Temperatnxe (Bolld-NDFH, C1releoData) 
Test B41.7

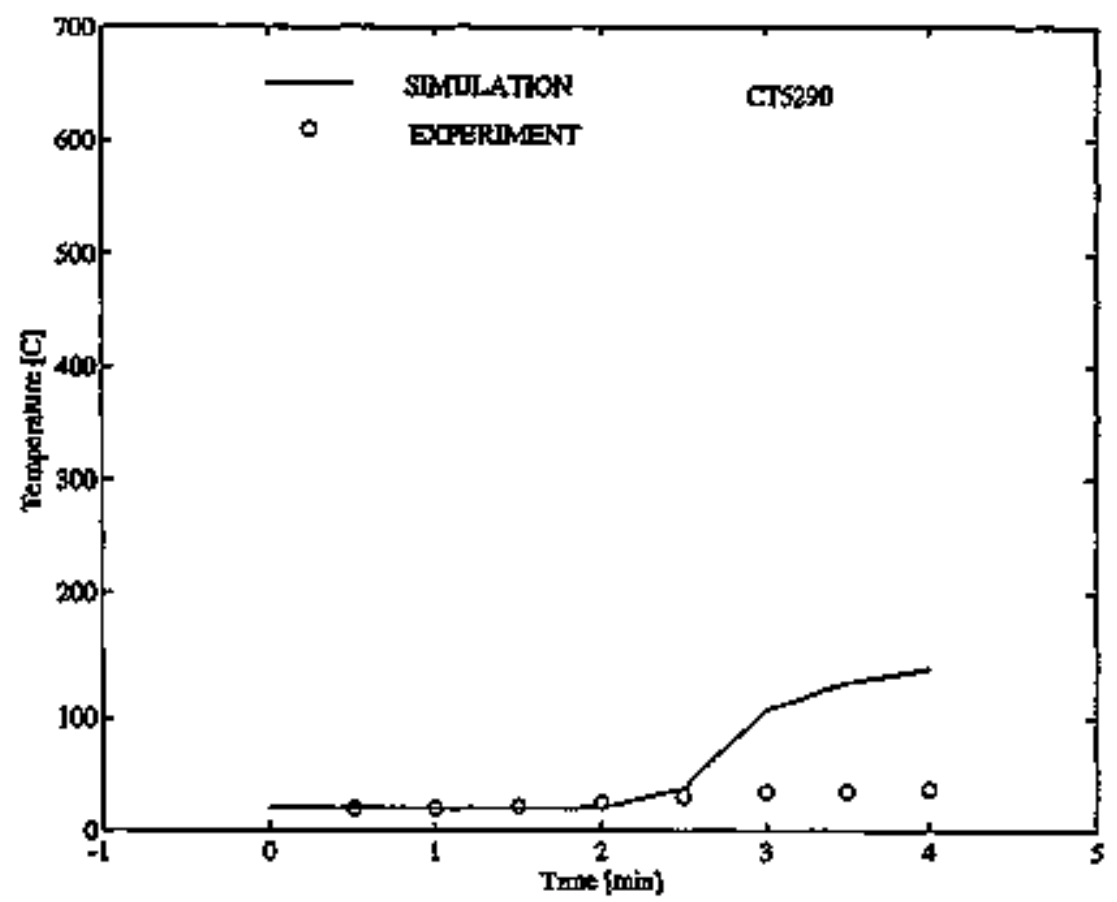

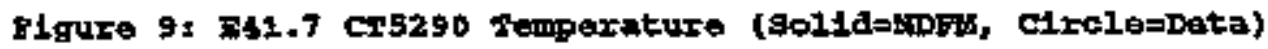

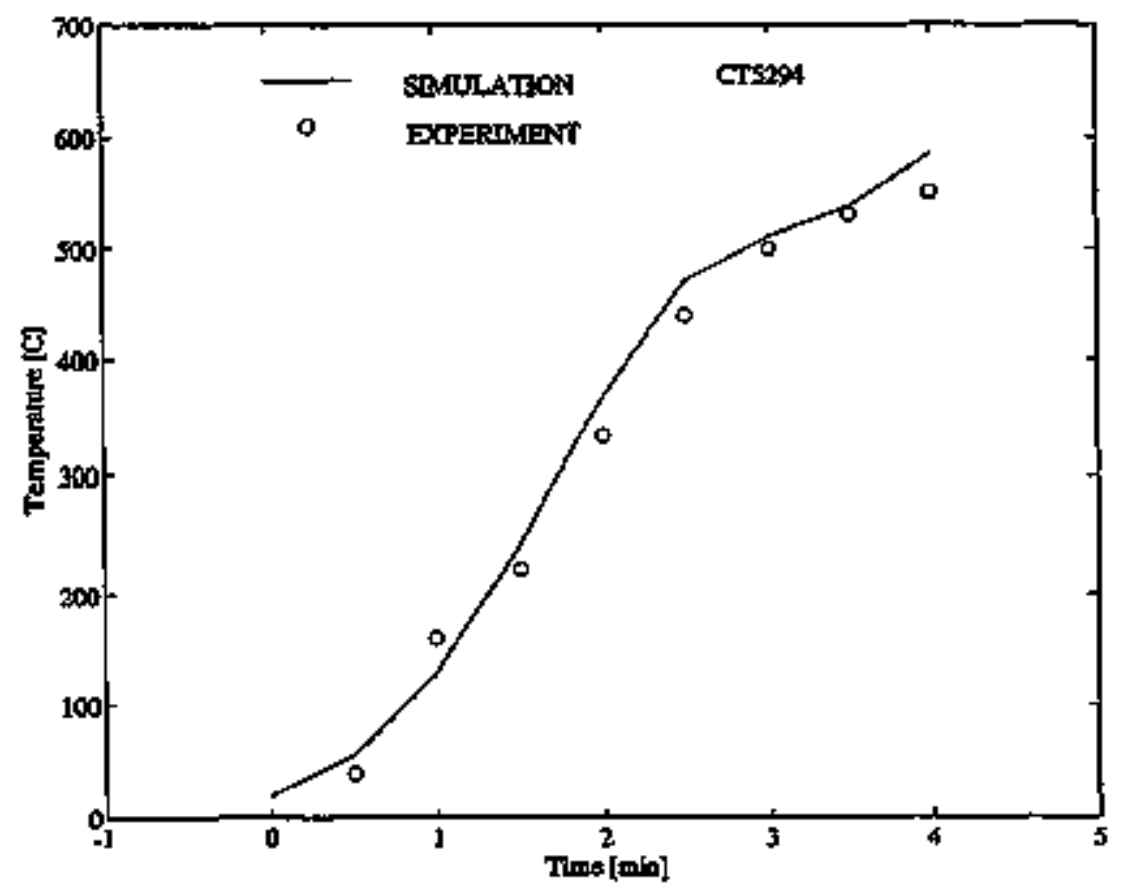

F1gure 10: E41.7 Cr\$294 Penperature (Bolid-NDFM, C1zele=bata) 


\section{F42.2 Fire Emperiment}

\subsection{Orerview of 842.2 Exper- iment}

The details of the test specification for test E42.2 are contained in the problem speciflcarion report (Karwat, et al., 1992). Test EA2.2 was a cable fire tert with high Eorced ventilation at the 1500 level of the HDR containment building (the same room that was used for the E41.7 test) - The ventilation rate for the fire room was specified as $1700 \mathrm{~m}^{3} / \mathrm{hr}$ (1) ACH) for the first 22 minutes of the test. According to the test specification, the doors to the fire room were to remain closed unttl 50 s of the fuel was involved in the fire.

Tho Eire room has a volume of $100 \mathrm{~m}^{3}$ (approximate ceiling height of $4.7 \mathrm{~m}$, and floor area of $22 \mathrm{~m}^{2}$ ). The floor and side wells are made of concrete and concrete blocks, respectively. The side walls are protected with Alsiflex mats $(2.5 \mathrm{~cm}$ thick). The ceiling is protected with Promatec (5.0 cri thick). The material properties can be found in the problem specification report.

This test differed signticantly from test 841.7 in that polyvinyl chloride (PVC) electrical cable insulation served as the source of combustible material in the room. The details of the PVC cable tray fuel loading can also be found in the problem speciflcation report.

There were 3 distinct phases to this experiment: Phase 1 - forced ventilation only, Phase 2 - door is opaned, exhaust turned on; and phase 3 - fire suppression activation. Note that Phase 3 (fire suppression activation was not included in the problem specification, and no comparisons between calculations and experimental deta should be made for this phase of the exporiment.
3.2 E42.2 zone Hodel Calculations Uating colmBRN

The COMPBRN III fire model as madified for the Pire Risk scoping Study

(Lambright, et al. 1989) was also applied to the B42.2 test. The goal of the B42.2 COMPBRN calculations was to perform blind post-test calculations for later comparison to the test data.

Test E42.2 was selected to be an International standard Problem (ISP) . Thus, there wexe strict cruidelines and much Eormality involved in the problem specification and submission of calculated results.

\subsubsection{E42.2 COMPBRN Assump- tions and Input}

The inpoxtant assumptions necessary to generate a COBPBRA III input aeck for test $\mathbf{8 2 2 . 2}$ will now be stated. A layout of the cable trays is shown in Figure 11 .

The cable trays that are covered with Alsiflex mats are not modeled in this simulation. They are included in the calculations, but no heat transfer is allowed to them. In the actual experiment, some of the trays covered with Aleiflex did tentusily becorpe involved (ignited), but this was not signtficant during Phase 1 twhich was the only phese of the expariment modeled with COMPBRN III).

The fire room (out to the doors) is madeled as a single scuare rocri of appropriate volume and surface area.

No cables in rack III are modeled, since most of thein were consumed in previous tests. Material properties assumed for the cables are in the input deck (see Figure 12).

The walls and ceiling are nodeled as Alsiflex, with the concrete material converted into an appropriate thickness of Alsiflex for the calculations. 
Test E42.2

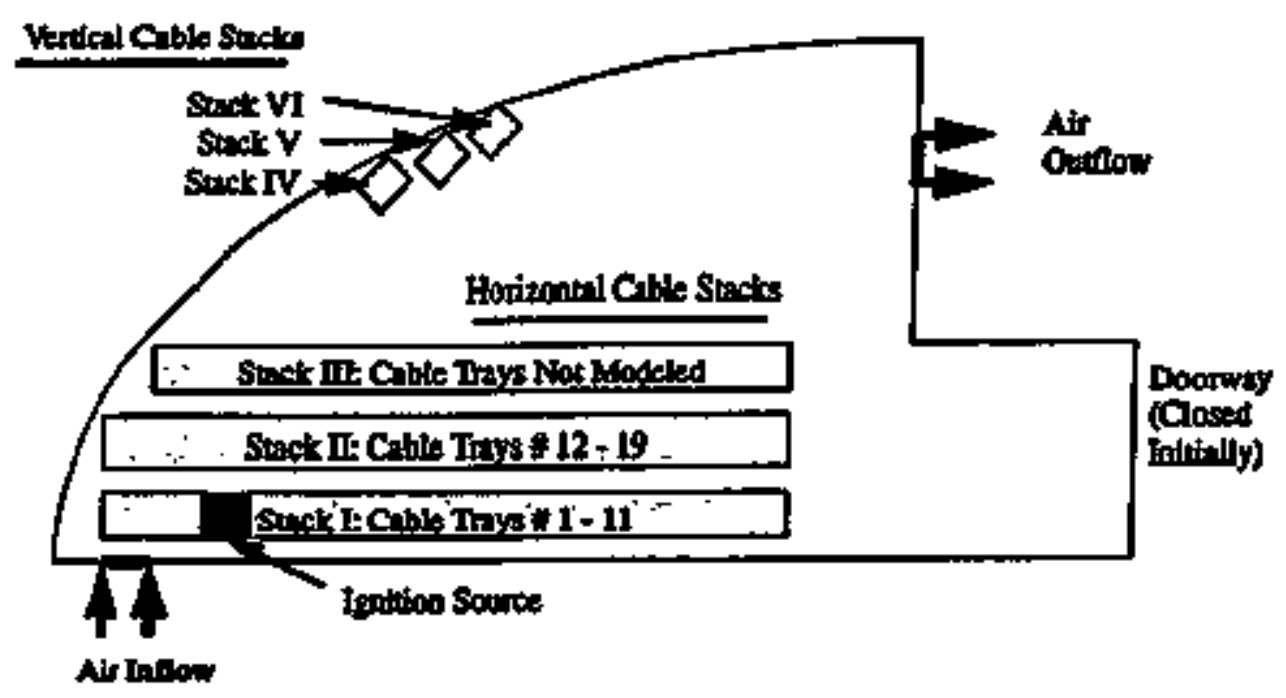

BIgure 11 B42-2 Cable Fray tegrout Diegrem (P1an VIar)

The heat of combugtion for the cables was assumed to be $17 \mathrm{~kJ} / \mathrm{kg}$ lat the upper end of whet was measured and reported in the problem specification report .

Calculations with $12 \mathrm{MJ} / \mathrm{kg}$ (the 1 wor end of that reported in the specsfication report) did not result in ignition of the surrounding trays.

An ignition temperature of $723 \mathrm{~K}$ (450 C) was astumed for the unpowered pvc cables. Thas value is consistent with the lowes limit of Sandia test data on PVC cable (Bowlen, 1989). Each of the cable trays was divided into 4 longitudinal sections for moaeling.

There was no radiation shiglding of any of the particlpating cable trays from the hot gas layer. Because of the manner in which COMPBRW models shielding, it is not possible to prohibit thermal rediation to a tray from the hot gess ley also prohibiting convective heat transfer Irom the hot gas layer.

COWPERW requires the user to input burning parameters that describe the fuel and the fire. A surface controlled burning rate of $0.0022 \mathrm{~kg} / \mathrm{m}^{2} \mathrm{~s}$ is assumed. with a radiation augmentation factor of $0.186 \mathrm{E}-06 \mathrm{~kg} / \mathrm{J}$. These values are coneistent with those used previously in other cable fire simulations (Lambright, et $a 1 ., 1989$.

A conbustion efficiency of 0.9 wes assumed for the calculations. Although this is unrealistically high for cable Insulation, it has been previously determined that such a value is necessary for COMPER to correct $1 y$ predict flame temperatures for cable fires (Nicalette, et. al. 1989).

\subsubsection{E42.2 COAPBRa Results}

Because the CoupBrt III Eire model is a zone model, the resulte of interest to us are the hot gar layer temperatures as a Eunction of time, the flre heat release rete, the ceble rabso loss rete, and the length of time until ignttion of the variour cable trays. Comperas

calculations were persormed for the parameters specified above.

Unfortunately, compBew III does not allow one to aimulate the case where a room is initialiy isolnted, and then the doors are opened at a iater time. Therefore. 


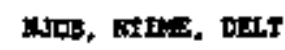

1560.

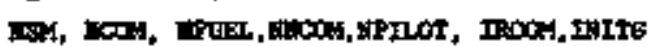

290451510

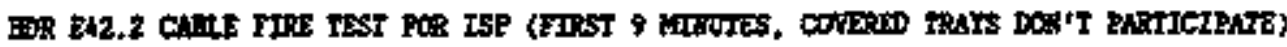

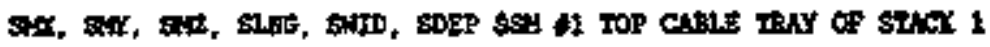

2.70 .052 .55 4. 0.3 . 0.5

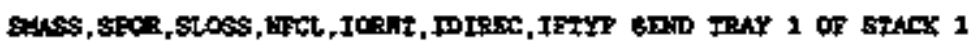

$25.33 .14 \quad 1.43 \quad 1 \quad 1$

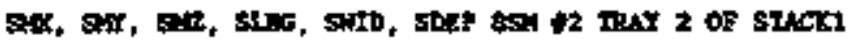

2.350 .652 .35 4. $0.3 \quad 015$

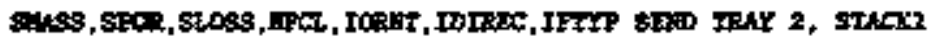

23. 3.24 1. 3131

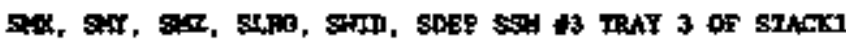

2.93 0.653 .25 4. $0.3 \quad .015$

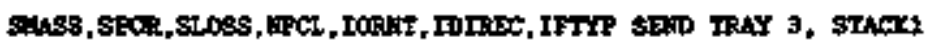

13.9 3.14 1.4 a 111

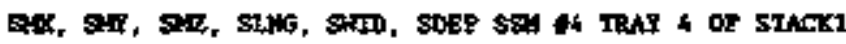

3.330 .031 .95 4. 0.3 .013

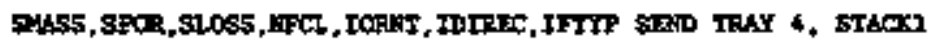

27.93 .24 1. 4301

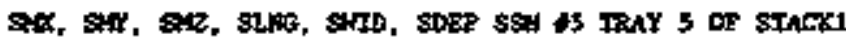

$2,330.051 .75$ 4. 0.30 .011

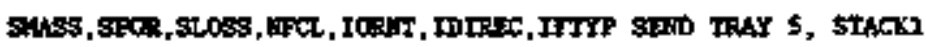

22. 3.14 1. 301

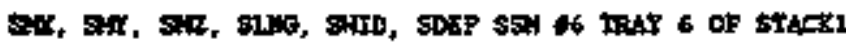

1.550 .352 .35 i. $0.3 \quad 015$

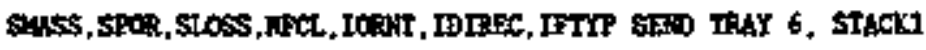

30. $3.14 \quad 1.4 .3 \quad 113$

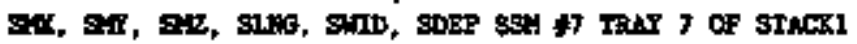

2.98 0.85 1.35 4. $\quad .3$.015

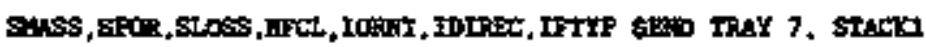

$\begin{array}{lllllll}22.3 & 9.24 & 7 . & 4 & 3 & 2 & 7\end{array}$

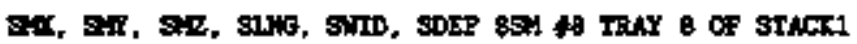

$2.93 \quad 0.851 .15$ 4. 0.3 . 015

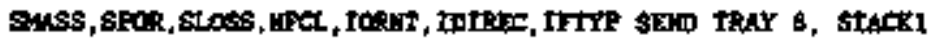

20.63 .14 1. 43131

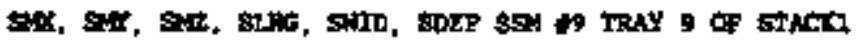

2.380 .850 .95 4. 0.3 .015

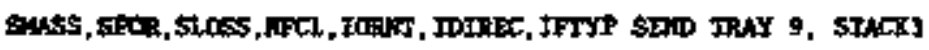

25. 3.14 1. $4 \begin{array}{llll}3 & 1 & 1\end{array}$

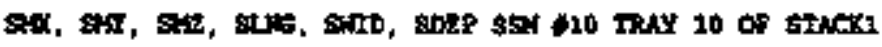

2.330 .85 0.75 4. 0.3 .015

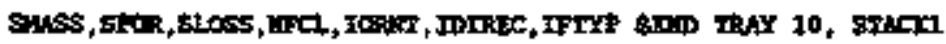

$20.3 \quad 3.14$ 1. $4 \begin{array}{llll}3 & 1 & 1\end{array}$

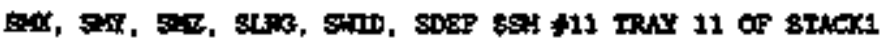

$\begin{array}{llllll}2.33 & 0.65 & 0.55 & 4 & 0.0 & 015\end{array}$

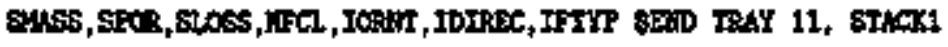

$\begin{array}{lllllll}39.6 & 3.14 & 1 & 4 & 3 & 1 & 1\end{array}$

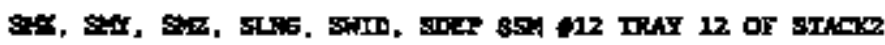

Flguxe 12: B42.2 Coupan III Input Detk 
2.391 .261 .95 4. 0.J 015

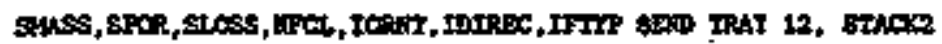
$\begin{array}{lllllll}37.2 & 3.16 & 1 . & 3 & 1\end{array}$

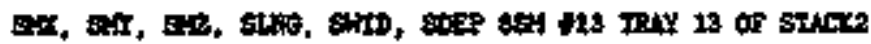

2.331 .961 .75 4. 0.3 .022

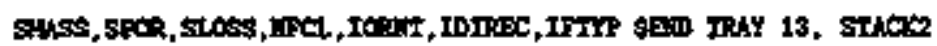
$\begin{array}{lllllll}4.7 & 3.14 & 1 . & 3 & 1 & 1\end{array}$

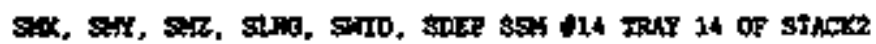

$2.931 .96 \pm .55$ 4. $0.3 \quad 025$

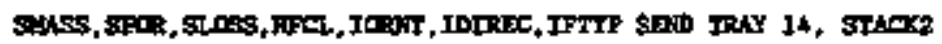
$\begin{array}{llllll}59.7 & 3.14 & 1.4 & 3 & 1 & 1\end{array}$

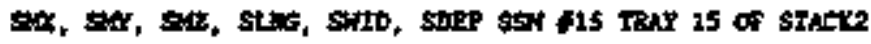

$2.331 .961 .35+0.3+015$

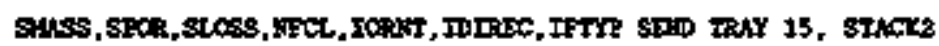

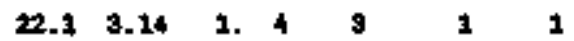

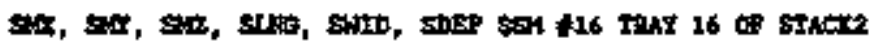

$2.331 .961 .15+0.3+025$

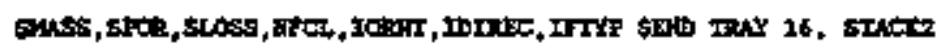
$\begin{array}{lllllll}16.2 & 3.14 & 3 . & 3 & 1 & 1\end{array}$

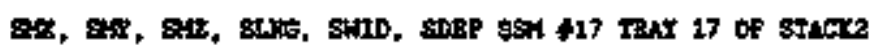

2.331 .960 .95 4. $0.3,015$

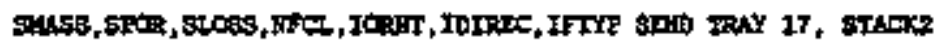
$16.3 \quad 3.263 .4351$

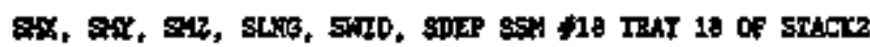

2.33 1.96 0.7s 4. $0.3,015$

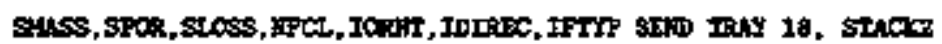
26. 3.14 2. 4301

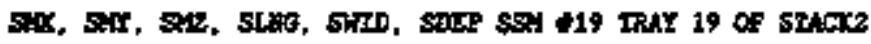

2.331 .960 .53 i. $0.3 \quad .013$

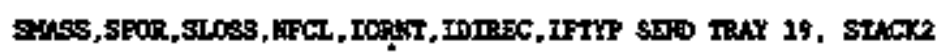

26. 3.14 1. $43{ }^{4} 1$

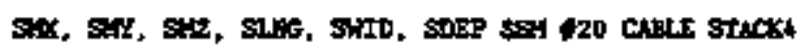

2.45 4.11 2.25 4.5 0.3 +015

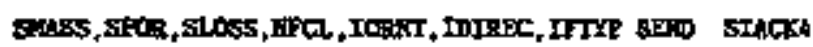

25. 3.14 1 . 420 3 1

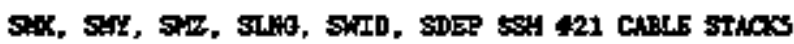

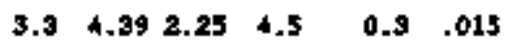

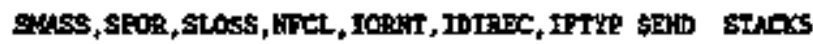

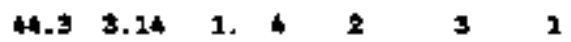

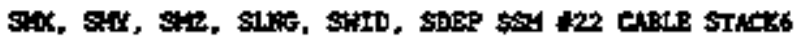

$4.15+.612 .25$ 4.5 $0.3 \quad .0 \pm 5$

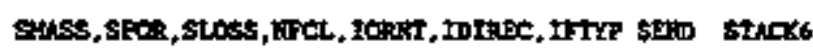

22.43 .141 .42301

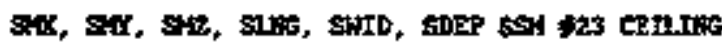

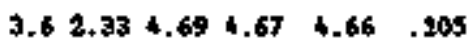

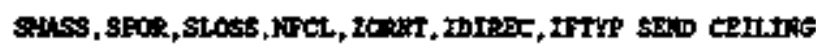

1. 1.1 . 1313

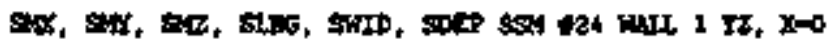

0. $1.552 .354,69 \quad 3,1 \quad$,4

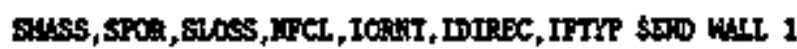

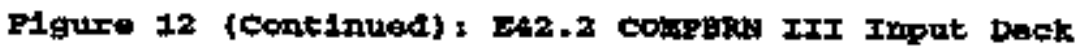




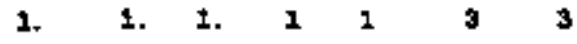

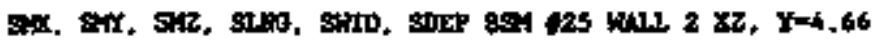

$2.33+.662 .35+.69+.66$.275

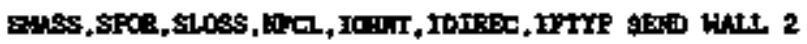

1. 1.1 . 1 z 303

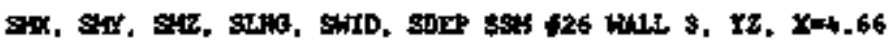

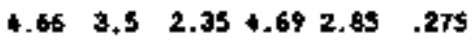

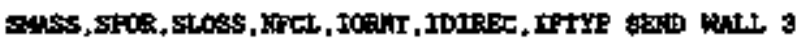

1. 1.1 . 1 . 130303

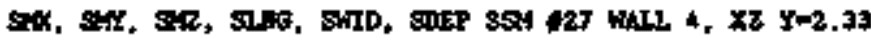

$6.095 .062 .35+.67 \quad 2.65 \quad .275$

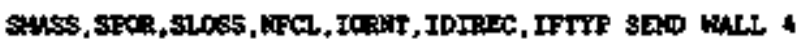

1. 2. 2. $1122 \quad 3 \quad 3$

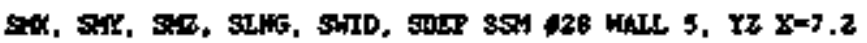

$7.2 \quad 1.632 .35$ \$.69 2.65 .275

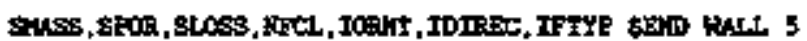

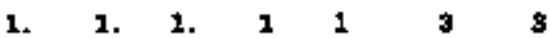

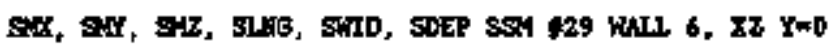

2.33 0. 2.354 .69 1.66 , 275

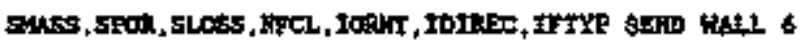

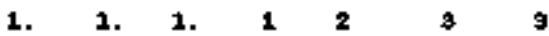

IFII, JPII, IFTur, twess

$5 \quad 2 \quad 1 \quad .05$

IFUal, DEFs, SERr

$1,40,20.2 \quad 1715 ., 2 * 130 ., 756.1045 ., 2 * 1000 ., 2090$.

TEIK EENT EFP

$.092,3+0.1 \quad 1.757,2+1, .4 .287 \quad .9,2 * 0 \ldots . .9$

ETCTP ETHW FIOTS

$729_{+}, 3 \div 2000,673_{+}, 3+2000+223_{+}, 3+3000$.

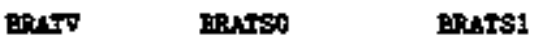

$.05,3 * 0 . \quad .0022,2 * 0 ., .062,1068-6,2 * 0,4.35-7$

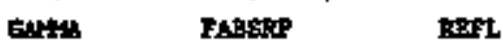

$4 * .3 \quad 4 * 1.4 *+2$

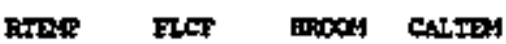

290. 23. $10 . \quad 0$.

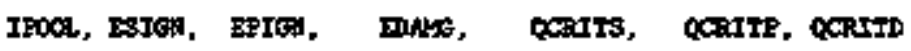

$\begin{array}{lllllll}1 & 1 . E 12 & 1.812 & 1 . E 12 & 1.89 & 3.6 \mathrm{Eg} & 7.289\end{array}$

seE: TF-1,3, $\mathrm{x}, \mathrm{t}$

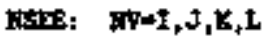

$1,8 B A, 3,11$

2, ista, 4,11

$3,888,5,11$

$+, a 8:, 6,11$

5, ase, 6, 11

$1, \mathrm{gak}, 14,19$

$2,884,14,19$

$3, \mathrm{Bt}, 14,19$

$4,989,16,19$

5, 984, 14,19

$1,908,21,28$

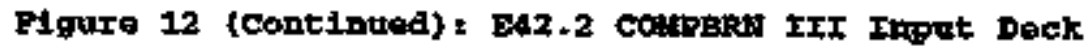




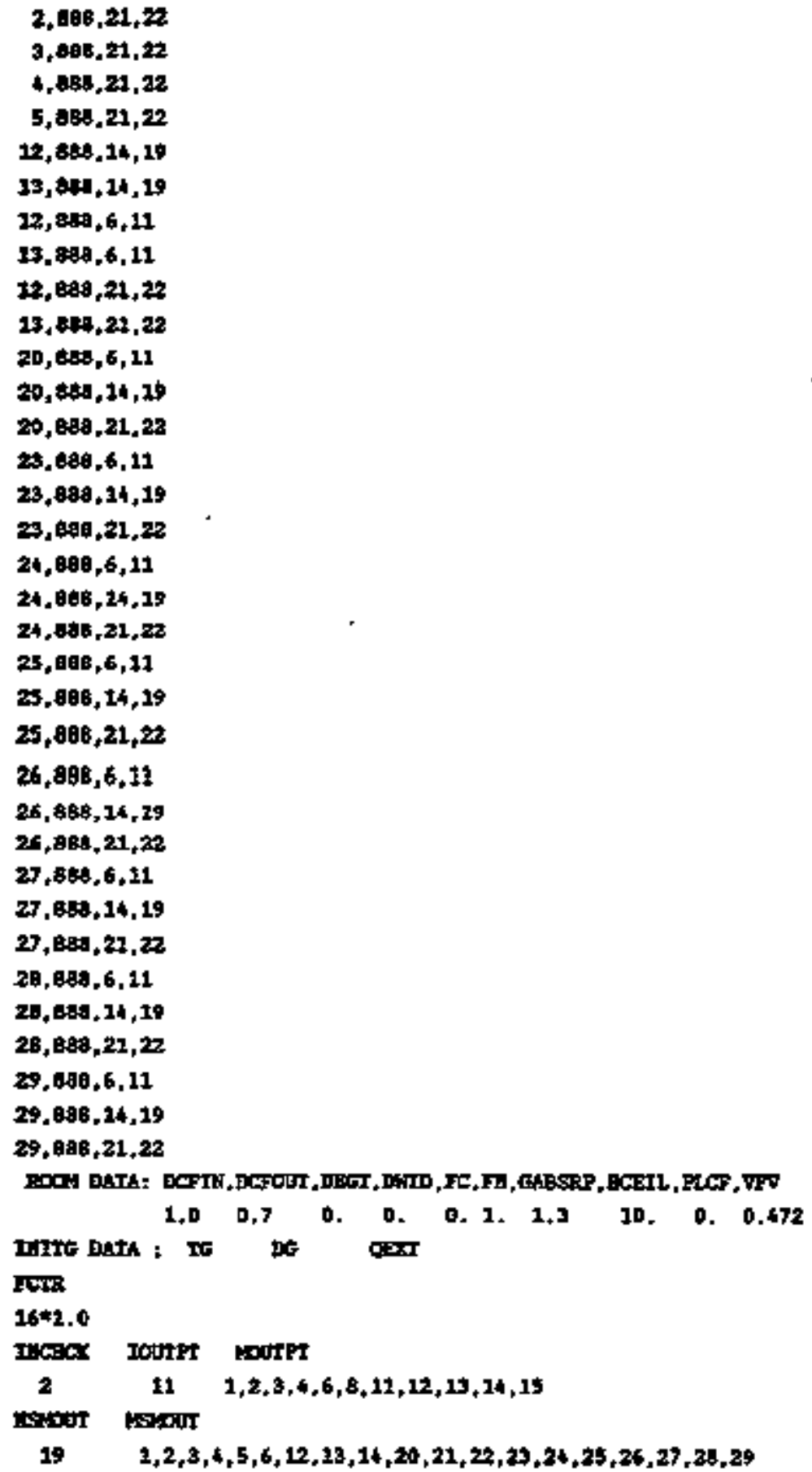

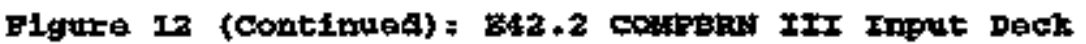


the calculattong could not be carried out for times greater than 9 minutes (Phase 1 .

The measured mass lass rete was supplied to all participants before the calculations were porformed. Some of the participants chose to airectly use the supplied mass loss rate for their calculations. For our purposes, the supplied values were used to guide some of the parameter selections in COAPBRN III. The fire modol then calculated a mass loss rate of its own.

The plots of the fire power output, the total energy released, and the mass loss rate are show in Figures 13-15,

respectively. of these three quantities, only the mass loss rate was measured in the actual test. As seen in Figure 15, COMPBRN III signiflcantiy under-predicts the mess loss rate during the first 5 minutes of the test. The calculations indicate that there is very little flame spread during this time. The non-burning cables are pre-heating, but have not roached the ignition teroerature. COMPBRN III does a reasonable job of predicting the cable mass loss rate during the 6 - 9 minute time frame, and slightly overpredicts the mass loss rate fron the cable trays. The calculated and experimental results have the same slope during this period.

The hot gas layer temperature as a function of time is shown in Figure 16. The Iasults indicate a steady rise in hot gas layer temperature between 4 and 9 minutes into the fire. This corresponds to the fgnition and subseguent burning of cable trays 2,3 , and 4 during this time period. The coupBR IIf results greatly underpredict the tenperatures measured with thexmocouple Cr5298 dursing the first 5 minutes of the test. This result is expected based on the large difference between the calculated and measured mass loss rates during thls time period. However, it is interesting to note that COMPBR calculates a HGL temperature of $405 \mathrm{C}$ at the 9 minute merk, which agrees well with the peasured value of $440 \mathrm{C}$.

In Table 3, the calculated time at which each cablo tray ignites is shown (in minutes). For cable trays which have not ignited by the 9 minute maxk, the aurface tenpexature of the cable trays is shown (in degrees Relvin) at 9 minutes. Note that since each tray was divided into 4 geginents in the COMPBRN model, the time/ temperature is given for each of the 4 secgments. From this table, we can deduce the following sequence of cable tray ignition and fire growth. One quarter of tray 5 of rack I is the only eable tray that buxns during the first 4 minutes of the fire. At 4 minutes, the quarter of trays 2,3 , and 4 of rack I that are directly above the burning quarter of tray 5 also igntte. At 6 minutes, the guarter of tray 1 of rack I that is firectly akove the burming guarter of tray 2 ignites. From 6 to 9 minutes, no new ignitions occur. However, at 9 minutes much of the remaining cable insulation ignites, or is very close to ignition. At 9 minutes, 2 quarters lout of the remalining 3 guarters) of trays $1-$ 5 igmite, so that $75 \%$ of these trays are burning or have been burned.

Additionaliy, 3 guarters of cable tray 30 of rack IV have ignited at the 9 minute mark, and all of the resalining cable instulation is seen to be within $50 \mathrm{C}$ of the assuned ignition temperature.

As seen in Table 3, a radicel change in the fire enviromment is predicted by COAGERN III at the 9 minute mark. All of the combustible cable insulation is either burning or within $50 \mathrm{c}$ of the ignition temperature. It appears that the fire room is very close to the flash-over point. Unfortunately, no longer times could be modeled due to the limitations of COMPBR III (the test specification indicated that the doors would be opened at this time in the test).

The results shown in Table 3 are in very good agreement with regard to the obsezved tining of cable tray ignition in the tests, with the exception of the initial stages of the fire. The test results indicate that all of the trays directly above the Inttial burning tray ignited within 2 minutes of the first tray (based on therpocouple data). whereas the calculeted results indicate 4 minutes (or more) is required to ignite any of these trays. This partly explains the large differences in calculated and messured cable tray mass loss rate during the early paxt of the test. This ney also be a result of the relatively long time 
step used in the COUPERN calculations i minute) .

The COHPBRN restults also indicate thet more than 508 of the combustible material in the fire room will be involved in the fire (buxning) by the 9 minute mark. This is in very good agreement with observations made during the test whlch Indicated that this occurred between $a$ and 9 minutes following ignition.

While these zesults are in fairly good agreement with the test data, the compBra III results wate noted to be very sensitive to the choice of input parameters. The above results are a strong function of the PVC heat of combustion, igmition terogereture, pVC thiekness used, discretization of the cable trays, time step size, and comblistion efficiency assumed. Por reasonable ranges of these paxameters, the results varied from no secondary ignition within 10 minutes following primazy igmition, all the way to full involvement of all of the fuel within about 4 minutes following primary ignition. The particular set of results discusaed above was selected as the nost realistic because it was closest to the mass loss rate data provided prlor to the calculations. Whille the abote results are Iimited to the COMPBRA III model, many of the other fire models used by the other participants exhibited similar gensitivities to input parameters.

Table 3 : Cable Iray Iontelon/Tenparature

\begin{tabular}{|c|c|c|c|c|c|c|c|c|}
\hline Rack \# & \multicolumn{5}{|c|}{$\mathbf{I}^{*}$} & \multicolumn{2}{|c|}{$\mathrm{II}^{*}$} & $\mathbf{I V}$ \\
\hline $\begin{array}{c}\text { cabl: } \\
\text { Tray }\end{array}$ & 1 & 2 & 3 & 4 & 5 & 12 & 13 & 20 \\
\hline Segureut 1 & 9 ants & 9 min & 9 miц & 9 min & 9 هن 9 & $718 \mathrm{~K}$ & $716 \mathrm{~K}$ & $707 \mathrm{~K}$ \\
\hline Segmedt 2 & 6 מנt 6 & 4 min & 4 ming & 4 min & 0 म' 0 & $722 \mathrm{~K}$ & $715 \mathrm{~K}$ & 9 מ 9 \\
\hline Segment 3 & 9 mig & $9 \min$ & 9 nin & 9 min & 9 min & $696 \mathrm{~K}$ & $695 \mathrm{~K}$ & 9 min \\
\hline Segurerd 4 & $705 \mathrm{~K}$ & $706 \mathrm{~K}$ & $701 \mathrm{~K}$ & $695 \mathrm{~K}$ & $688 \mathrm{~K}$ & $677 \mathrm{~K}$ & $677 \mathrm{~K}$ & 9 min \\
\hline
\end{tabular}

* Humberg ingicate the tine at which the cable tray sepowe ionited, or the grifface

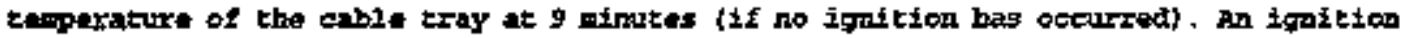
cengerscure of $723 \mathrm{k}$ was assumed for the calcutations. 
Test E42.2

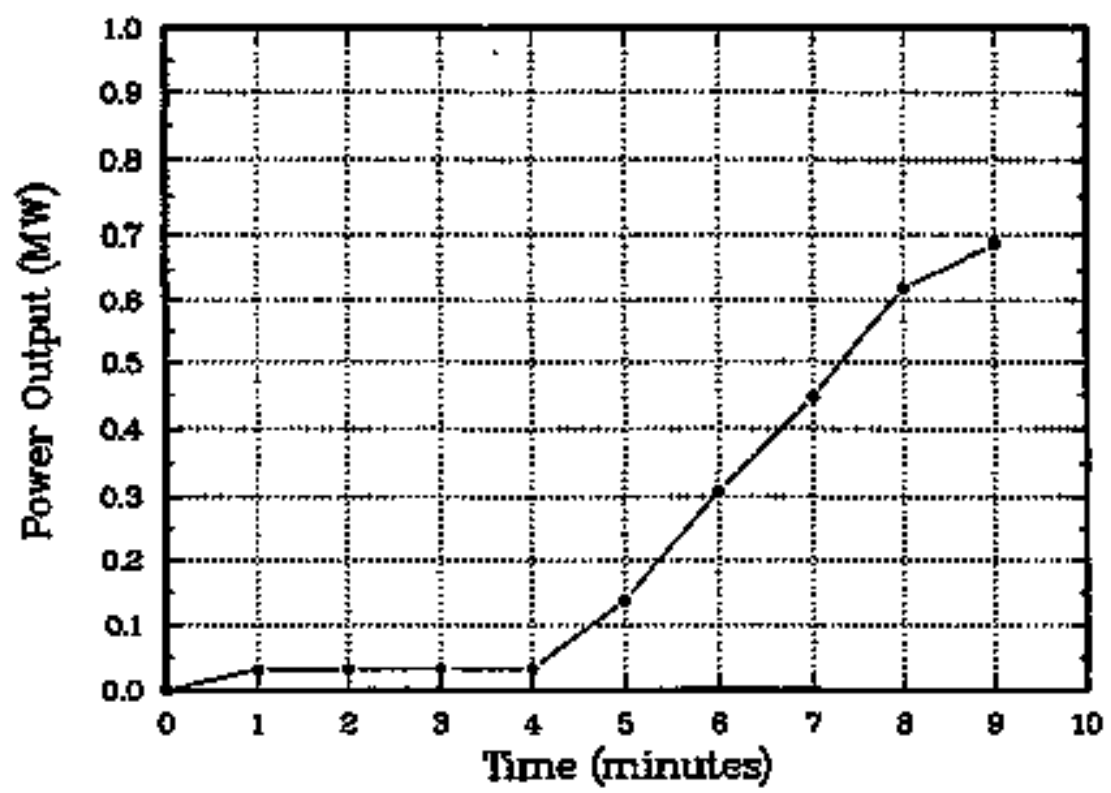

B1gure 13: COLPara BA2.2 F1Ie Power Ontput

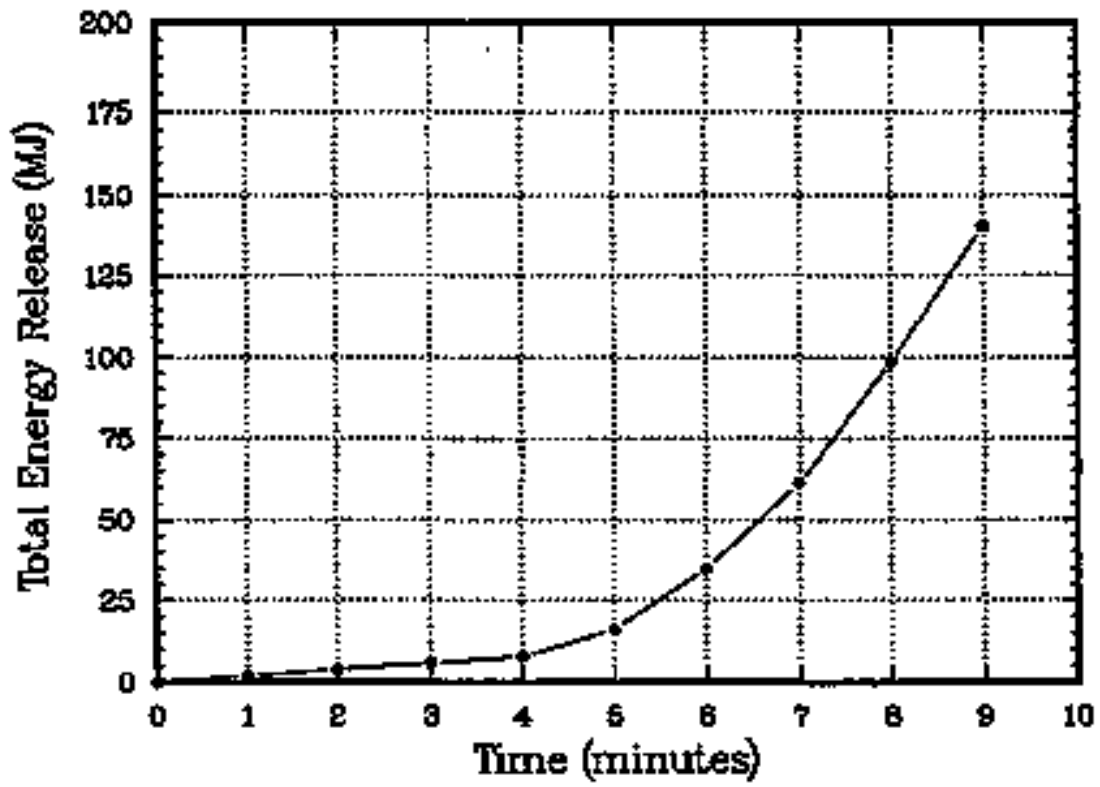

F1gure 14: COMPBEN E42.2 FLre Total Enersy Output 


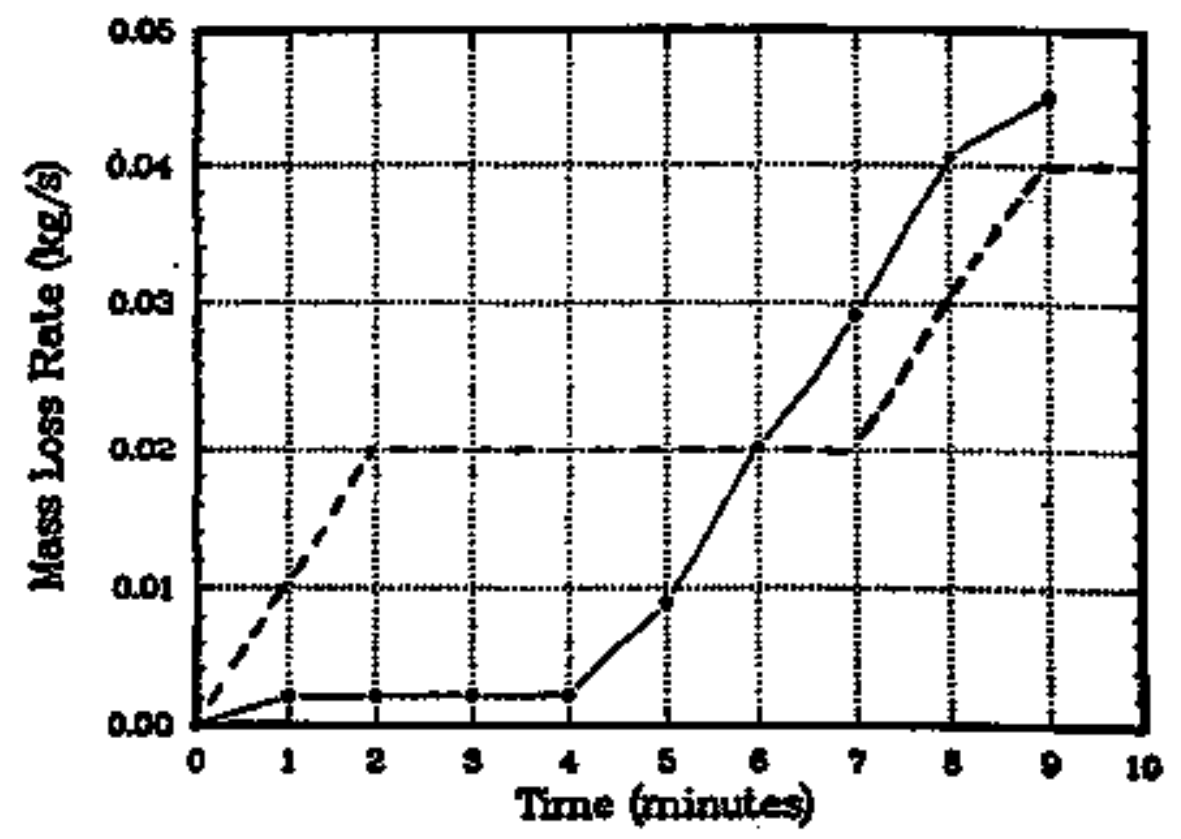

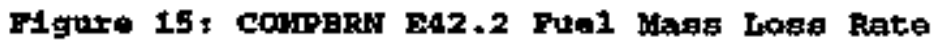
(\$olta - conpar raaults, Dagh = Hoasurwa)

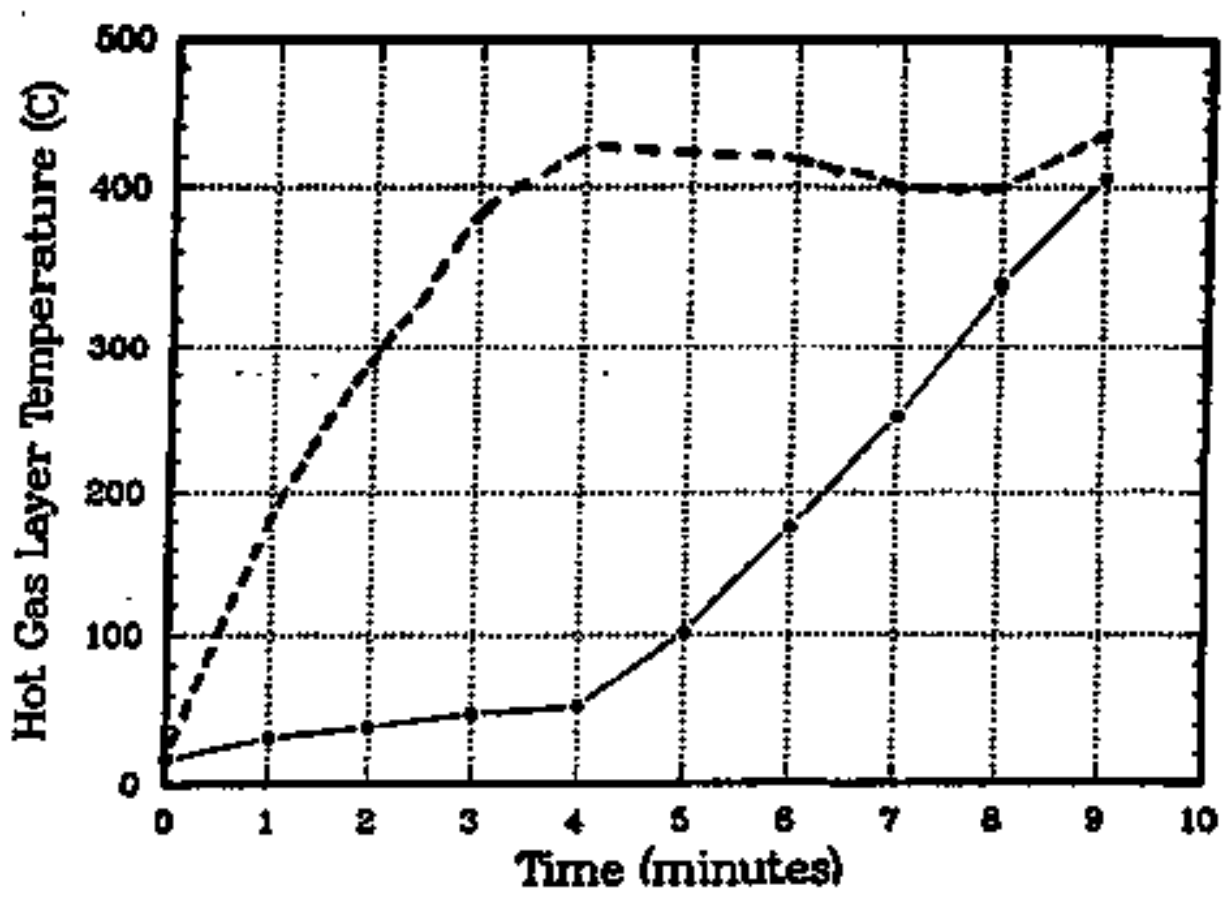

Flgure 16: Coireka D42.2 Hot Gas Inyor Tomeratures

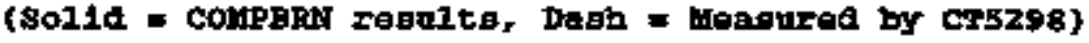




\section{Other HDR Fire Nodeling Feforts}

Because the HDR program has been international in scope, there have been ineny inter-related efforts by researchers in many countries. In this chaptex, the participants for anch set of calculations and their results will be discussed. Appendix A contains a brief description of some of the fire models that have been used by these researchers.

\subsection{E41.7 Participant:}

A list of participants atteoding the E41.7 problem specification meptings is shown in Table 4 . These meetings were

Table At Fd1.7 Partielpants

\section{Name}

k. Müller

H. Rowekanp

W. Rruger

K. Junģling

v. Mucolette

K. Fischer

R. Dobbernack

R. Huhtamen

o. Keski-Rahkonen

H. Jahn

B. Schwinges

A. Roche

R. Rzekiecki

R. Schmidt

R. Volk

U. $\operatorname{tax}$

\section{Instikntiou/Cantry}

KfR, Germany

GRS, Germeny

SAA, Germany

TUV, Germany

SNL, USA

Battelle, Genany

TUB, Germany

VTT, Finland

VTT, Finland

GRS, Germany

GRS, Germany

CEA, France

CEN, France

Pichtner, Geringmy

HDR, Germany

v. Raesel, Germany held in May 1990 in Kahl, Germeny, and were chaired by $\mathrm{Mr}$. $\mathrm{K}$. Mullez of $\mathrm{kfR}$.

It is interasting to note that the majority of participants at this meeting indicated that they would use zone models for the modeling of test B41.7. The only exceptions to this were Sandia, WIT, and Battelle-Frankfurt, which indicated that they mould use field models or hybrid models for the calculations (possibly in addition to any zone model calcu,lations) . The other participants were vory skeptical that field rodeling could be applied to such a complex problem, and were openly cublous of the possibility of succeeding. In fact, the geometric information that KF distributed to gll participants was not nearly as detailed or extensive as required for an accurate fiela model calculation of the whols contatrment. This necessitated getting the information from an extended plant walk-down or from plant layout drawings at each elevation.

There were also many lively discussions at this meeting between the people conducting the experiments and those trying to model the resulting fires. These discussions point to the need for experimentelists and fire modelers to work closely together, if progresi is to be made in fire modeling. It is critical that the poople conducting a fire experiment understand the sensitivity of fire model predictions to such factors is couplex geomatries, ventilation boundary conditions, and fuel properties.

Likewise, it is critical that the people developing and validating fire models have a good understanding of the technical issues faced by the experimentalistis in attempting to conduct a realisetic test.

At times in the HDR discussions, there was obviously a wide gap between the perspectives of the experimentalists and those of the modeling people. The exper1mentalists ware determined to conduct tests that would be as realistic as posstble, complete with changing ventilation rates, doors opening. filters clogging, actual electrical 
cables, etc. This goal is very praiseworthy, and es a result, a wealch of very unicue experimental data was generated on realistic fire environments in a nuclear power plant contrinment.

Infortunately, fire models are generally not well developed pnough to handle these very real elements of a fire. (For exemple, some of the models require that the lser must input the burning rate of the fuel as a known parameter.) As a conseguence, some of the test scenarios were beyond the capabilities of any fire modiel thet has been develoged to date.

While the alscussions concerning the HDR experiments and modeling efforts were sometimes heated, they were very eaucational. As a consequence of these discussions, the people involved in the HDR experiments as well as those involved in the modeling eftarts gained a deeper appreciation for the problens faced by the other cemp. Hopefully, this will result in tighter integration of experimentalists and modeling people in tire modeling development and validation efforts (as well as in fire test efforts) in the future.

\subsection{F41.7 Calculations by Other Paxticipant:}

Only a brief summery of the E41.7

calculations by other participante will be gfven. Sandia was the only participant to apply a fteld model to this problem (in addition to a zone model). All of the othex paxticipants applied anlti-room zone modiels or control volupe models to test $\mathrm{E} 41.7$.

The level of agreement of the model results with the test megsurements is a strong function of location in the containment, Within the flre room itself, the HRPC (see Appendix A) model (applied by Schnetder and Lebeda of the Univ. of Wien, Austrifi) and the BRI2 (see Apopndix A) model (applied by $J$. Rockett of Fire Analysis Hodeling and 0 . Keski-Rahkonen and $\mathrm{L}$. Heiktila of VTr, Finland) appeared to give the best agreament in the hot gas layer region. Th1s can be seen in Eiguras $17 \mathrm{a}$ and $17 \mathrm{~b}$.
In both figures, the dark line represents the measured thermocouple temperatures.

Hote that these two models were the only two that were consistently within $250 \mathrm{C}$ of the measured temperatures. This poor agreement was heavily influenced by the fact that the fire room was virtually a fireball, wich most fire models are not designed to model. In generisl, the agreemert became worse (and the disparity wider) as roons other than the fire room were exantined.

This level of agreement land the wide disparity in modeling results) reflects on the state of the art in fire modeling, and why it js sometimes considered to be more of an art than a science. In meetings with the other participants, the large influence that moteling

assumptions have on the model results was often the focus of the discussion. Again, it must be recognized that the results of a fire model are not only a function of the model itself, but are also a strong function of the experience and judgement of the one who applies the moalel.

\subsection{E42.2 Participants}

A list of participants attending tho E42.2 problem specification mestings is shown in Table 5 . These meetings were held In Karlszuhe, Gemmany, in Way 1992. ara were also chaired by Lr. $\mathrm{K}$. Mitler of KfR. Notice that this group of fire modeling participants is lazgar and broader than that for the EAl.7 test. At these meetings, each participant was asked to indicate the fire models that thoy were planning to apply to the ISP. These fire models are listed in Table 6 . A brief description of some of these fire models is given in Appendix $\mathbf{A}$.

of particular note is the fact that most of the E42.2 participants expressed gralt interest in field models. While only a fow indicated that they might try to use Eield models for the $\$ 42.2$ calculations, most participants openly discussed the development of (and need for) itxe field models. Compared to opinions expressed at the 841.7 meeting 2 years previous, this represented quite a shift in international opinion within a very short time Erame, and reaulted to a large 


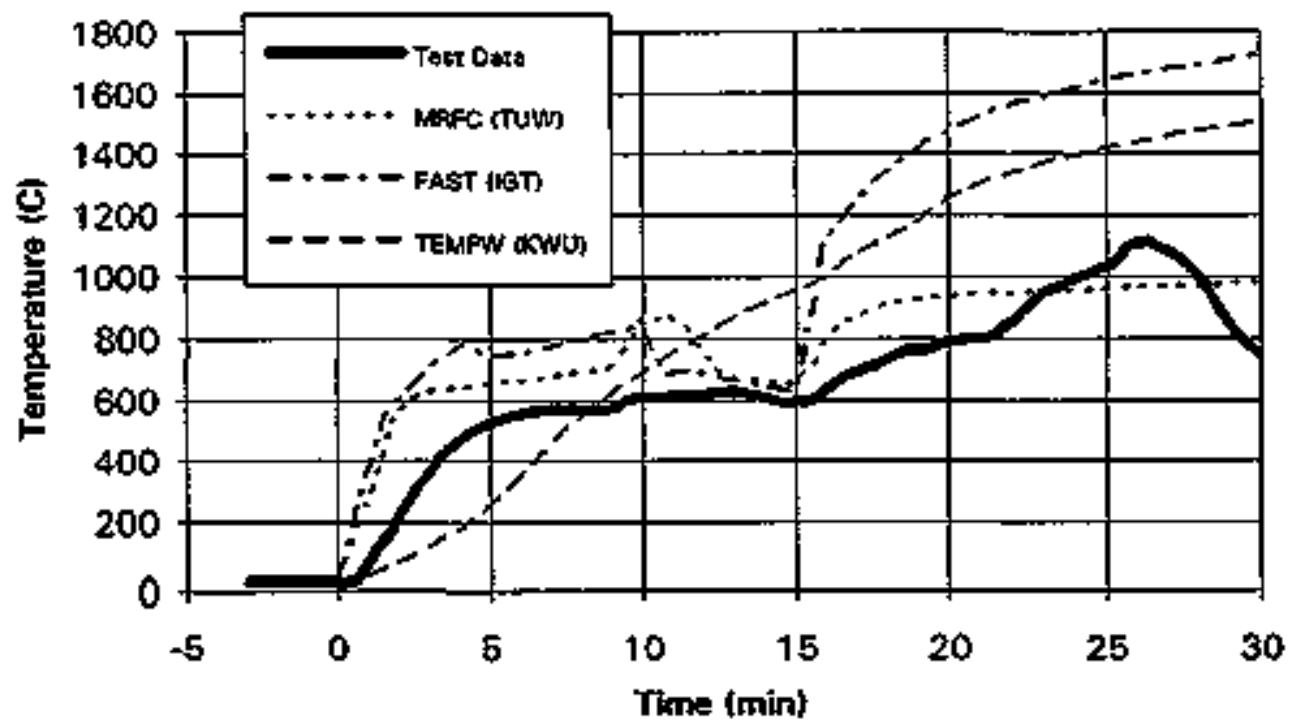

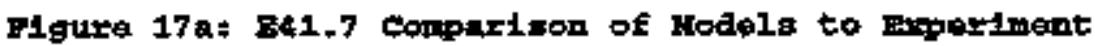

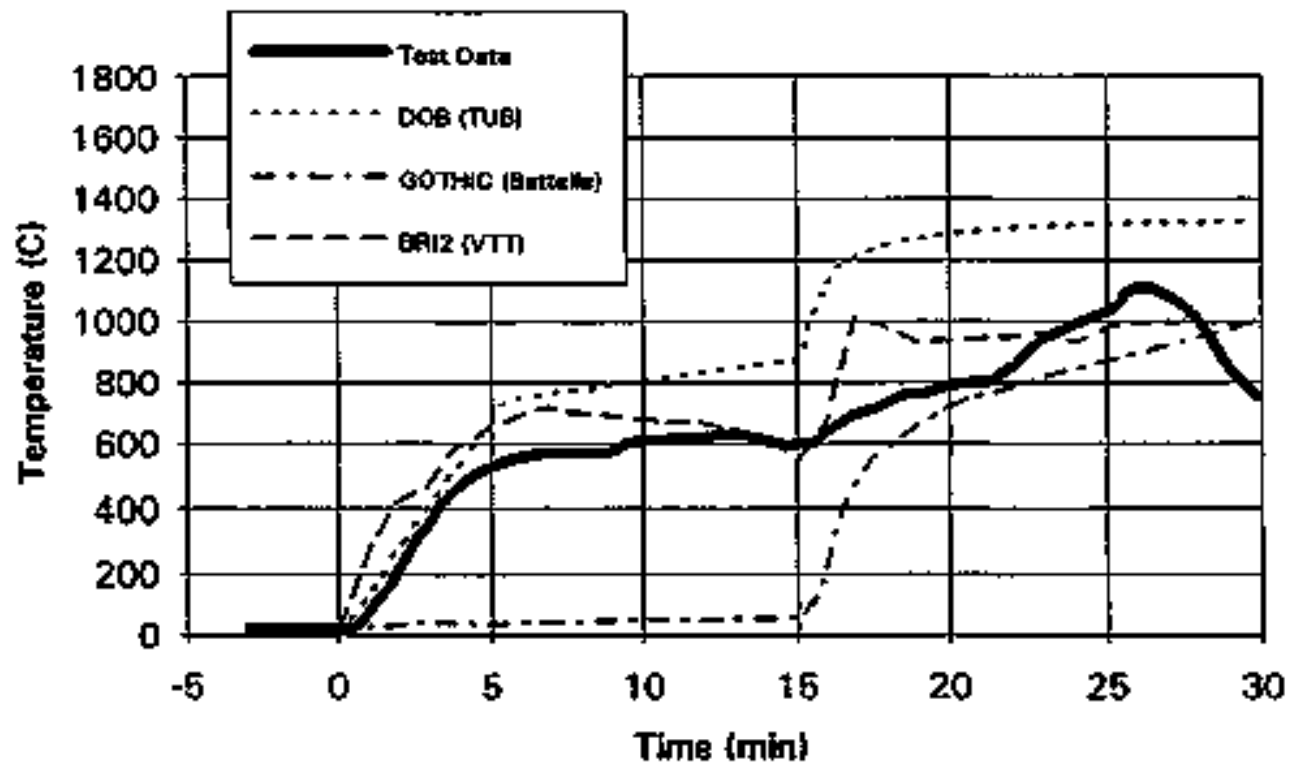

Flgure 17b: 541.7 Compartson of wodels to Bxperinent 
extent) from the successful application of a field modol to the King's cross fire (Slmcox, tt al, 1988).

\subsection{E42.2 Calculations by other Participants}

only a brief summary of the E42.2 calculations by other pattielpants will be given. Hore detailed information is available in the Proceedings of the 1993 Structural Mechanics in Retctor Technology (SMiRT) Conference, PostConference Seminar 6 , in Heidelberg, Germany, August 1993

(KfK 1994). A final report from the Buropean Commission $1 \%$ also avalzable (Karwat, 1994).

Test E42.2 was an 1nternational standard problem, and the moteling regults were coordinated and assembled by Professor karwat of the Univiersity of Munjeh. As mentioned previously, all of these calculations were performed in a blind fashion, except thet the messured cable mass burning rate (not the HRR) was given.

of the approximately 25 organlations originally interested in partłcipating in the ISP (soe table 5), only 8

(including Sandia) submittea

calculations (indicated in Teble 6). This was perhaps due in part to the complexity of modeling cable tray fires. It was also interesting to note that there wexe no field model calculations submitted by any of the participants. This reflects the fact that it is generally not cost. justifiable to apply cPv-intensive field motels to fire scenarios in which the heat source (input to the field model) is poorly defined (as in a dable tray exre), since the heet source fnput drives the fiela model talculations.

Two general comments can be made concerning the compartsons of all of the particjpant's calculations to the E42.2 test data. First, in every case the calculated hot gas layer temperatures in the flre room lag far behind the measured tenperatures (Figures 18a and b). This may result from the use of quilesent plume correlations in all of the models, when in fact, slgnificant velocities can be generated in the surrounding air for fires in enclosed spaces. The use of quiescent plurin correlations for such fires can result in significant underprediftion of the air entrainment and fuel burning rates (Rockett, et al, 1992).

The second comment that can be made from the results is that a good madel for cabie pyrolysis and burning is not presentiy available. There was great disagreement between the burn rates predicted by the various models. This points to the ract that the rodeling of solid material combustion (pyrolysis and burning) is perhaps the most imuature aspect of fire modaling. All participants expressed the need for further research in this aren in particular. Even knowing the mass loss rate of the cable trays, the HRR estimates varied greatly among the alfEerent models.

of note in this regard, fixe models generally reguire the user to input the heat of combustion of a metexial as a constant value. During discussions of the $\mathrm{EA2}, 2$ resules, Mr. Kesk1-Rabkonen of vist pointed out that the heat of combustion for a teal material is generaily a function of time. One should not expect that the energy released (and the rate of releasel Ior volatile components that are produced initially in a fixe will be the sarue as that of the remaining charred meterial. tr. Reski-Rahkonen was weli-cualified to discuss this issue, as he had experimentally measured the hest of combustion for the cables used in test B2.2. His measurements indicate that the heat of combustion varied over the cange of $10=37 \mathrm{~kJ} / \mathrm{kg}$, depending upos the time into the fire and the incident heat flux to the cables. 
Tablo 5x Hor s42.2 calculation Eartiolpanta (originally Intoregted)

\begin{tabular}{|c|c|}
\hline Name & Affiliation \\
\hline V. Nicolette & Sandia National Labs., USA \\
\hline fi. Holzbaner & $\begin{array}{l}\text { Battelle Institute, Frankfurt, } \\
\text { Gernany }\end{array}$ \\
\hline o. Kesk $\ddagger-R a h k o n e n$ & VTT, Finland \\
\hline W. Gregory & Los Alanos Lab., USA \\
\hline P. Buttner & Bnergiewerke Nord GmbH, Gezmany \\
\hline c. Wheatley & AEA Technology, UR \\
\hline A. Samman & Siemeng KorU, Germany \\
\hline พ. Hensel & Siemens KWD, Germany \\
\hline R. Rzekiecki & CEA, Cadarache France \\
\hline U. $\operatorname{Sax}$ & Univ, of Kassel, Germany \\
\hline c. Lebeda & Tech, Univ, of Wien, Austria \\
\hline Eatcher & EDE, Iyon Prance \\
\hline Chabert & EDF, Paris France \\
\hline Mosse & EDF, Lyon Prance \\
\hline A. Ranelletti & FFEr, Italy \\
\hline R- Dobbernach & $\begin{array}{l}\text { Tech. Unty. Braunschwelg, Ger- } \\
\text { many }\end{array}$ \\
\hline P. Stolze & Tech. Jniv. Munchen, Gezmany \\
\hline M. Rowekasup & GRS, Roln Germany \\
\hline A. Alemberti & Ansaldo, Italy \\
\hline
\end{tabular}


Toble 6: Fire Models for ISP (Originally Plewed)

\begin{tabular}{|c|c|c|}
\hline Institution & Fire Model & Type* \\
\hline GRS & CRDLOC & 3,4 \\
\hline Sandia & COMABRN III & 1 \\
\hline Battelle Frankfurt*** & GOTHE & 4 \\
\hline VTT*** & BRI2 & 2 \\
\hline Los Alamos & FRAC \& FLOW3D & $1,3,5$ \\
\hline Energtewerke Nord"* & FAST & 2 \\
\hline AEA Tzchnology & FLOW3D & 5 \\
\hline Stemens - KWU** & TEMPW & $1,2,3$ \\
\hline CEA & FLAMME \& LIQUTNET & 1 \\
\hline ENEL & COMPBRN III & 1 \\
\hline EDF** & MAGIC & 2 \\
\hline Tech. Unv. Wien & MRPC & 2 \\
\hline Anstaildo & COMPBRIY III & 1 \\
\hline Tech. Univ, Braunschweig ** & DOB or FIGARO & 1,2 \\
\hline
\end{tabular}

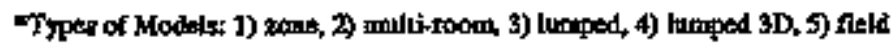

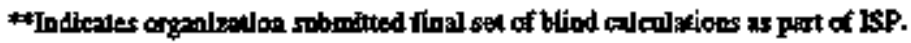




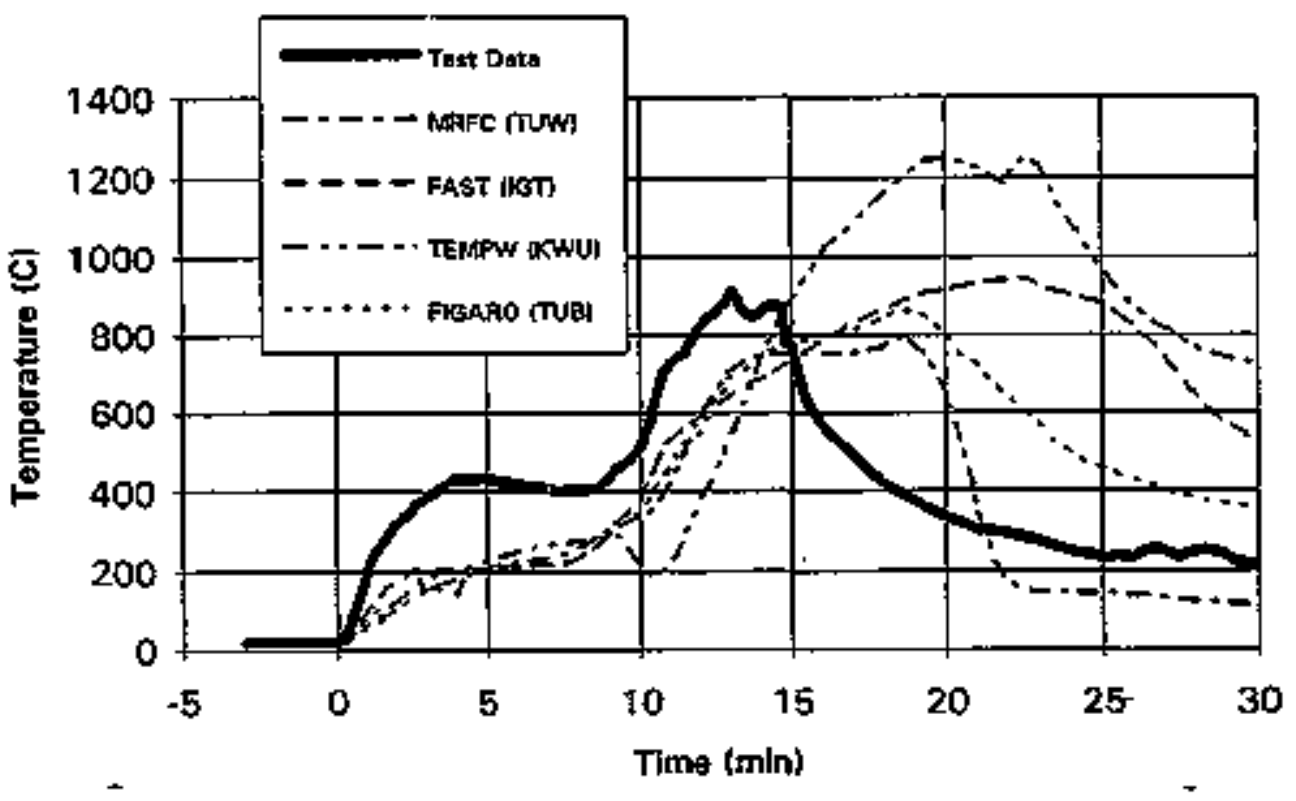

F1gure 18as F42.2 Comparlson of todels to Experiment (Hot gas 1ayer temperatures from cr539g in fire roon)

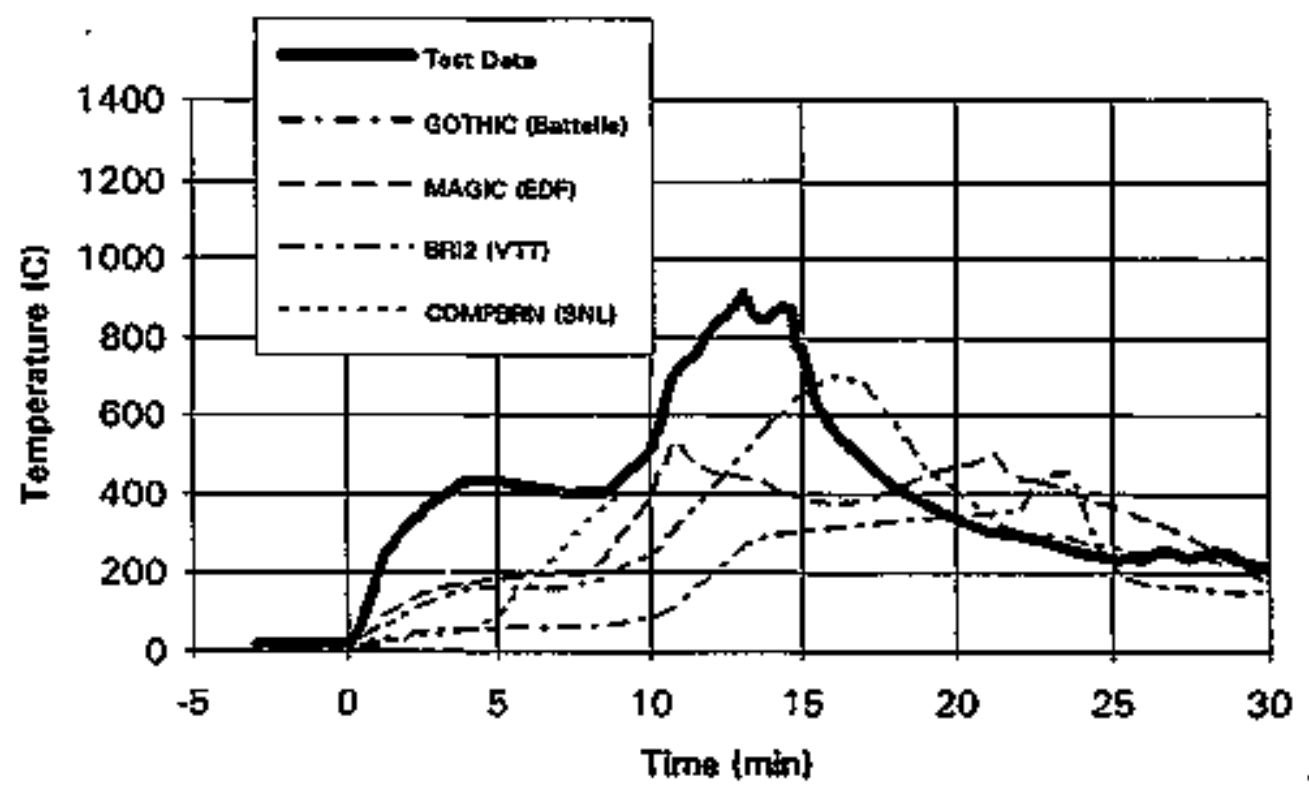

Fignre 18b: 342.2 Comparison of Hode1: to Experiment (Hot gas layor taporatures from ch5298 in fira room) 


\section{Sammaxy}

Keny lessons have been learned regarding nucleer power plant tire modeling as part of this work. These lessons are not specific to the fDR containment and the tests conducted therein, but have a broader application to fire modeling in generel.

\subsection{D41.7 Lessons Isearmed}

The E41.7 COMPRR calculations could not be obtained beyond 4-7 thinutes into the fire (depending on the input parameters) aue to numerlcal instabilities in the COMPBRN code. The calculations becarne unstable tue to the large radiative heat fluxes that arecalouleted. These results indicete that coupBan cannot model very large fires in stiplell rooms (it tas not cevoloped with Ifires of this type in mind). The limitations of the model are also seen in that the opening of a doox part way into the test cannot be modeled with the code.

The E41.7 Notre Dame Fire Hodel

calculations demonstrate the capabtlities of a fire field model. Good agreement is obtakned for gas temperatures that are in the hot gas layer but outside of the fire plume. The limitations of the model are seen to be its lack of a combustion model to repregent the flame volume, and the Iarge CPU time required to operate it.

The lessons learned from the results of the other BAI.7 participants can be summarized as follows. The level of agresement of the dfEferent nodel results with the test measurements is a strong function of location in the containment. Whin the fire room itself, only two of the models were consistentiy wtth th 250 C of the measured gas temperatures. This poor agreement was heavily influenced by the fact that the fire room was virtually a fixeball, which most zone fire modeis are not designed to model. Zone tixe models assume that the fire develops as a typical pool fire (or jet fire). In generel, the agreement became worse land the aisparity wider) as rooms other than the fire room were examined. This is a conseguence of inaccuracies in the roomto-roont transport sulmodels.

In meetings with the other participants, the large influence that modeling assurutions have on the model results was often the focus of the aiscussion. Thus, it must also be recognized that the results of a fire model are not only a function of the model itself, but are also a strong function of the experience and judgenent of the one who applies the model.

\subsection{E42,2 Iessons Learned}

The E42.2 COMPBas results demonetrate the types of fires for which COAPBR will rield reasonable results: small to zhedium sized fires (a pre-flashover compaxtment). Hote that results were only obtained early in the fire, betore the fire room door was opened. This also corresponded to the time when the fire was not yet a very large fire. The strengths of COMPBFN are seen to be tts ability to model the transient ignition and burning of eable tray tires. very Iew other fire rodels possess this festure.

Agreement of the COMPBRA III results with E42.2 experimental data is reasonable, but hot gas layer temperatures and cable tray prass lass rates are significantly underpredicted during the initial stages of the Elre. The timing and sequence of cable tray lonition were well-predicted by coupBrN, with the exception of the early stages of the fire. In particular, the time to involvement of 50\% of the combustible natertal was in good agreement with the test observations. Unfortunateiy, the COMPBRN restlts were very sensitive to the user's choice of input parameters.

The lessons learned froin the results of the other B42.2 participants cen be summarized as follows. First, for every model applifed to this test, the calculated hot gas layer temperatures lag far behind the measured terperatuxes. 
This may result from the use of guiescent plume correlations in all of the models, when in fact, significant velocities can be generated in the surrounalng air for fires in enclosed spaces. Second, it wes obvious froin the large disparity in model resuits that a gook suodel for cable pyrolysis and burning is not presently available. This points to the fact that the modeling of solid material combustion (prrolysis and burning) is perhaps the most imnature aspect of fire nodeling. Third, the heat of combustion for a real material is generelly a function of time. and fire models are generaliy not set up to handle this.

\subsection{Genaral Observat ton: from HDR Fire Modeling}

Some general abservations can be made rectarding fire modeling of nuclear power plants bases on the HDR fire modeling effort. These observations are based on the opinions and experiences of those who have participated in the HDR fire modeling efforts, and should be regarded as such.

Fire modeling continues to grow and develop in maturity. However, comparea to most other areas of science, it is still relatively inonature. Its development has been hindered by the complexity and tight coupling of the mon-linear phenorana involved. In many respects, there is still somewhat of an art to making accurate fire roodeling falculations. Experience with a perticular fire model is essential to deteraine its weak areas and potential pitfalls. Unfortunately, many podels recuise the input of parameters which are not well known, and to which the results are very sensitive.

Tust a fow years ago, fire modeling efforts were dominated by zone moleis and control volume models. With advances in computers and computational methods such as computationel flusd aynamics (CPD), many of the fire modeling efforts woxidwide are moving in the direction of tield model development. These models are ropidly improving in their capabilities and ease of use. They have oliminated the need for some of the ill-defined input paraneters which other models require (such as flow loss coefficients). The development of graphical user interfaces has greatly faciliteted the necesiaty input of information and grid generation. It is not expected that fire field models wil1 replace the other types of fire models, but rather will serve to complement the suite of fire analysis tools avafiabie for Ixte sefety analyses.

Validation of fire models remains an important isstie. The HDR cordparisons have demonstristed that fire models perform poorly when used outside of the realn for which they were designed. Thas should be no surprise, since many of the models rely extensively on experimental correlations derived for a specific geometry and ventilation condition. Thus, validation of the models against more fire data representative of fires in nuclear power plants is needed. This is especialiy important for fire ficta models, which are relatively new and consequently, have not been validated to the sarre extent as the other types of models.

Validation of tire modele also raises the issue of the need for experimentalists and fire modelers to work closely together, if progress is to be made in fire modeling. It is critical that the people conducting a fire experiment understand the sensitivity of fire model predictions to such factors as complex geometries, ventilation boundary conditions, and fuel properties. Itikewise, it is critical that the people developing and valiating fire models have a good undexstanding of the tochnical 1ssues faced by the experimentalists in attempting to conduct a realistic test. As a consequence of the HDR fire project, the peaple involved in the experiments as well as those involved in the modeling efforts gained a deeper appreciation for the problems faced by the other camp. Hopefully, this will result in a tighter integration of experimentalists and modeling perople in fire modeling development and validation efforts in the future.

In conclusion, the HDR fire tests and modeling efforts have contributed a wealth of information regarding fires in 
nuclear power plant containments, and the strengths and weaknesses of present day fire modelo for simulating these Eires. Based on oux experiences with the HDR tire modeling efforts, fire models can potentially contribute to improved fire sefety of nuclear power plants, when they are used within their realm of applicebility. Defining thas realm of applicability, and the sensitivities inherent in today's fire models, is a task that remains to be completed. 


\section{References}

Ho, V., A. Siu, G. Apostolakis, "CONPERN III - A Computer Code for Modeling Compartment Fires," UCIA-ENG-8524, college of Engineering, Universtty of California at tos Angeles, Novenber \{1985\}.

Karwat, $\mathrm{H}$, "Prediction of Effects Caused by a Cable Fire Experiment within the HDR factlity." European Comission, Nuclear sexence and Technology Report ElfR 15648, August (1994).

Karwat, H., K. Muller, and t. Max, "CEC Standard Problem: Prediction of Effects caused by a Cable Fire Experiment within the HDR Contairment," Fechnische Universitat Munchen and Karnforschungszentrum Karlsrube (KfK) Germany, revised July (1992) .

KfK, "Pcoceedings of 3 cd International Seminar on Fire Safety of Nuclear Power plants," held in conjunction with 12th International Conference on Structural Mechanics in Reactor Technology, Angust 23-24, 1993, Hexdelberg, Germany. Kernfortchungszentrum Karlsruhe Work Report PHDR 40.070/94 (1994).

Lambright, J.A. and M.P. Bohn, "Analysis of Core Damage Freguency: Peach Bottom Unit II External Events," NUREG/CR-4550, vol. 4, Part 4, January (1989a).

Lambright, J.A. and M.P. Bohn, "Mralysis of Core Damage Frequency Due to External. Events at the DOE N-Reactor" SANDB91147, Sandia National Laboryatories, Albuquerque, NM, March (1989b) .

Liu, V.K., and K.T. Yang, UNDSAFE-II: A Computer Code for Buoyant Turbulent Flow in an Enclosure with Thermal Radiation, Iniversity of Notre Dame, Notxe Dame, IN, TR-79002-7B-3, July (1976).

Lambright, J.A., S.P. Nowlen, V.F. Nicolotte, and M.P. Bohn, "Fire Risk Scoping Study: Investigation of Nuclear Power Plant Fire Risk, Including Previously Unaddressed Issues," NiREG/CR-5086, SAND88-0177, Sandia National Laboratories, Albuquerque, NM, January $\{1989\}$.
Muller, K., and U. Mass, "Input Data set for E41.7 Blind postcalculations of an OIl Fire in a Closed subsystem with Ventslation system Connected, "PHDR Report No. 40.036/91, Rernforschungszentrum Karlszuhe (KfK) Germany, Deceraber (1991).

Nicolette, V.F., and S.P. Nowlen, "Bire Models for Assessment of Nuclear Powex Plant Firøs," Nuclear Engineering and Design, vol. I25, Pp. 369-394 (1991).

Nicolette, V.F., S.P. Nowlen, and J.A. tambright, "Observations Concerning the COSPBRN III fire growth code,"

troceedings of the International Topical Meeting on Probability, Reliabllity, and Safety Asgassment: PSA '89, yol, 2, PP. 1279, Pittsburgh, Aprị1 2-7 11989).

Nowlen, S.P., "A Summay of Nuclear Power Plant Fitro Safety Research at Sandia National Laboratories, 19751967, "NUREG/CR-5384, SAND89-1359, Sandia National Laboratories, Albuguerque, NM (1989).

Nowlen, S.P., "A. Sumuary of the Fire Testing Prograrn at the German HDR Test Facility," NUREG/CR-6173, SAND94-1795, Sandia National Laboratories, September 1995.

Rockett, J.A., O. Keski-Rahkonen, and I. Heikkila, HDR Reactor Containment Fize Modeling with BRT2, Technical Rosearch Center of Finland (VTT), VTT publication 113 (1992).

SFPE Handbook of Fire Protection Bngineering, First ed., Society of Fire Brotection Engineers, Boston, PA (1988).

Simcox, \$., N.S. Wilkes, and I.P. Jones, Fire at King's Cross Underground station 18th Hovember 1987: Wumerical Solution of the Buoyant flow and Heat Transfer, AERE-G 4677 (1988). 


\section{Appendix A: Brief Description of Fire Models Used by other IDR Participant:}

\section{A.1 Introdnction}

During the course of this project, many different fire models were discusied with the other HDR participarts. Some of these models may not be familiar to fire modelers in the J.s, and in other countries. A brief description of some of these models is included here for information purposes, and also as somewhat of a status report on what the rest of the nuclear power plant fire modelfing commuity has recently been doing. It is in no way intended to be exhaustive in either scope or in detail.

The information herein was gathered over the course of gevexal years in

discussions with fDR fire modelers from around the world. In this regara, it may not be quite up to date. It is

intentionally presented in a somewhat

informal style to reflect this

consideration.

\section{A.2 Zone Models}

\section{FIALALE}

The French have developed a zone model known as FtuAlute. Two versions of the codp presently exist. The first version has been taliflated for liquid pool fires. The second version handiles multiple fire sources within a roou and has not yet been valianted. Elther version.can be connocted to a ventilation model so that multiple roors can be modeled. At the Hay 1992 meeting, discussions 1adicated that the French are now moving in the airection of the other Fuxopean Community (EC) members in developing 2-dimenstonal and $3-$

axmensional fire field models for use in their fire risk assessmentis.

DOB

Faculty at: the University of

Braunschwelg have developed a zone mode1, named DOB. It was used as the basis for designing tire experiments in the HDR in terms of heat release rates, maximm hot gas layer temperatures, fuel loading). This model is a milticompartment model.

MRPC

The University of Kassel has used several zone models for calculation of fires in the HDR. One of these models (intermaliy developed is called the thiti-Roon Fire bodel (MFFC). They have also applied the PAST code developed at the Mational Institute of standards and Technology (NIST) ) to the HDR. They have mentioned that these models have great difficulties when the hot gas layer reaches the floor of the fire colwertment.

\section{A.3 Hybria (Control volume) Model.}

\section{RALOC}

GRs has used the kALOC code for both hydrogen distribution and etre calcuiations in the HDR. This control volume code does not hate 泉 combustion model in it. Their work has demonstitated that the model can the sensitive to the user's choice of nodelization (i.e., how the containment rooms are subativided and represented as contexol volumes) and flow loss coefficients, and that, in some instances the user must know beforehand in which alrection the flow from room to room will be, in order to properly construct a nodalization. They have had reasoneble success in predicting HDR Iire mass loss rates. The alioc code was developed by the German government, and its availability outside cermany is not clear. 


\section{CRDLOC}

H. Jehn of the Technical University in Munich is the primary develoger of tho CRDLOC code the atso was largely responsible for the RALOC codel. This code is similar to RAJoc, but has a Chemieal Ractions and Dibtributions (CFD) submodel for modeling pyrolysts and devoletilization rates. The code also models convection, radiation. evaporation, and condensation phenomena. The evaporation end pyrolysis models are not well verified. When appliea to pool fixes, they have sean some instabilities due to thermal feedback to the pool accelerating the evaporation rate which in turn enhances the thermal fecdback.

\section{FIREIN (See FLOW3D in A.4)}

\section{PATHOMS (GOTHIC)}

Another model that somewhat fits this category is the FArHOWS (GOTHIC) model developed by iAI, in Richland, Washington. This model can be used as a zone, control volume, or fleld fodel for any combination of the aboves. However, its field modieling capabilities are somewhat limited, so it has been included in the hybrid models section. Battelle Frankfurt has applied FATHous to the HDR fires.

This code has an interesting history laccording to discussions with those who have followed it). The origins of this model are in the coBRa-NC code developed at Battelle Northwest with ISNRC funding. The developers of COBRA-ric left Batteile and formed their own company [NiI b about 1988. They proceeded to modify and impxove the model, and developed a new version known as FATHOLS. This code can be leased from WAI + In 1989, wAI received a contract from EPRI to improve FATHOMS. The new code is known as Gortic.

This code is available to $\mathrm{U}+$ \$. Utilities through EPRI. It is expected that it will be used to address equipment gualffication questions (such as maximum local air tempertetres near operating equipment) and to addrees details of licensing procedures (such as bydrogen recombiner lacations\}. It could elso be woed for utility fire risk essessments. In fact, this model has been used by thestinghouse to adiress design issues for the AP600 plant.

The FATHOAS (GOrHIC) model is extremely versatile. This code tan be used as th 1, 2-, or 3-dimensional model, and in either a control volume or field model approach. It models the gas/vapor. droplets, and liguid pools with separate equations. It was originally developed to th two-phase flow code for reactor thermal hydraulics. One of the latest versions has the MAEROS aerosol model [developed by F. Galbara, sendie National Laboratories, for the CONThIN code) in it. The code presently doss not have a combustion model. The nice feature of the code is that regions of the containment can be modeled in a lumped fashion while others can be modeled with a field modeling approach as desired. This model also has a very easy to use preprocessor that greatly facilitates the input deck generation.

tsexs of the FATHOMS/GOTHIC modil have stressed the importance of proper selection of flow loss coefficients for the geometry of interest. This is absolutely critical to the performance of any contral volume model ise previaus comments on the Ravoc modely. In application of FATHOMS/GCTHIC to the HDR fires, it has been possible to alter the atrection of flow in the containment by slightly changing the relative values of the flow loss coeffictents. This implies that txuly 'blind' calculations with these types of models are potentially aubject to considerable error.

The field modeling capgbilities of FATHONS/COFHIC are 11 mited. Only Cartesian coordinates can be inodeled. The turbulence model is an algebraic Prandt mixing length model. The code is somenhat inefficient in that it always solves the droplet and liguid conservation ecultions, even when there is none prestot. It is also linited to about 1,000 nodes, which may be too few to properly capture the physics of a Eire emvironment. 


\section{A.4 Field Hodels}

\section{PHOENICS}

WT Finland has tsed the PHoEvrCs ftela model (a proprietary code licensed from CHAy) for the HDR calculations. Thets work appeared to bo a tremendously tedious task, as obtaining all of the necess하마 geometric information for the HDR containment whs not straight forward. Their calculations indicate that $90 \%$ of the energy is deposited in the wall 2 s and equapment of the contaimment. They used the corabustion model in coupBris to generate heat release inforation.

Finland has recently enbarked on a joint program with sweden and the UR to develop a non-proprietaxy fire field modeI. The UR participants include the Pire Research Station and Cranfield Technołogy. The model will bave an unstructured grid to allow the user freecom to refine areas of the mesh of particulat interest. Their goel is that whthin a few years time, they will have a model with the same capabilities as the TASMLN' code. JASMrNE 15 a proprietary fire field model (bassd on PAOENICS) that is maxketed by $D$. spalding's cham corporation in the UR.

\section{Fints}

T. Travis (formerly of Los Alemos Mational Laboratories) has applied his 3-dimensional field model (HMS) to the HDR containment for hydrogen digtxibution calculations, but not for simulation of the fire tersts. He pexeonally developed all of the necessary geometric information for field model calculations for the HDR containment. The VTT field jodeling effort as well as the sandia/Notre Dame fiela modeling offort benefited from his work.

\section{FLOW3D (Los Alamos)}

Los Alamos National Laboratortas artginally planned to apoly the RLOW3D code developod at Los Alamos to the ISP. However, for unknown reasons, no calculations were subnttted. They are also pursulng the development of a compartment fire madel to couple with their ventilation systen model (FIRAC). This compartment fire model will be a descendant of the FIREIY code, and is being developed in cooperation with Battelle, Northwest. The Los Alamos system model pIRAC is a very unique model, ns it is capable of modeling the clogging of filters due to aerosols (such as soot).

\section{CFDS FLOW-3D (Harwell/AEA)}

This proprietary code is different than the Los Alamos Firow3D code mentioned above. It was developed at AEA Technology (formerly Harwell) in the DK. It is avallable contuercially, and has been used with some success for modeling large-scale fires. The successful apolication of this code to the King's Cross sulway fire gained much attention worid-wide.

\section{KAMELEON FiIe}

The KamELEN Fire tield model was developed at SiNhEP/NTH in Trondhejm, Norway. This model has been successfully applied to laxge-scele open and enclosed fires. The majority of applications has been to offshore drilling pletforms in the forth Sea. Recently, the model has also been applied by Sandia kational Leboratories (Albucuerque, isu) with very good success to large, open pool fires involving aviation fuel.

Sandid has entered into a collaborative agreement with SINIEE/NTH to advance the capebinities of the existing model. Development of this advanced model began during the paet $y$ ear. 


\section{Appendix B: University of Notre Dame Field Model Calculationg for HDR Test $\mathbf{2 4 1 . 7}$}

The following raport on the Dotre Dame Field Hodel Calculations for HDR Fest E41.7 is incluaed as a stand-aIone xeport. It has been published in computational Mechanics, vol. 14, No. 5, pp. 468-479, August 1994 . 


\title{
FIELD MODEL SDMULATION OF FULE-SCALE \\ FORCED-VENTILATION ROOM-FIRE TEST IN THE \\ HDR FACILITY IN GERMANY
}

by

\author{
K. T. Yang and $H$. J . Huang \\ Department of Aerospace and Mecharical Engineering \\ University of Notre Dame \\ Notre Dame, IN 46556 \\ and \\ V. F. Nicolette \\ Thermal and Fluid Engineering (Dept. 1513) \\ Sandia National Laboratories \\ Albuquerque, NM 87185
}

\begin{abstract}
A full-scale forced-ventilation room fire test is simulated numerically based on a fire fiek model. The fire room, located inside a decommissioned nuctear reactor at the Heiss Dampf Reaktor (HDR) facility in Germany, is characterized by a very complex 3-D geometry. The field model utilized in the simulations accommodates full compressibility, turbulence, wall losses, surface-to-surface and surface-to-flame radiation exchange, and the specific geometries associated not only with the fire room itself, but also with the elevated fuel bed and forced veatilation inlet and outlet. Good correspondence between the measured temperatures at different locations in the fire room and those from the simulations has been found for the first four minutes into the fire during which all fuel in the fuel pan is depleted. Some of the discrepancies in the temperature comparison are explained in terms of shortcomings in the field model.
\end{abstract}

\section{DNRODUCTION}

In fire modeling, the unique advantages of field models and their use in predicting the spread of fire and smoke in rooms and compartments have long been recognized. These include their capability to predict detailed unsteady movements of both fire and smoke and to account for fluid and thermal interactions among different parts of the fire room. While significant shortcomings still exist for field models in general, especially in the formulation of turblent 
combustion stabmodels, freld models have not been utilized to a great extent in recent years, primarily because their use was very computing intensive and access to high-power computing resources was, in general, rather limited. However, with increasing accessibility to supercomputers, mini-supercomputers, high-power workstations and high-speed desk-top personal computers, field modeling corpputations bave since received increasing attention among fire modelers. This fact alone will undoubtedly spur more research and code development in making field models a timely, viable tool in our efforts to mitigate loss of lives and properties due to fire.

Increasingly, fire field models have been utilized to simulate real fire situations, at least in cases with limited objectives. For instance, the use of the Harwell-Flow 3D code to simulate the air flow in the King's Cross underground station fire in London in 1987 is a good example. Other instances can be found in discussions held at the 1990 Eurotherm Seminar on Fire Modeling (Jones, 1990). While existing field models can indeed be applied to real compartment fire sitbations and produce quantitative results, it is not well established that such results are sufficiently accurate for real world applications. Consequently, model validation by experimental data in reatistic fires is extremely important before the field models can be used with confidence. Such experimental data, especially for full-scale room fires, are difficult and very expensive to obtain, but are critically needed to provide validation for fire models including the field models. Also, these data provide critical information on the deficiency of fire models to guide future development efforts.

In the last several years, an intemational cooperative effort has been ander way to use the Jatest fire models (both zone and field models) to simulate the full-scale fire tests conducted in a decommissioned nuclear reactor st the Heiss Dampf Reaktor (HDR) facility in Germany in order to assess the viability of using such fire modeis for future fire-hazard mitigation in nuclear reactors. It is interesting to note that these are the only fire tests ever conducted inside an actual nuclear reactor containment building. The Sandia National Laboratories has been involved in this program as technical consultants to the United States Regulatory Commission (NRC), and has utilized both the COMPBRN III zone model for steady comparment fires deveioped at UCLA (Ho et al, 1985) and the field model UNDSAFE developed at the University of Notre . Dame (Nies, 1986; Raycraft et al., 1990, Yang et al., 1992).

Two series of full-scale fire tests were conducted in the same designated fire room inside the HDR building for the purpose of providing data for comparison with model simulations. One series, designated as the E41.5 Test, deals with a naturally-ventilated tire (Mueller and Volk, 1990), while the second series, known as the 41.7 Test deals with a forced-ventilation fire (Mueller and Max, 1991). Results of the numerical simulation of the E41.5 Test based in the 
Notre Dame field model have been given previously by Yang et al. (1992), and the purpose of this paper is to report results for the E41.7 Test with forced ventilation in the fire room.

\section{DESCRIPTION OF FORCED-VENTHATION FULL-SCALE FIRE TEST}

Details of the geometry of the containment building including the fire room and materials and the liquid fuel, can be found in the two reports by Mueller and Volk (1990) and Mueller and Max (1991). Briefly, the containment building is in the form of a vertical pressure vessel, about $60 \mathrm{~m}$ in height and $20 \mathrm{~m}$ in diameter, and the bottom of the building is about $11 \mathrm{~m}$ below grade. The fire room foor is located $4.5 \mathrm{~m}$ above ground and is shown in Figure 1 . The main fire room has a height of $5 \mathrm{~m}$ and that of the entry room, which contains two double doors at the right wall, is about $3 \mathrm{~m}$. The ventilation exhaust, located above the entry room on the right wall of the main fire room can also be seen in the Figure 1. The combined room has a total volume of about 100 $\mathrm{m}^{3}$, and a floot or ceiling area of about $23 \mathrm{~m}^{2}$. The side and rear ctarved walls are made up of largely $10 \mathrm{~cm}$ thick and $15 \mathrm{~cm}$ thick of Ytong, respectively, $\left(\overline{\mathrm{p}}=340 \mathrm{~kg} / \mathrm{m}^{3}, \bar{c}_{\mathrm{p}}=0.95 \mathrm{~kJ} / \mathrm{kgK}\right.$, $\overline{\mathrm{k}}-0.19 \mathrm{w} / \mathrm{mK}$ ); the floos is covered by a $25 \mathrm{~cm}$ thick Ytong layer, and the ceiling is covered with insulation made up of $3 \mathrm{~cm}$ of Promatec $\left(\bar{\rho}=250 \mathrm{~kg} / \mathrm{m}^{3}, \bar{c}_{\mathrm{p}}=0.84 \mathrm{~kJ} / \mathrm{gK}, \overline{\mathrm{k}} \sim 0.13 \mathrm{w} / \mathrm{mK}\right)$ and $2.5 \mathrm{~cm}$ of Alsiflex $\left(\bar{\rho}=130 \mathrm{~kg} / \mathrm{m}^{3}, \dot{\mathrm{c}}_{\mathrm{p}}=1.0 \mathrm{~kJ} / \mathrm{kgK}, \overline{\mathrm{k}} \sim 0.1 \mathrm{w} / \mathrm{mk}\right.$ ). Also, most of the walls and floor are also covered with $2 \mathrm{~cm}$ of Alsiflex mats.

The oil fuel pan, equipped with fuel loss weighing scale is elevated $0.61 \mathrm{~m}$ from the floor to accosmodate a $0.3 \mathrm{~m}$ in diameter ventilation inlet underneath. The fuel oil is SOL-T made by Shell Compasy which produces only dry soot which is not greasy. It has a density of 0.756 $\mathrm{kg} / \mathrm{m}^{3}$ as $20^{\circ} \mathrm{C}$, a flash point at $54^{\circ} \mathrm{C}$, and a heating value of $42,500 \mathrm{~kJ} / \mathrm{kg}$.

In the test, the oil in the fuel pan was depleted at the end of 4 minutes into the fire, during which the two doors were closed and the forced ventilation was maintained at $0.85 \mathrm{~m} 3 / \mathrm{s}$. The forced ventilation had been tumed on before the fure was ignited. Ignition was achieved using alcohol and electric discharges. Extensive measurements of gas and fiame temperatures, various gas concentrations, mass rates of flow, pressures, and doorway velocities were made. For the namerical simuiations in the present study, which covers the first four minutes of the fire, similated temperatures at various locations in the fire room and the entry area are compared to those from the test. These resalts will be interpreted and discussed on the basis of stortcomings in the field model as well as the local details of the unsteady temperature field.

\section{THE FIRE FILLD MODEL}

As pointed out previousiy, the fire field model utilized in the present study has been under continuous development at the University of Notre Dame in recent years. Early efforts were concentrated on two-dimensional room fire problems accounting for strong buoyancy, full 
compressibility, turbulence, one-d̈mensional (ceiling to flow) radiation exchange, simple rectangular geometry, but not including effects of combustion and wall losses. Under the code name of UNDSAFE University of Notre Dame \$moke and Eire in Enclosures), the field model was successfully applied to a variety of room and external fure situations (Yang et al., 1984; Yang and Lloyd, 1985; Satoh et al., 1983; Kou et al., 1986). More recently, this field model has been extended to three-dimensional compartments including wall losses and pressurization in closed compartments (Nies, 1986), complex geometries (Raycraft et al., 1990), intemal ventilation in closed compartments (Houck, 1988), effects of sprinklers (Chow and Fong, 1993), and a simulation of full-scale fire tests (Delaney, 1992, Yang et at, 1992).

Despite the versatility of the application of this field model, it is still not complete and validation, especially for large fires, has been insufficient to ascertain its general validity. This is essentially the case for all existing field models. For the Norre Dame field model, still lacking is a combiration of a viabie turbulent combustion model for complex fuels and the incorporation of multi-dimensional radiative transfer for participating media based on reasonable models for gas and soot radiation spectral propoerties. For the latter, basic information is essentially available, even though its implementation into a fire field model is still complex. However, the lack of detailed knowledge on combustion kinetics for complex but realistic fuels will impede the development of complete fire field models for some time to come.

In the present study, the same fire field model as that used recently by Yang et al. (1992) is utilized with the exception that the model has been modified to incorporate the elevated fuel pan and the forced ventilation in and out of the fire room. This model is now briefly described as follows.

. In the present formulation, no combustion model is used, and the heat release rate is taken to be prescribed as volumetric heat sources, and the flame region is also postalated. It is of interest to note that even in the tests, the heat release rate was not measures, but must be determined through the fuel loss data, the heat value of the fuel, and some assumed combustion efficiency. Another deficiency of the moxiel is that gas and soot radiation is neglected, but the surface-surface and surface-flame radiation exchanges are accounted for in the model. It, however, should be noted that the net effect of participating mediun is to produce a more uniform temperature field and therefore the model tends to overpredict the heat losses through the wall and ceiling regions where temperatures are high. As it will be shown later, within the first short four minutes into the fire, the heat losses through the ceiling and walls are only a small portion of the beat from the fre, and consequently the effect of participating medium is not expected to be significant. Under these conditions, the species equations need not be considered, and the dimensionless goveming field equations for turbulent baoyant compressible flow (Yang et al., 1992) can be written in tensor forms as: 


$$
\begin{aligned}
& \rho_{1}+\left(\rho u_{i}\right)_{, i}=0 \\
& \left(\rho u_{i}\right)_{, t}+\left(\rho u_{i} u_{j}\right)_{, j}=-p_{i}-\rho G+\left(\sigma_{i j}\right)_{, j} \\
& \left(\rho c_{\mathrm{pun}} T\right)_{, \mathrm{t}} \div\left(\rho \mathrm{u}_{\mathrm{i}} \mathrm{c}_{\mathrm{pm}} \mathrm{T}\right)_{, \mathrm{i}}=\left(\mathrm{kT} \mathrm{T}_{\mathrm{i}}\right)_{\mathrm{i}}+\mathrm{Q}_{c}
\end{aligned}
$$

where the dimensionless shear stress tensor $\sigma_{\mathrm{ij}}$ and mean specific heat $c_{\mathrm{pm}}$

$$
\begin{aligned}
& \sigma_{i j}=\mu\left(u_{i, j}+u_{j, i}-\frac{2}{3} \delta_{i j} u_{k, k}\right) \\
& c_{p m}=\frac{1}{T-1} \int_{1}^{T} c_{p} d T
\end{aligned}
$$

where $\delta_{\mathrm{ij}}$ is the Kronecker delta function. It is noted here that both viscous dissipation and pressure work can be neglected in the fire phenomena. The above dimensionless quantities are normalized as follows: The coordinates $\hat{\mathbf{x}}_{i}$ with the height of the fire room $\mathrm{H}$; the time vasiable $i$ with $H / u_{R}$ where $u_{R}$ is a constant reference velocity; all velocity cormponents $i_{i}$ with $u_{R}$; absolute temperature $T$ with $T_{R}$ where $T_{R}$ is again a reference temperature normally taken to be the air inlet temperature; the pressure difference $\left(\overline{\mathrm{p}} \cdot \overline{\mathrm{p}}_{\mathrm{e}}\right)$, where $\left(\overline{\mathrm{p}}_{\mathrm{e}}\right)$ is the hydrostatic equilibrium pressure, with $\rho_{R} p_{R}^{2}$ where $\rho_{R}$ is a constant reference air density based on $\bar{\rho}$ and $T_{R}$; the gravitational acceleration $G=(0,0, \mathrm{~g})$, with $\mathrm{u}_{\mathrm{R}}{ }^{2} / \mathrm{H}$; and the thermophysical properties $\dot{\rho}$ (density), $\bar{c}_{p}$ (specific heat), $\bar{\mu}$ (viscosity) and $\overline{\mathbf{k}}$ (thermal conductivity), with, respectively, $\rho_{R}, c_{p R}, \rho_{R}{ }_{R} H$, and $\rho_{R} c_{R R}{ }_{R} H$ where $c_{p R}$ is a constant reference specific heat evaluated at $\mathbf{T}_{\mathbf{R}}$. All $\overline{\mathbf{u}}_{\dot{i}}$ and $\overline{\mathbf{T}}$ are Reynolds averaged quantities, and $\bar{\mu}$ and $\overline{\mathbf{k}}$ consist of both Iaminar and turbulent quantities. In addition, $\mathrm{Q}_{\mathrm{c}}$ is a dimensionless volumetric heat source, prescribed inside the flame zone and zero outside the flame zone. Also, for convenience, the origin of the coordinate system is fixed at the left front comer of the fire room. Thus, the $i$-coordinate is in the direction from the fire room to the entry room; the $j$ coordinate is in the direction of the depth, from the front to the rear, and the $\mathbf{k}$-coordinate is from the floor to the ceiling (see Figure 1). 
Since during the first four minutes of the fire the two doorways are closed, the combined room is all closed except the inlet and outlet of tie forced ventilation, and the boundary conditions are relatively simple to write. All velocity components vanish at any solid surface. At the ventilation inlet, the normal air velocity at $T_{R}$ is distributed uniformly over the inlet area so that the flow rate is that of the prescribed vensilation rate. At the outlet, all velocity components and temperature have zero gradients normal to the outlet area. The temperature boundary condition at the walls, ceiling and floor is in accordance with a heat balance and is coupled to the conduction through the solid thicknesses. The heat balance here involves surface radiation fluxes from the rest of the surfaces including those of the flame, the convection fluxes from the fluid flow, and conduction fiuxes into the solid. Details of this theat balance will be described later in the wall-loss submodel.

The formulation of the fire field model is cot complete until several submodels are incorporated. Compressibility is inherent in the govening difterential equations and density is computed from the perfect gas law, with pressure nesrly constant throughout the rooms due to ample ventikation. Strong buoyancy is accounted for in Equation (2) without involving the Boussinesq approximation. Other submodels for wall losses, turbulence, radiation and combustion are described in the following.

Heat transfer through the walls, ceiling and floor is taken to be that of one-dimensional unsteady conduction through the solid material. The boundary conditions are that at the inner surface the arriving heat fiux is that due to a combination of radiation and convective heat fluxes, while at the exterior surface of the walls and ceiling. a convection boundary condition utilizing prescribed constant coefficient of heat transfer $h$ ard ambient temperature $T_{R}$. The floor, in view of its thickness of $25 \mathrm{~cm}$, is taken to be insula natural ventilation tests E41.5 (Yang et al., 1992), the rest lasted over 18 minutes into the fire and the heat loss through the walls and ceiling was constcerable. In the current forced-ventilation test E41.7, numerical simulation only covers four mirutes into the fire during which most of the heat was absorbed by the solid. Consequently, losses to the ambient were very small and hence a reasonable coefficient of heat trarsfer $h$ is all that is needed.

While several field models such as, for instance, Harwell-FLOW 3D (Simcox et al., 1988) and KAMELEON (Holen et al, 1990) utilize the standard $k-\varepsilon$ model of turbulence, the Notre Dame field model has always advocated a much simpler mixing length type of algebraic turbulence model which accounts for stratification effects and has sufficient accuracy for the fire phenomena, as validated by experiments (Yang and Loyd, 1985; Raycraft et al, 1990). Such an algebraic model is retained in the current simulation sajdy and is given by the following: 


$$
\frac{\mu}{\mu_{R}}=1+\frac{\left(\frac{I}{H}\right)^{2} \sqrt{\sum_{j}\left(\frac{\partial u_{i}}{\partial x_{j}}\right)\left(1-\delta_{i j}\right)}}{2+\frac{R i}{P_{r_{t}}}}
$$

where

$$
\begin{aligned}
& \bar{H}=K\left\{\frac{\sqrt{u_{i} a_{i}}}{\sqrt{\sum_{i j}\left(\frac{\partial u_{i}}{\partial x_{i}}\right)^{2}}}+\frac{\sqrt{\sum\left(\frac{\partial u_{i}}{\partial x_{j}}\right)^{2}}}{\sqrt{\sum_{j}\left(\frac{\partial 2 u_{i}}{\partial x_{i} \partial x_{j}}\right)^{2}}}\right\} \\
& R i=\frac{H}{u_{n}^{2}} \frac{\left(\frac{\partial T}{\partial n}\right) \tilde{n} \cdot \bar{\xi}}{\sum_{i}\left[\left(\frac{\partial u_{i}}{\partial n}\right) \tilde{\pi} \cdot \bar{g}\right]^{2}}
\end{aligned}
$$

where $\mathrm{Ri}$ is the gradient Richandson number, $\ell$ is a mixing length, and $\tilde{n}$ is a unit vector in the direction opposite to gravity. The quantity $\mathrm{P}_{\mathrm{t}}$ is a turbulent Prandtl number, which is also used to provide a model for the effective thermal conductivity $\mathrm{k}$ (molecular plus turbulent):

$$
\frac{k}{k_{R}}=\left(1-\frac{P_{t}}{P_{T_{t}}}\right)+\frac{P_{t}}{P_{T_{t}}} \frac{H}{P_{R}}
$$

where Pr is the molecular Prandtl number, which is also taken as a function of temperature $\dot{T}$. In this algebraic model, $\mathrm{Pt}_{\mathrm{t}}$ is assigned a numerical value of unity, for simplicity. Equation (6) clearly shows the stratification effect as represented through the use of the Richardson number. It should be mentioned here that the $\mathbf{k}-\varepsilon$ model of turbulence does produce a more accurate estimate of the strain rates in the turbelent flow which could be useful in relating nurbulence to the combustion process (Candel et al., 1990).

As indicated previously, the hot gas in the rooms is taken to be transparent and only surface to surface radiation exchange is incladed in the present field model. Consequently, the radiation flux only comes into play in the thermal boundary conditions at the walls, ceiling and floor. Furthermore, the flame surfaces are taken to be opaque and are treated the same as any other solid surface. Each surface, which, for corvenience, coincides with the computational cell, 
is taken to be gray and diffuse, and the radiation flex there is calculated by the standard radiosity method (Siegel and Howell, 1992) in terms of the surface enissivity and view factors. All view factors are determined once for all, taking into account shading doe to obstructions along the line of sight. Partial blockages are accommodated by modifying the surface areas involved. In general, nonzero view factors are calculated by using the view factor definition, treating each surface as a sufficiently small area. This formulation is not accurate for two surfaces in close proximity, in which case the exact view factors based on finite areas are utilized (Howell, 1982). Even though this specific field model does not consider a participating medium, it can be included without any fundamental difficulty, despite the fact that this would create wuch additional complexity in the radiative transfer calculations (Yang, 1986). For instance, such a scheme based on P-N approximations and exponential wide-band models for participating gases, together with a combustion model, is now being incorporated into a computer code for dealing with compartment fire problems (Londino, 1993).

From a fundamental point of view, a turbulent combustion model is needed in a complete fire field model and, together with appropriate turbulence and gas radiation models, will provide information about fuel and combustion product species concentration distributions, flame zones, and time-dependent heat release rates and their spatial variations in the fire. Since a combustion model is not utilized in the current field model, information must be provided on the flame size and shape, and the volumetric heat release rate and distribution. This simplification is another reason that the effect of participating medium is not considered here because it does not bave any meaning withont a combustion model. In the present numerical simulation, the following provisions are made. The overall heat release rate used in the simulations does not come from the experimental data, since at the outset of the entire stody, it was understood that for all simulations based on our model as well as on other fire models, no experimental data were allowed, so that an objective assessment on the merits and failings of the various fire models can evertually be made. In the present simulation, the heat release rate is given by that determined by the fire zone model COMPBRN III developed at UCLA (Ho et al, 1985) under quasi-steady conditions as well as with an estimated combustion efficiency of $70 \%$. Details of this formulation can be found in the reference by Nicolete and Yang (1993). This numerical data will be described later. In addition, the flame or fire plume envelope is taken, for convenience, the same as that of the fuel pan, and extends from the fuel pan all the way to the ceiling. The volumetric heat source within this flame envelope is taken to be uniformily distributed. This assumption is obviously incorrect, since normally for a large fire, the maximum heat release rate occurs at about one third of the height from the fuel pan. However, as the simulation results will show, they indeed underpredict the tempenatures in the plume region above the fuel pan. On the 
other hand, since the total heat release is preserved in the simnlation, temperatures away from the fuel pan and in the kot gas layet at the ceiling agnee mowh betrer with those in the test.

The numerical algorthm in the Notre Dame field model is based on a finite-volume finite-difference staggered-cell formulation (Raycraft et al., 1990, McCarthy, 1991), which is a direct extension of the 2-D formulation in our earlier room fire studies (Yang et al., 1984, Yang and Lloyd, 1985) with several improvements. One improvement is that in the local pressure correction algorithm to satisfy flow continuity, the temperature and density fields are recatculated in each iteration. A second improvernent is that the convective terms in the governing equations (2) and (3) are discresized on the basis of the QUICK scheme (Leonard, 1983) to minimize numerical diffusion effects. Also, a global pressure correction routine is included to accommodare possible global pressure build-up due to insufficient ventilation (Nicolette et al., 1985). Also, as mentioned previously, the numerical algorithm incoporates the heat loss calculations at any solid boundary. The radiation fluxes ariving at the boundary cells are updated once every several time steps to reduce computation time and the view factors are calculated only once and are stored in the form of a lookup table for subsequent radiative flux calculations.

The numerical algorithm as applied to the HDR combined fire room and entry room has been numerically validated in the earlier E41.5 natural-ventilation fire test simulation (Yarg et al., 1992) in terms of heat balances and mass flow belances, and hence it will not be repeated here.

\section{SIMULATION RESULTS AND COMPARISON WITH TEST DATA}

In the numerical simulation utilizing the Notre Dame fire field model, the geometry of the combined fire and entry rooms is simplified somewhat to eliminate the curvature in the rear wall, and is shown in Figure 2. A uniform cell grid is adopted, and each cell has a side of $\Delta=273$ mim. Altogether there are 12,768 calculation cells. The cells are designated by indices I, J, $\mathrm{K}$ as also shown in Figure 1. To improve the calculation resolution, both the ventilation inlet and outlet have 4 adjacent cells, and are thus larger than they are in reality. The coefficient of heat transfer on the exterior surfaces of the walls and ceiling is taken to be $85 \mathrm{w} / \mathrm{m}^{2} \mathrm{~K}$, corresponding to that of a mixed convection condition. As pointed ont previously, the exact value of this coefficient is not critical because the simulation only covers the first four minutes of the fire. The emissivity of all solid surfaces is taken to be a constant of 0.9 and that of the flame surfaces, 1.0. The heat release rates, in accordance with the COMPBRN III simnlation (Nicolette and Yang, 1993), are closely given by 


$$
\begin{array}{rlr}
Q & =1.9625 \overline{\mathrm{i}} & 0 \leq \overline{\mathrm{t}} \leq 2.0 \\
& =1.2615 \mathrm{i}+1.402 & 2.0 \leq \overline{\mathrm{t}} \leq 4.0
\end{array}
$$

where $Q$ is in $\mathrm{MW}$ and $\overline{\mathrm{t}}$ is in minutes from ignition. The average power of the fire in the four minutes is $3.6 \mathrm{MW}$. Also, the simulation started with forced ventilation only and the fire commenced only after the flow field was already established.

The entire simulation was run on an IBM RISC 6000 computer. The time steps ranged from 0.05 to 0.001 second as called for by numerical stability requirements and the total CPU time for the four-minute simulation was abont 50 real hours.

Much data can be exrracted from the results of the simulation. However, limited space only allows showing a limited dara set. In the following, the general temperature field behaviors at six different sections through the rooms are first shown and discussed physically. Temperature data at certain specific locations are then compared with the test data and also discussed in terms of the adequacy of the field model.

Figure 3 shows the isotherms and the isomerrics of the temperature fields at section $\mathrm{I}=9$ for the two time instants $\vec{i}=2 \mathrm{~min}$ and $\vec{t}=4 \mathrm{~min}$. This section goes from the front to the back at close to the center of the fuel pan. The fire plume region can be seen in the isometrics plot. Other than this plume region, the temperanure field is already stratified to a large extent even at $\overline{\mathrm{t}}=2 \mathrm{~min}$. This feature persists at $\overline{\mathrm{t}}=4 \mathrm{~min}$, even though the hot gas already is penetrating into the floor region. The packed isotherms, signifying steep temperature gradients, generally indicate locations of walls and ceiling where heat losses occur. The isotherms are spread out close to the floor even at $\overline{\mathrm{i}}=4 \mathrm{~min}$ because of the relatively low temperature there. The void on the right of the figures is outside the computational domain due to the curved wall at the rear of the fire room (see Figure 1). Figure 4 refers to another front-back section, now at $I=25$, which is located in the entry room. The top and right side of the isotherms are again locations outside the computational domain. Figure 4 displays just a hot gas coming in at the ceiling and cool air leaving near the floor, and the temperature field is very much stratified. This is true at both time instants, except that more heat loss exists at the ceiling at $\overline{\mathrm{i}}=4$ min due to much higher temperatures in the ceiling layer.

The same type of information is shown in Figure 5 for the left-right vertical section at $\mathrm{J}=$ 9 just beyond the center of the fuel par. For both time instants, the fire plume regions can be clearly discerned. The much thicker ceiling hot gas layer can also be seen at $\mathfrak{i}$ m 4 min, with temperatures exceeding $600^{\circ} \mathrm{C}$ there. Another left-right vertical section at $\mathrm{J}=14$ (Figure 6) is located just beyond the back wall of the entry room and aiso close to the forced-ventilation 
outlet. In the right lower comer region, the hot gas has reached aimost to the floor, even at $\overline{\mathrm{i}}=$ 2 min, where there is essentially little flow. The effect of the ventilation outlet can also be seen on the right upper wall at both time instants.

The section $K=9$ is a horizontal section located about midheight of the fire room. The slanted zig-zagged isotherms shown in Figure 7 are those on the clerved rear wall, which is approximated in the simplations by a suraight line, and the zig-zags are plotting artifacts. The fire plume, the retuming hot wall jet, and the ventilation outlet effects can all be seen in both plots. It is also seen that, except for the two peak temperature regions, the temperatures are essentially uniform throughout, another indication of strong stratification. Figure 8 is at $\mathrm{K}=18$ for a similar horizontal section very close to the ceiling, and therefore is definitely in the ceiling layer. The temperanures are even more uniform except for the wall loss effects, giving credence to the ceiling layer having a uniform temperature This behavior is essentially the same for both time instants, except for the different temperature levels.

It may be of interest to note that according to the numerical simulations, heat loss throughout the boundary surface amounts to only abour $7 \%$ of the total heat release rate. Before the simulation restlts are compared to the test data in terms of temperatures at specific locations, it is pertinent to mention two minor uncertainties. One is the uncertainty regarding the exact instant $i=0$. In the test, ignition is accomplished by burning alcohol by electric ignition first, which is then in contact with the fuel to initiate its combustion. Even though this ignition period is relatively short, if does take a finite time especially in terms of sensor responses. This point should be kept in mind in interpreting the comparisons. In addition, simulated temperatures at the computational cell centers may not be at the exact locations of the thermocouples. However, the differences in the locations are never over $1 / 2$ the cell size, which is $273 \mathrm{~mm}$. Slight variations can be expected in regions of large temperature gradients.

Comparison of the temperature data at themocouple CT 5246 is shown in Figure 9. This thermocouple is located above the doorway in the right upper comer of the entry room when viewed from outside this room. The simulation underpredicts the temperatures there, even though the time-dependent rend is still reasonable. A likely reason for this discrepancy is that while the two doors are closed, there is always infiltration at the doorways due to the slight pressurization caused by the forced ventilation system. This would tend to bring more hot gas into the entry room at the ceiling. Incidentally, the anevenness of the simulated temperature curve is due to the fact that only simulated temperatures at $0.5 \mathrm{~min}$ intervals are used in the plotting and straight lines are used to connect adjacent data points.

Figures 10 and 11 show the comparisons of temperature dath at thermocouples CT $\$ 203$ and CT 5204, respectively, which are located right above the fuel pan in the fire plume. Thermocouple CT 5203 is at close to midheight, while CT 5204 is in the hot ceiling layer close 
to the ceiling. For CT 5203, the simalation grossly underpredicts the test data. The obvious reason is that in the simulation a uniform volumetric beat release rate is assumed, while in reality this thermocouple is likely to fall right in the maximum heat release rate zone above the region of fuel gasification. The very fact that the simulation predicts the temperatures at CT 5204 well is an indication that the ceiling layer temperature is much less sensitive to the heat release rate nonuniformity, but only depends on the total heat that is released. The dip in the temperanure at CT 5204 prior to $i=4$ min is likely due to enharced heat loss through the ceiling.

Thermocouples CT 5290, CT 5293 and CT 5294 are tocated on a vertical line in the comer of the fire room next to the entry room opening. The thermocouple CT 5290 is close to the floor, CT 5294 is located next to the ceiling, and CT 5293 is only a short distance below CT 5294. For CT 5290, as shown in Figure 12, temperatures are very low for obvious reasons, and the test data show very slight cemperature rises in the 3-4 min period. A likely reason for this is the infiltration of $\mathrm{col}$ air through the doots close to the floor. The higher kemperature rise in the simulated resuits is due to the hot gas descending into the fioor region. The comparisons at thermocouples CT 5293 and CT 5294 are shown is Figures 13 and 14, respectively. Good agreements can be seen, especially at CT 5294. This is really somewhat surptising in view of all the uncertainties in the submodels of the fieid model.

\section{CONCLUDING REMARKS}

This paper describes a fire field model which is utilized to simulate a full-scale forcedventilation fire test in a fire room with an adjoining entry room located in a decommissioned nuclear reactor containment building in Germany. The simulation results show that during the first four minutes of the fire the hot gas has already penetrated into the floor region. Other than the fire plume region and regions that are immediately affected by the ventilation inlet and outlet, the temperature fields are essentially stably stratified into layered structures. The numerical simulations, which are completely independent from the test data, predict temperature behaviors reasonably well over the four-min simulation period. Serious discrepancies only occur in the region directly above the fuel pan because of the unzealistic assumption on the spatial distribution of the heat release rates used in the simulations.

While this numerical simulation study can be considered as reasonably successfol and the results do capture much of the physics contrined in the full-scale fire test, further refinements of the field model are clearly needed. The lack of a turbulent combustion model and the neglect of gas and soot radiation represent serious shortcomings that must be overcome before the field model can be considered as complete. The prospect of developing a generic turbulent combustion model is still not very encouraging primarily because of the lack of data on combustion kinetics for common liquid and solid fuels. In the meanwhile, the approach adopted 
in the present study, namely, the joining of a field model and a zone model, may represent a viable aliemative. Such a combined tool, which is now available, may have sufficient accuracy to play a valuable role in many fire mitigation efforts, as demonstrated in the present study.

\section{ACKNOWLEDGMENT}

The support of NRC Grant FIN L1330 is gratefully acknowledged. The aathors are also grateful for the support and help of the University of Notre Dame Computer Center.

\section{NOMENCLATURE}

\begin{tabular}{|c|c|}
\hline$c_{p}$ & Dimensiontess specific heat \\
\hline $\mathbf{G}$ & Dimensionless generalized gravitation vector \\
\hline $\mathbf{g}$ & Dimensionless gravity \\
\hline$\overline{\mathbf{g}}$ & Gravitaional vector \\
\hline $\mathbf{H}$ & Height of fire room, $m$ \\
\hline h & Coefficient of heat transfer, W/m $\mathrm{m}^{2} \mathrm{~K}$ \\
\hline $\mathbf{I}, \mathbf{K}$ & Coordinate indices \\
\hline $\mathbf{K}$ & Constant in turbulence model, $\mathrm{K}=0.4$ \\
\hline $\mathbf{k}$ & Turbulent kisetic energy, $\mathrm{m}^{2} / \mathrm{s}^{2}$ \\
\hline $\begin{array}{l}k \\
\ell\end{array}$ & $\begin{array}{l}\text { Dimensiontess effective thermal conductivity } \\
\text { Mixing length in trmbulence model, m }\end{array}$ \\
\hline$\tilde{\mathbf{n}}$ & Unit vector in direction opposite of gravity \\
\hline $\mathbf{P r}$ & Molecular Prandt number \\
\hline $\mathbf{P r}_{\mathbf{t}}$ & Turbulent Prandrl number \\
\hline $\mathbf{p i}$ & Dimensionless pressure difference \\
\hline $\mathbf{Q}$ & Heat release rate, $\mathrm{MW}$ \\
\hline $\mathbf{Q}_{c}$ & Dimensionless Volumetric heat source \\
\hline $\mathbf{R i}$ & Gradient Richardson number \\
\hline $\mathbf{T}$ & Dimensionless temperature \\
\hline $\mathbf{u}_{\mathbf{i}}$ & Dimensionless velocity components \\
\hline$x_{i}$ & Dimensionless coordinates \\
\hline$\Delta$ & Spatial step size, mm \\
\hline$\varepsilon$ & Dissipation rate of turbulent kinetic energy, $\mathrm{m}^{2} / \mathrm{s}^{3}$ \\
\hline$\mu$ & Dimensionless effective viscosity \\
\hline p & Dimensionless density \\
\hline$\sigma_{\mathrm{ij}}$ & Dimensionless shear stress tensor \\
\hline
\end{tabular}


Dimensional quantities

\section{SUBSCRIPTS}

$\begin{array}{ll}\text { e } & \text { Equilibritum conditions } \\ \text { j } & \text { Derivatives with respect to } x_{\mathbf{i}} \\ \text { tn } & \text { Mean conditions } \\ \mathbf{R} & \text { Reference conditions }\end{array}$

\section{REFERENCES}

Candel, S., Veynante, D., Lacas, $F_{+}$Maistret, E., Darabiha, $N_{\text {., }}$ and Poinsot, T., 1990, Flamelet Description of Turbulent Combustion, Proceedings of the 9th International Heat Transfer Conference, Vol. 1, Hernisphere Publishing Co., New York, pp. 113-128.

Chow, W.K. and Fong, N.K., 1993, Application of Field Modeling Technique to Simolate Interaction of Sprinkler and Fire-Induced Smoke Layer, Combustion Science and Technolory, Vol. 89, pp. 101-151.

Delaney, M.A., 1992, Numerical Field Model Simulation of Full Scale Fire Tests in a Closed and an Open Compartment, M.S. Thesis, Naval Postgraduate School, Monterey, CA.

Ho, V., Siu, N. and Apostolakis, G., 1985, COMPBRN III-A Computer Code for Modeling Compartment Fires, Report UCLA-ENG-8524, College of Engineering, University of California at Los Angeles.

Holen, J., Brostrom, M. and Magnussen, B.F., 1990, Finite Difference Calculation of Pool Fires, Twenty Third Symposium (International) on Combustion, The Combustion Institute, pp. 16771683.

Houck, R.R., 1988, Numerical Field Model Simulation of Full-Scale Fire Tests in a Closed Spherical/Cylindrical Vessel with Internal Ventilation, M.S. Thesis, Naval Postgradnate School, Monterey, CA.

Howell, J.R., 1982, A Catalog of Radiation Configrration Factors, McGraw-Hill Book Co., New York

Jones, I.P., 1990, Fire Modelling, Eurothrm Seminar No. 13, Abstract of Papers, Harwell I.aboratory, England.

Kou, H.S., Yang, K.T., and Lloyd, J.R., 1986, Turbulent Buoyant Flow and Pressure Variations around an Aircraft Fuselage in a Cross Wind Near the Ground, Erre Safety Science. in Broc. First International Symposium pp. 173-184. 
Leonard, B.P., 1983, A Convectively Stable, Third-Order Accurate Finite Difference Method for Steady Two-Dimensional Flow and Heat Transfer, Numerical Ptoperties and Methodologies.in Heat Transfer, ed. T.M. Shih, Hemisphere Publishing Corp., Washington, D.C. pp. 211-226.

Londino, J., 1993, Turbulent Buoyant Flow in an Opea Comparment with Participating Medium and Combustion, Ph.D. dissertation research in progress, Department of Aerospace and Mechanical Engineering, University of Norre Dame.

McCarthy, T.G., 1991, Numerical Field Model Simulation of Full Scale Fire Tests in a Closed Spherical/Cylindrical Vessel Using Advanced Computer Graphics Techrique, M.S. Thesis, Naval Postgraduate School, Monterey, CA.

Mueller, K, and Max, U., 1991, Input Data Set for E41.7 Blind Postcalculations of an Oi Fire in a Closed System, Kernforschungszentrum Karlsruhe GmbH.

Mueller, K. and Volk, R, 1990, Characteristics of an Oil Fire in a Closed Subsystem with the Ventilation System Connected and Variable Degrees of Door Opening, Design Basis Report, Kemforschungszentrum Karlsruhe GmbH.

Nicolette, V.F., Yang, K.T., and Lloyd, J.R., 1985, Transient Cooling by Natural Convection in a Two-Dimensional Square Enclostre, Iotemetional Jorntal of Heat and Mass Transfer. Vol. 28, No. 9, pp. 1721-1732.

Nicolette, V.F, and Yang, K.T., 1993, Modeling of HDR Oil and Cable Fire Tests, paper presented at the Conference on Structural Mechanics in Reactor Technology (SMIRT 93), Fire Safery Seminar, Heidelberg, Germany, August 24-28, 1993.

Nies, G.F., 1986, Numerical Field Model Simulation of Full Scale Tests in a Closed Vessel, M.S. and M.E. Thesis, Naval Postgraduate School, Monterey, CA.

Raycraft, J., Kelleher, M.D., Yang, H.Q, and Yang, K.T., 1990, Fire Spread in a ThreeDimensional Pressure Vessel with Radiation Exchange and Wall Heat Losses, Mathematical and Computer Moilelling, Vol. 14 pp. 795-800.

Satoh, K., Lloyd, J.R., Yang, K.T., and Kanury, A.M., 1983, A Numerical Fintte-Difference Study of the Oscillating Behavior of Vertically Vented Comparuments, in Numerical Properties and Methodologies in Heat_Transfer_Ed. T.M. Shih, Hemisphere Publishing Corp., Washington, D.C., pp. 517-528.

Siegel, R. and Howell, J.R., 1992, Thermal Radiation. Hea: Transfer, 3rö Ed., Hemisphere Publishing Co., Washangton, D.C.

Simcox, S., Wilkes, N.S., and Jones, LP., Computer Simulation of the Flows of Hot Gases from the Fire at King's Cross Underground Station, AERE-G4782, 1988.

Yang, K.T, 1986, Numerical Modeling of Natural Convection-Radiation Interactions in Enclostres, Keynote Address, in Broceedings of the 8sh International Heat Transfer Conference. Vol. 1, Hemisphere Publishing Co., Washington, D.C, pp. 131-140.

Yang, K.T. and Lloyd, J.R., 1985, Turbulent Buoyant Flow in a Vented Simple and Complex Enclosure, in Natural Convection-Fundamedals and Applications.Eds. S. Kakac, W. Aung and R. Viskanta, Hemisphere Publishing Co., Washington, D.C., pp. 303-329. 
Yang, K.T., Lloyd, J.R., Kanury, A.M., and Satoh, K., 1984, Modeling of Turbulent Buoyant Flows in Aircraft Cabins, Combastion Science and Technology Vol. 39, pp. 107-118.

Yang, K.T., Xia, Q., and Nicolette, V.F., 1992, Simulation of Surong Turbulent Buoyant Flow in a Vented Complex Enclosure, Computational Mechanics '92, Eds. S.N. Aliuri, G. Yagawa, P. Tong, and R. Jones, Technology Publications, Atlanta, Ga.n p. 235 . Also to appear in Computational Mechanics.an International Joumal, 1994. 


\section{LIST OF FIGURES FOR APPENDIX B}

Figure 1 HDR Fire Room Geometry

Figure 2 Computational Dorain

Figure 3 Calculated Temperature Fields at $I=9$ and $\bar{t}=2$ and 4 minutes

Figute 4 Calculated Temperanure Fields at $\mathbf{l}=25$ and $\mathbf{i}=2$ and 4 minutes

Figure 5 Calculated Temperature Fields at $\mathrm{J}=9$ and $\overline{\mathrm{t}}=2$ and 4 minutes

Figure 6 Calculated Temperature Fields at $J=14$ and $\bar{t}=2$ and 4 minutes

Figure 7 Calculated Temperature Fields at $K=9$ and $\bar{t}=2$ and 4 minutes

Figure 8 Calculated Temperature Fields at $\mathrm{K}=18$ and $\mathrm{t}=2$ and 4 minutes

Figure 9 Comparison of Temperamure Data at Location of Thermocouple CT 5246

Figure 10 Comparison of Temperanure Data at Location of Thermocouple CT 5203

Figure 11 Comparison of Temperature Data at Location of Thernocouple CT 5204

Figure 12 Comparison of Temperature Data at Location of Thermocouple CT 5290

Figure 13 Comparison of Temperature Data at Location of Thennocouple CT 5293

Figure 14 Comparison of Temperature Data at Location of Thermocouple CT 5294 


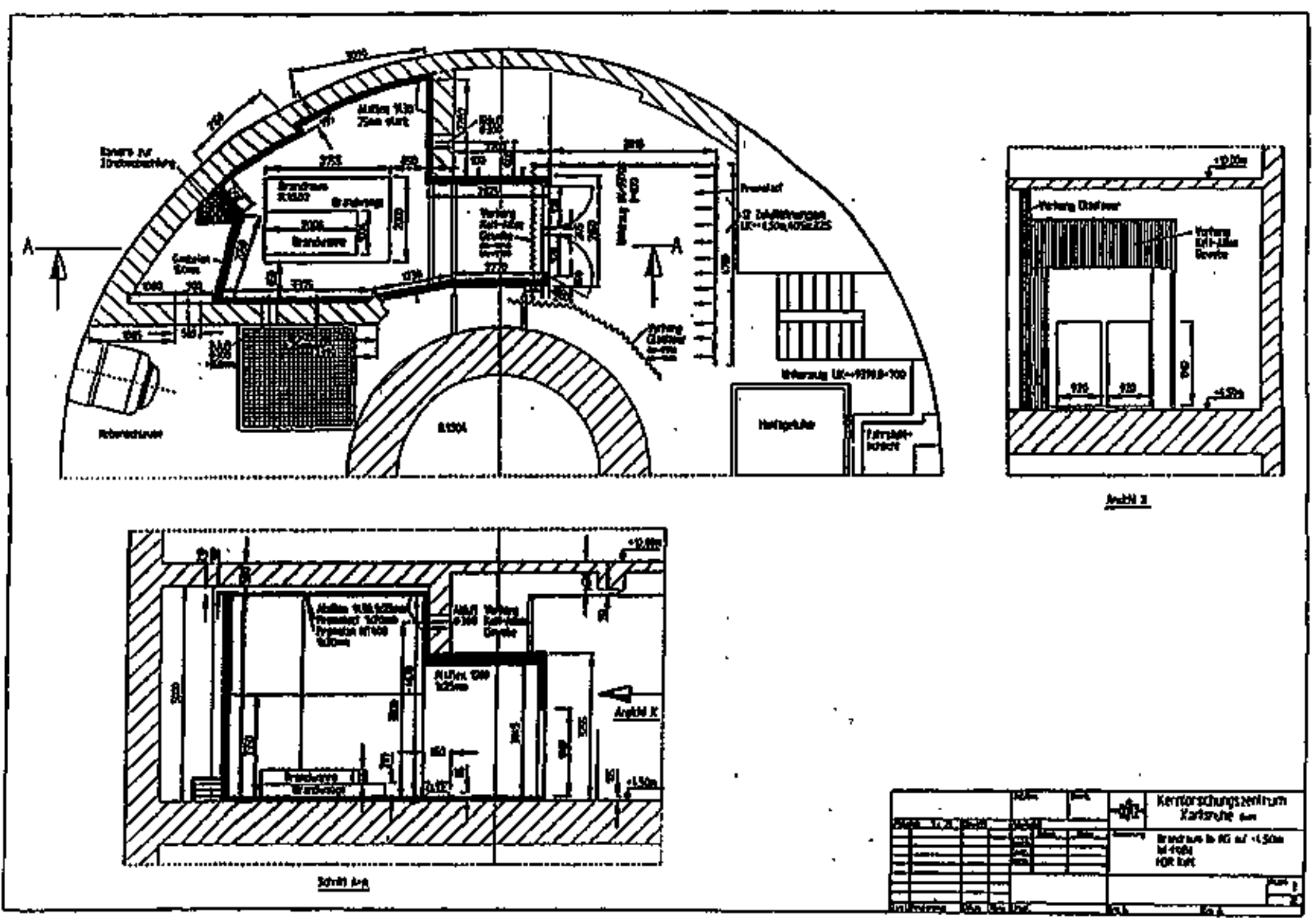

Figure B-1 HDR Fife Room Geoinetry 


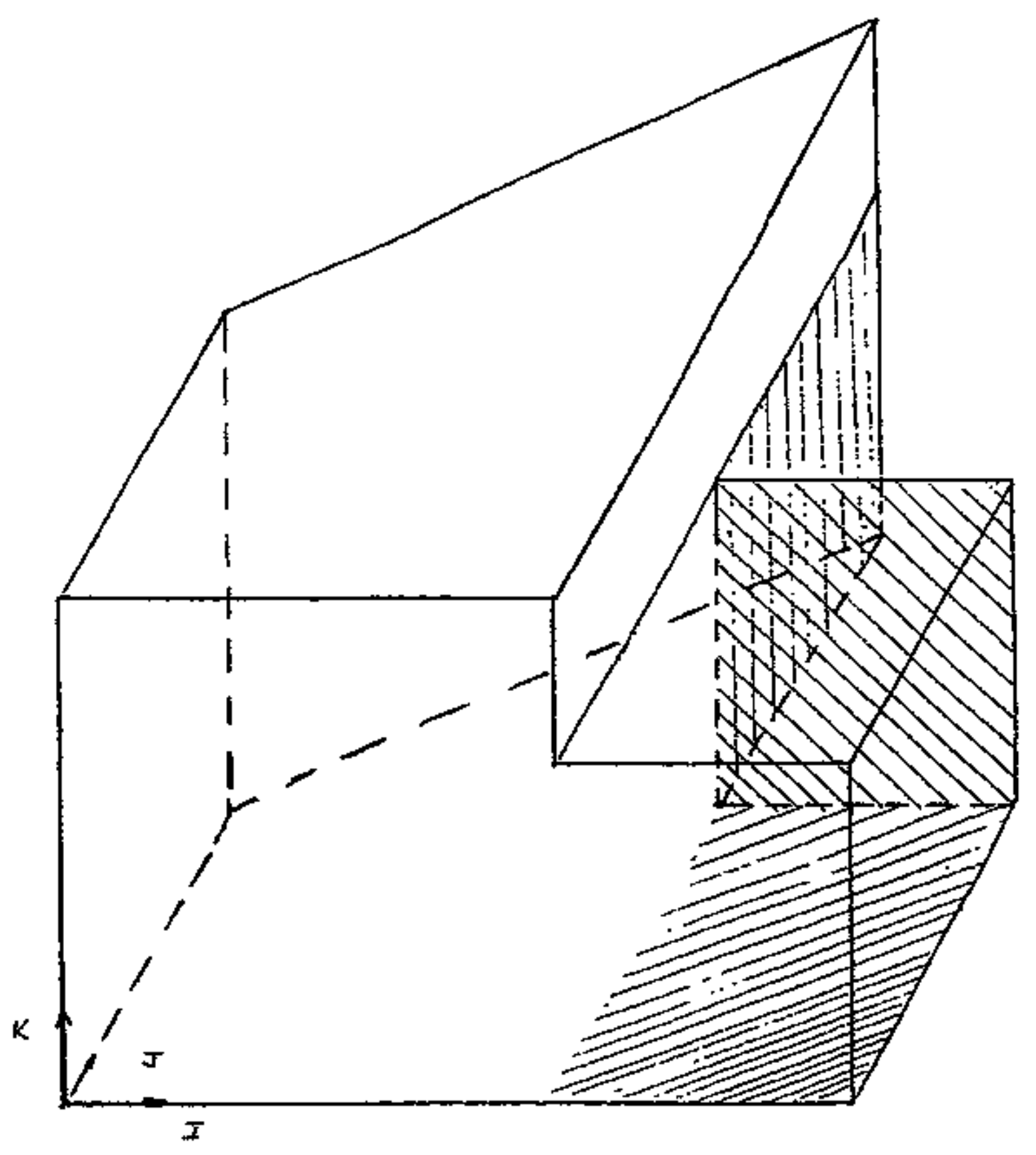

Figure 8-2 Computational Domain 

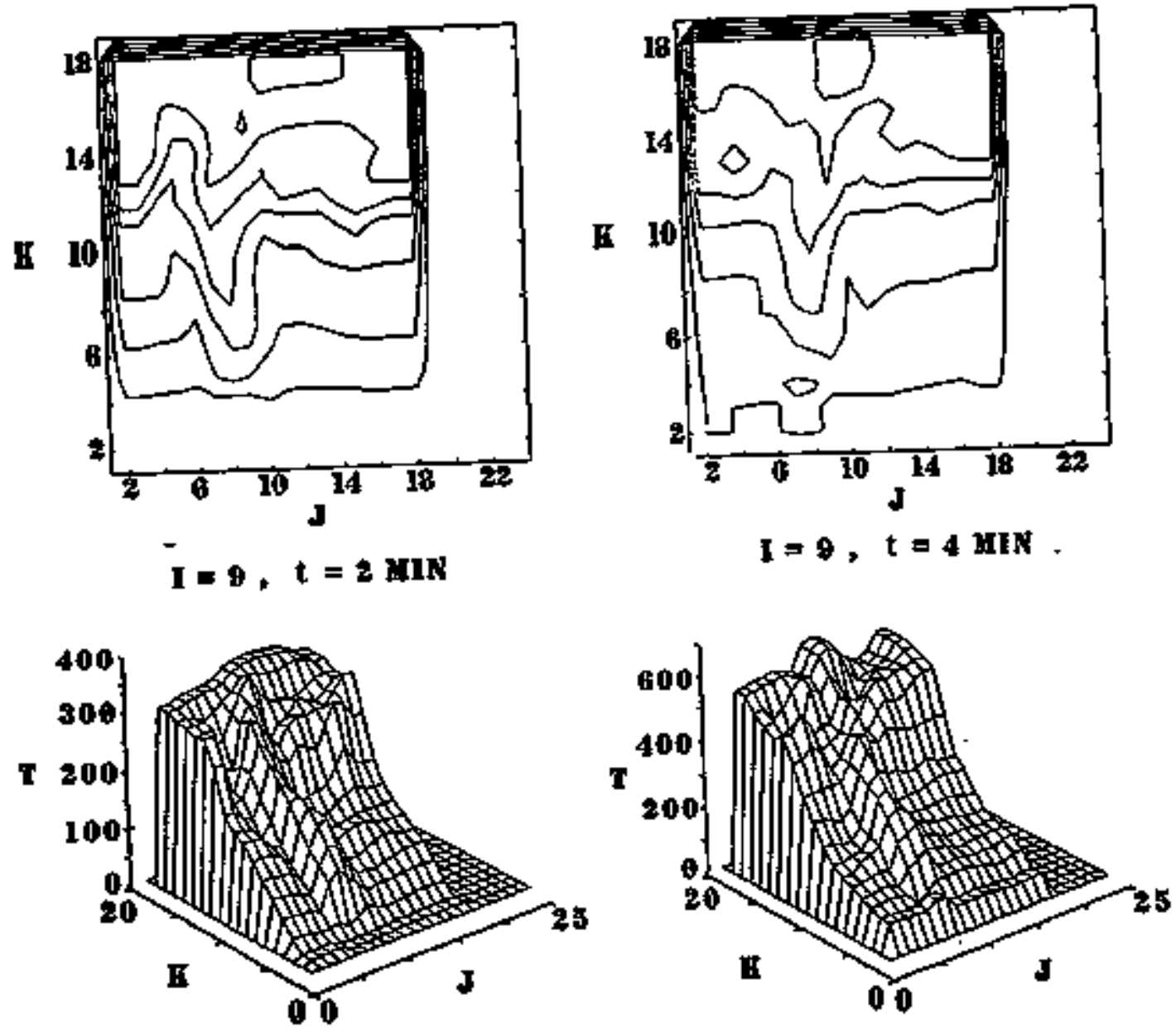

Figure $B-3$

Calculated Temperature Fields at $\mathrm{I}=9$ and $\mathrm{t}=2$ and 4 minutes 

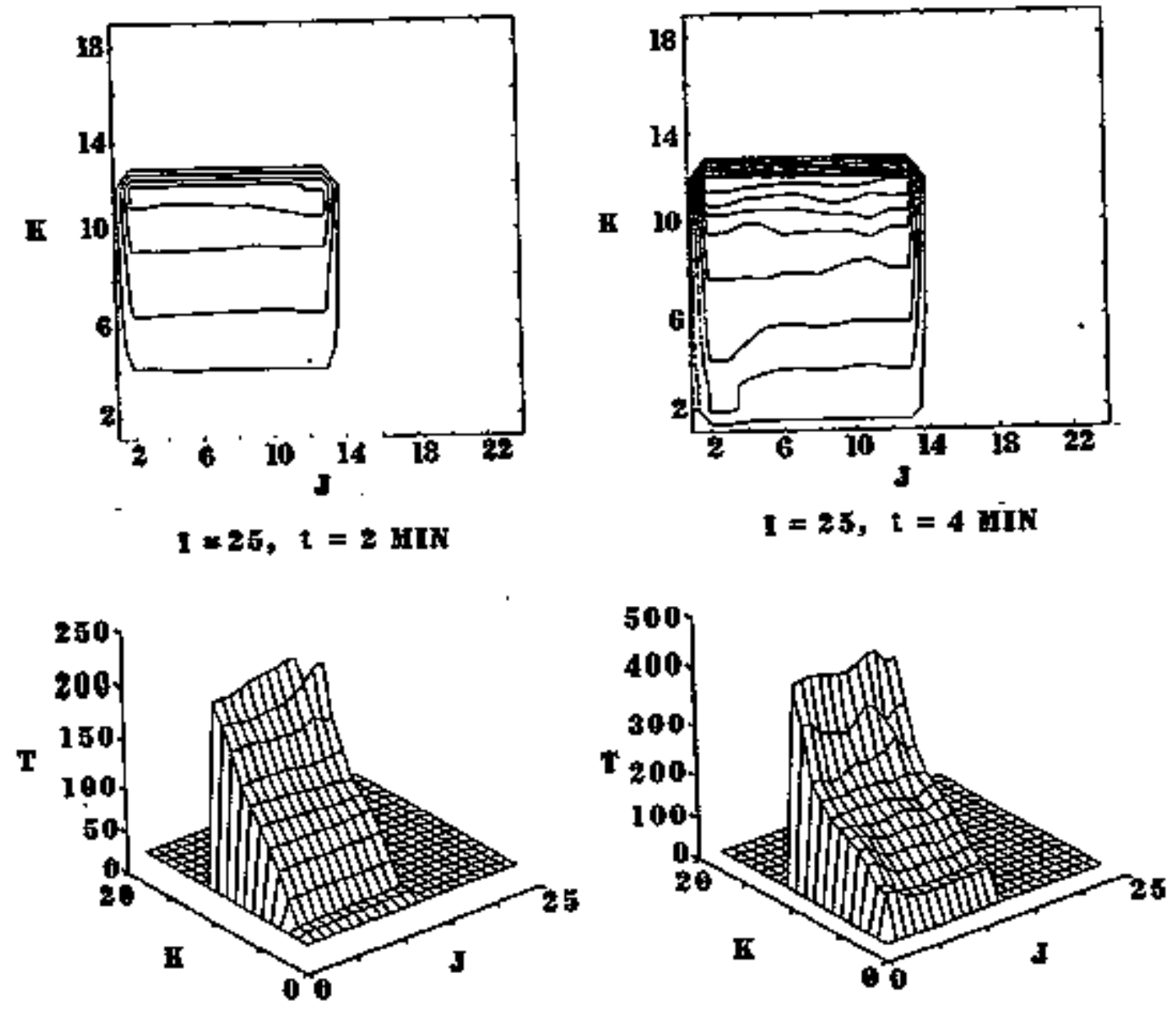

Figure 5-4

Calculated Temperature Fields at $\mathrm{I}=25$ and $\mathfrak{t}=2$ and 4 minutes 

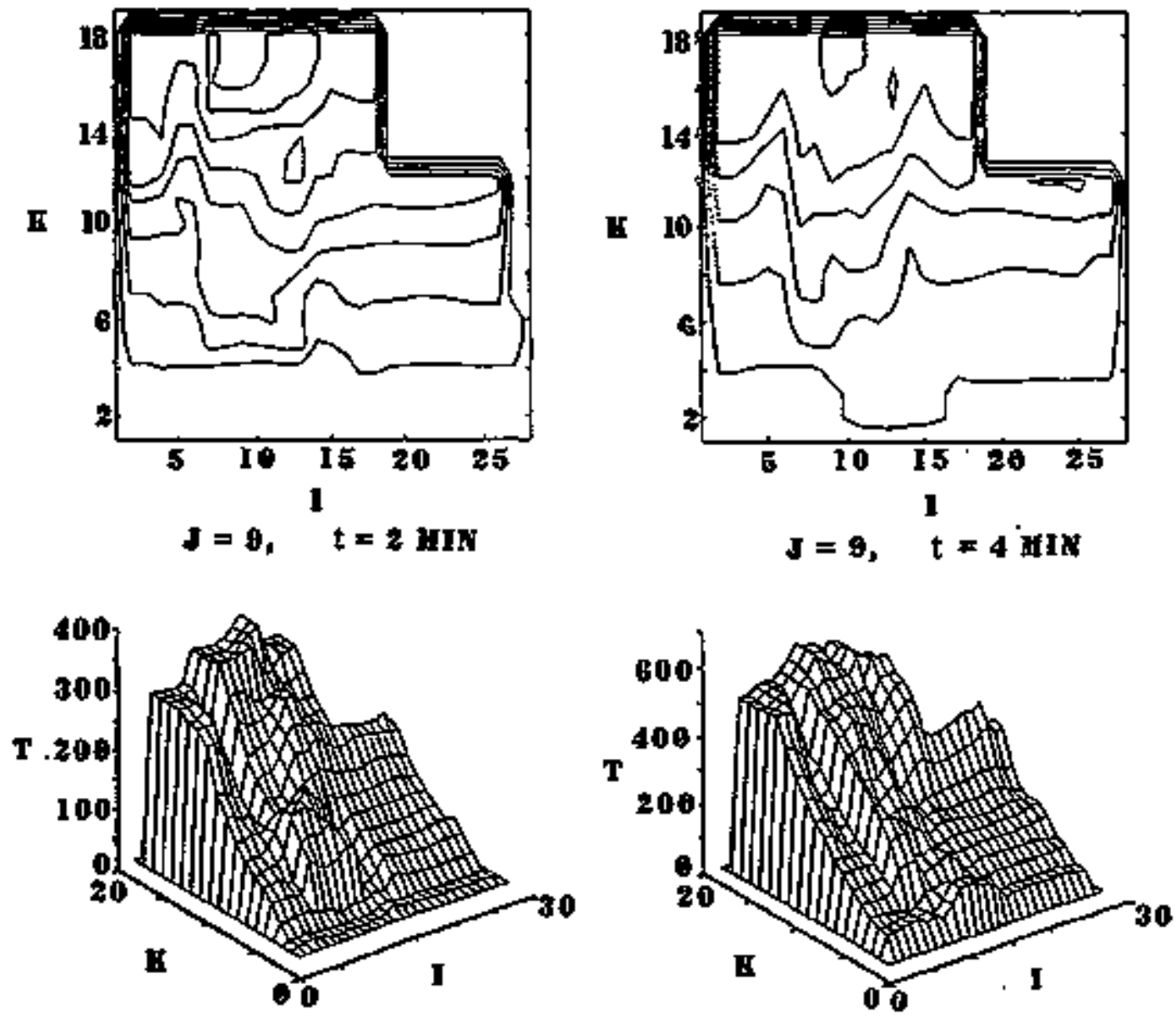

Figure B-5

Calculated Temperature Fields at $\mathrm{f}=9$ and $\overline{\mathrm{t}}=2$ and 4 minutes 

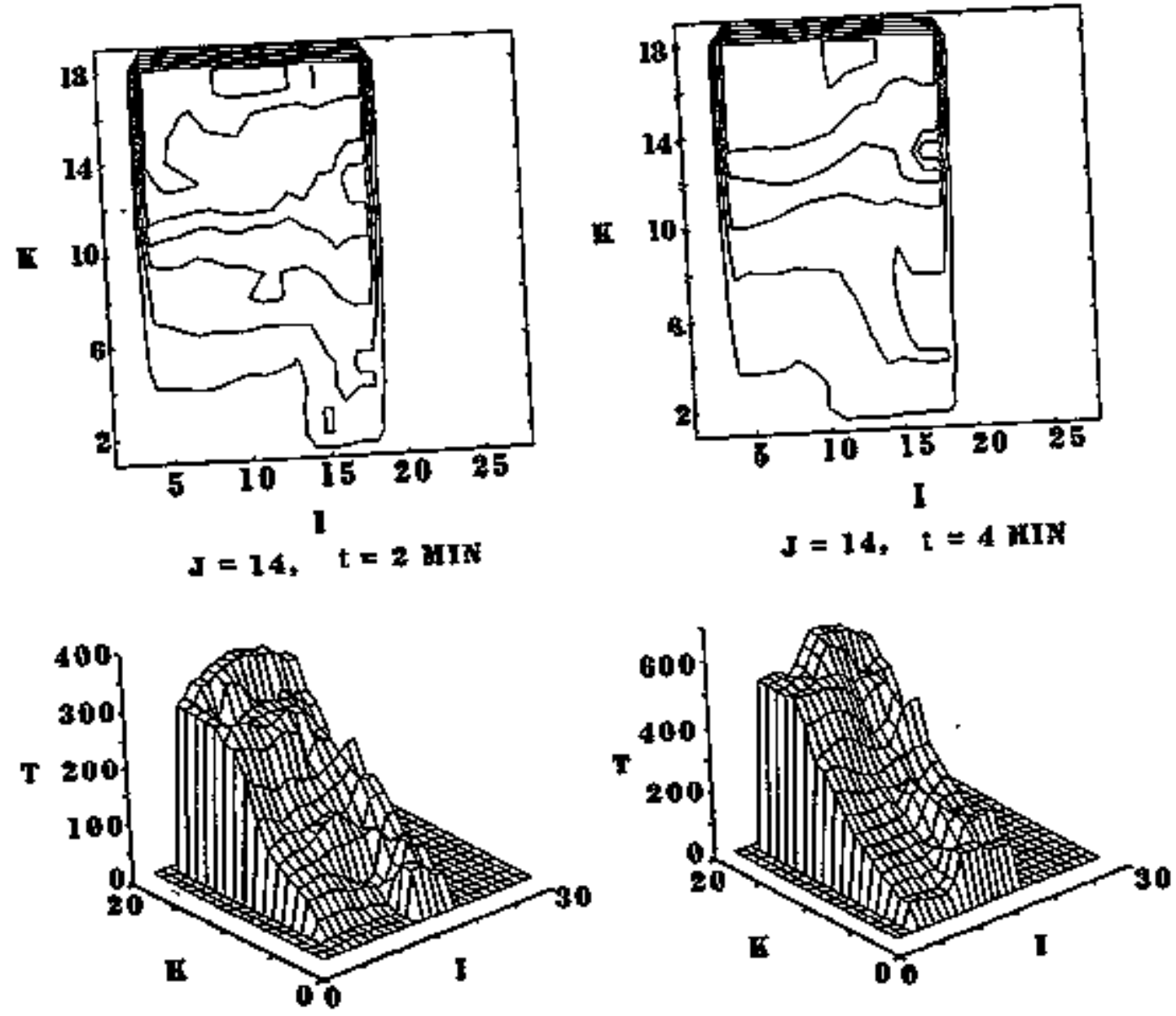

$$
\text { Figure B-6 }
$$

Calculated Temperanure Fields at $J=14$ and $t=2$ and 4 minutes 

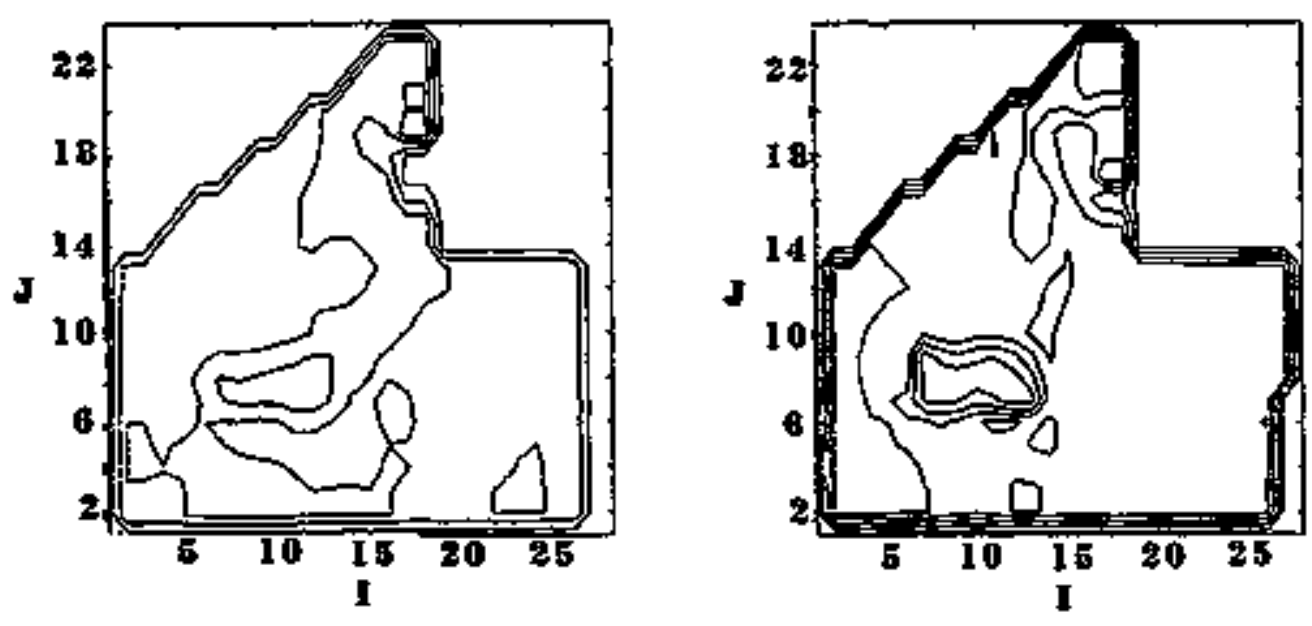

$$
\text { H= 0, } t=2 \text { HIN }
$$
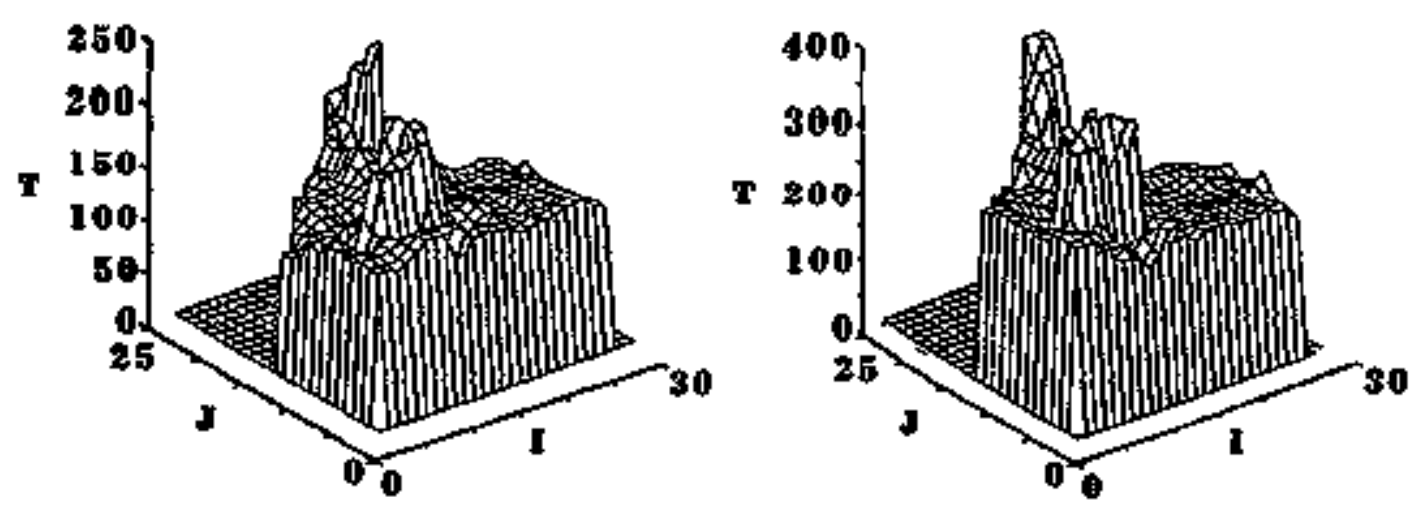

Figure B-7

Calculated Temperature Fields at $\mathrm{K}=9$ and $\mathrm{i}=2$ and 4 minutes 

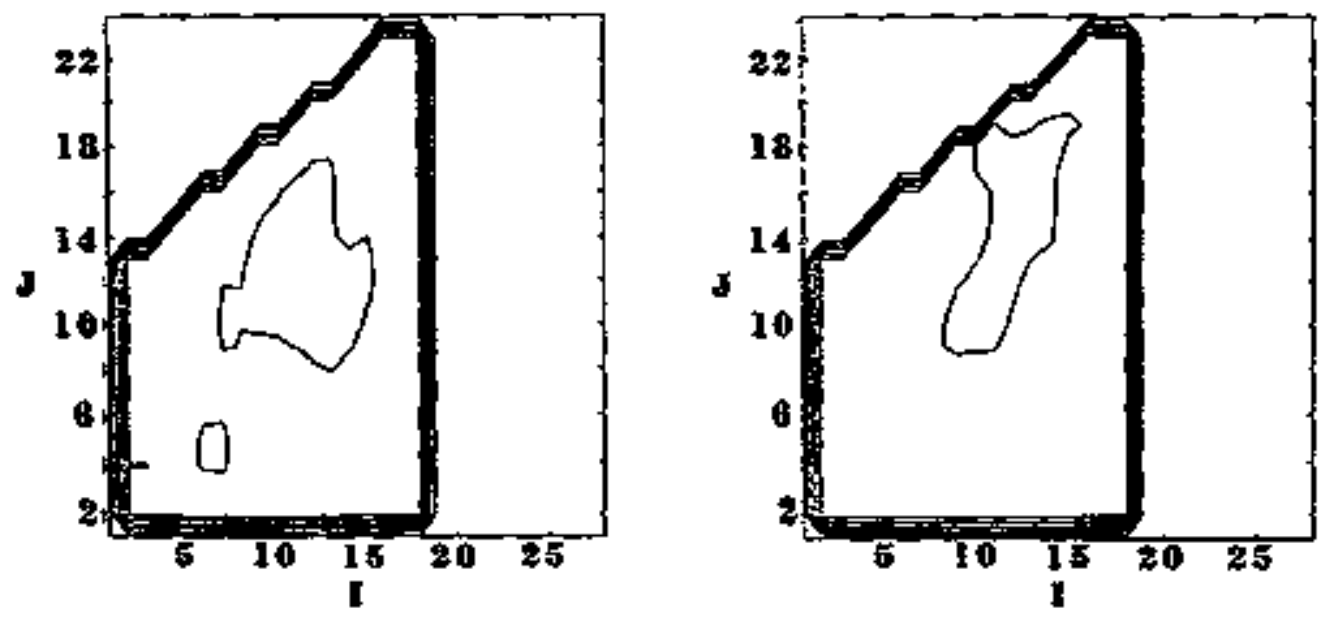

$\mathrm{F}=10, \mathrm{t}=\mathbf{2} \mathrm{HIN}$

$\mathrm{L}=18, t=4 \mathrm{HIN}$
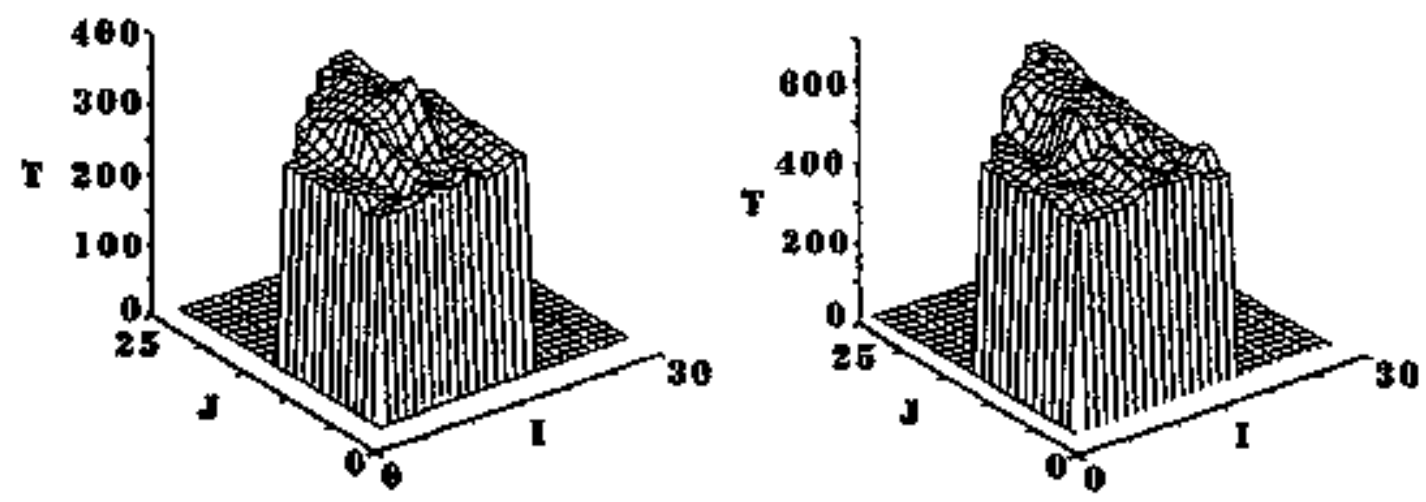

Figure B-8

Calculated Temperature Fieloss at $\mathrm{K}=18$ and $\mathrm{i}=2$ and 4 minutes 


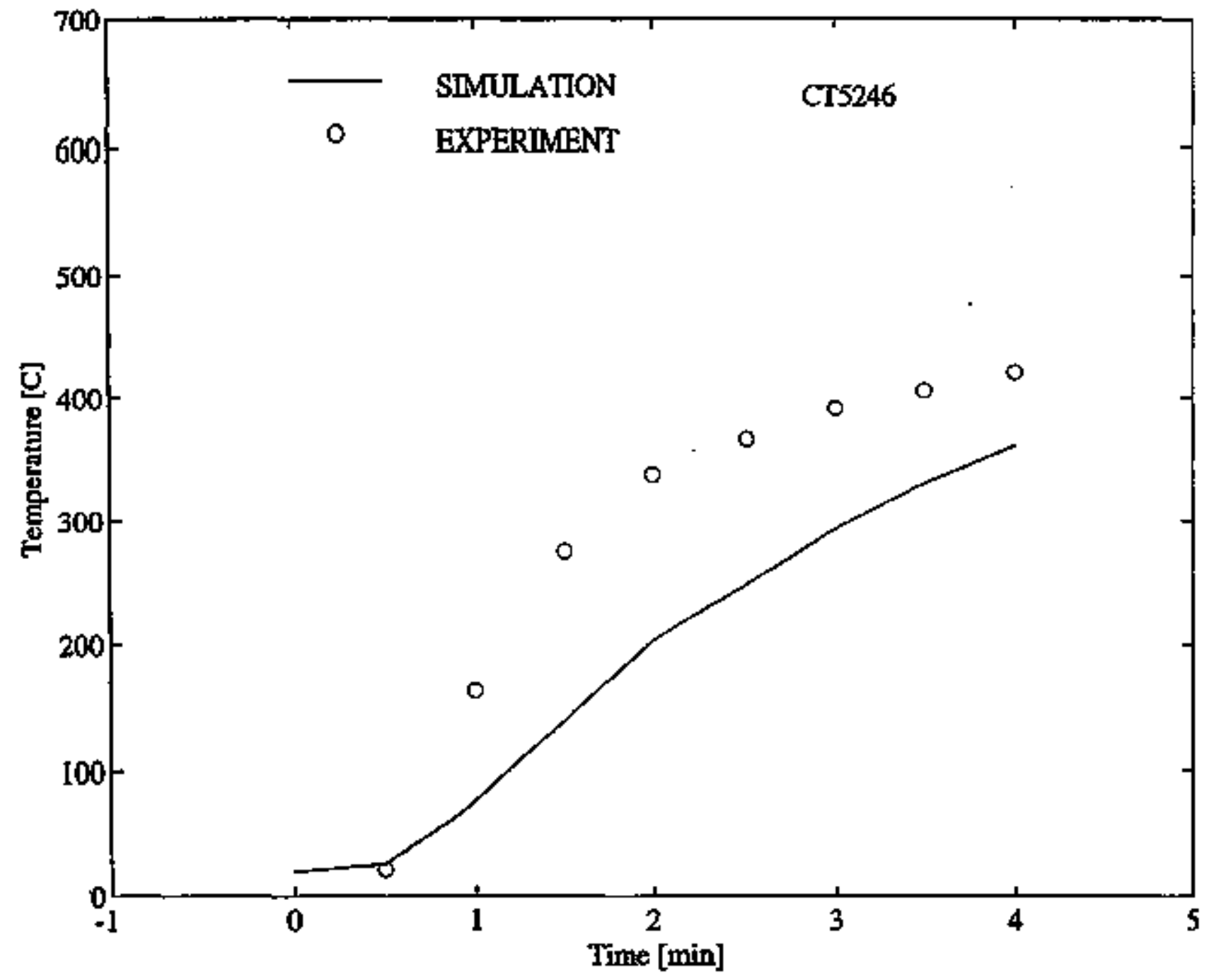

Figure $\mathbf{B}-9$

Comparison of Temperatare Data at Location of Thermocouple CT 5246 


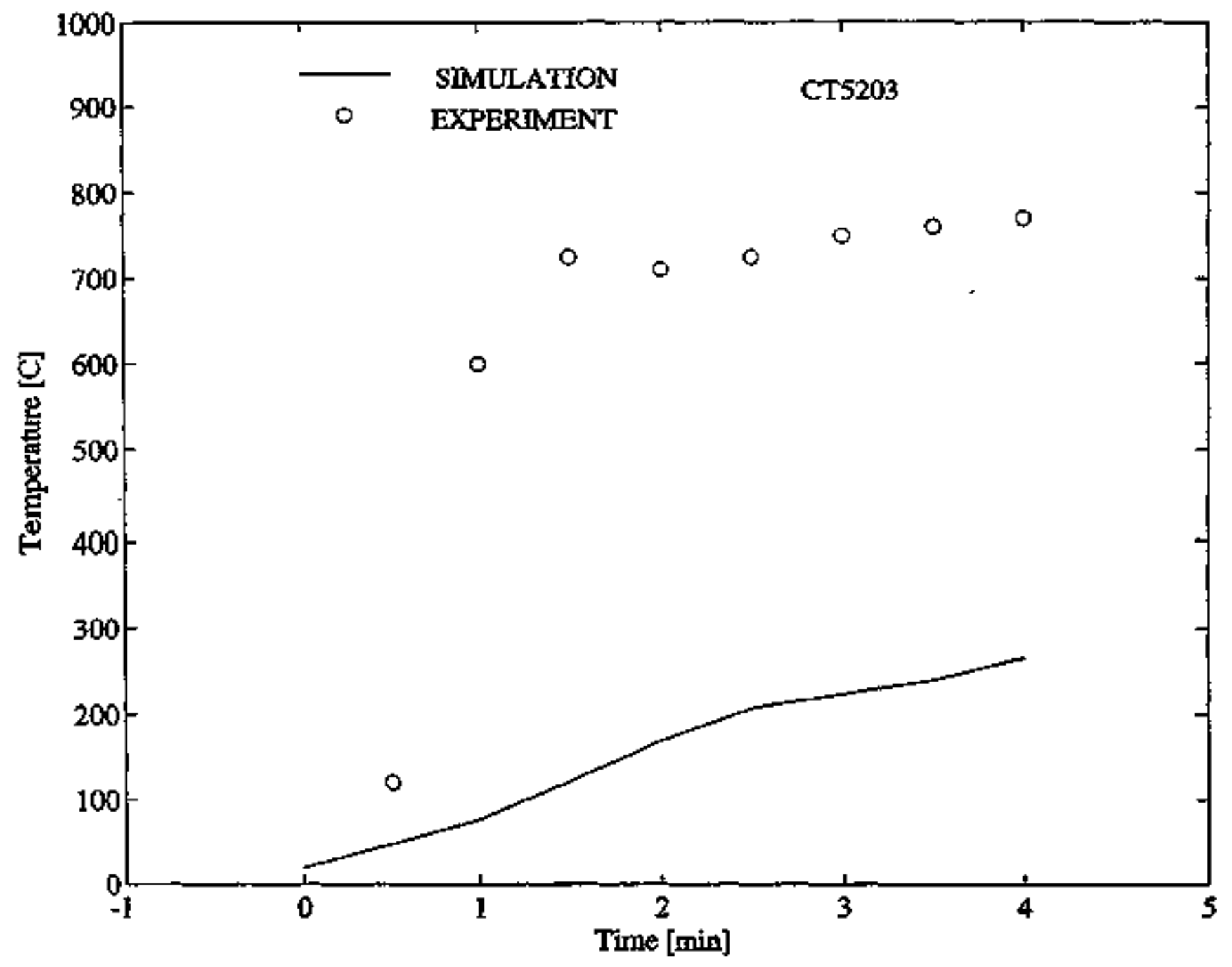

Figure B-10

Comparison of Temperature Data at Location of Thermocouple CT 5203 


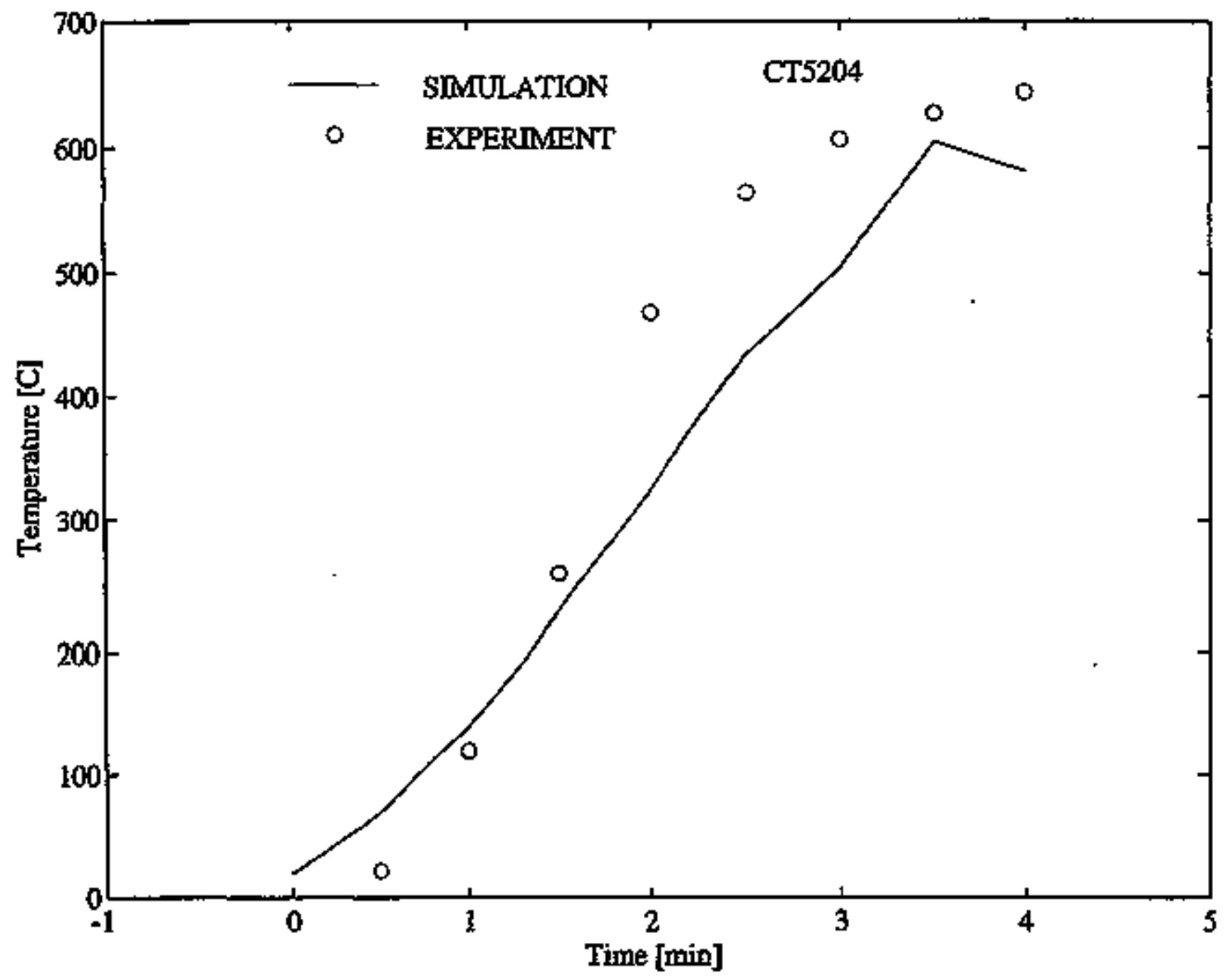

Figure B-11

Comparison of Temperature Data at Location of Thermocouple CT 5204 


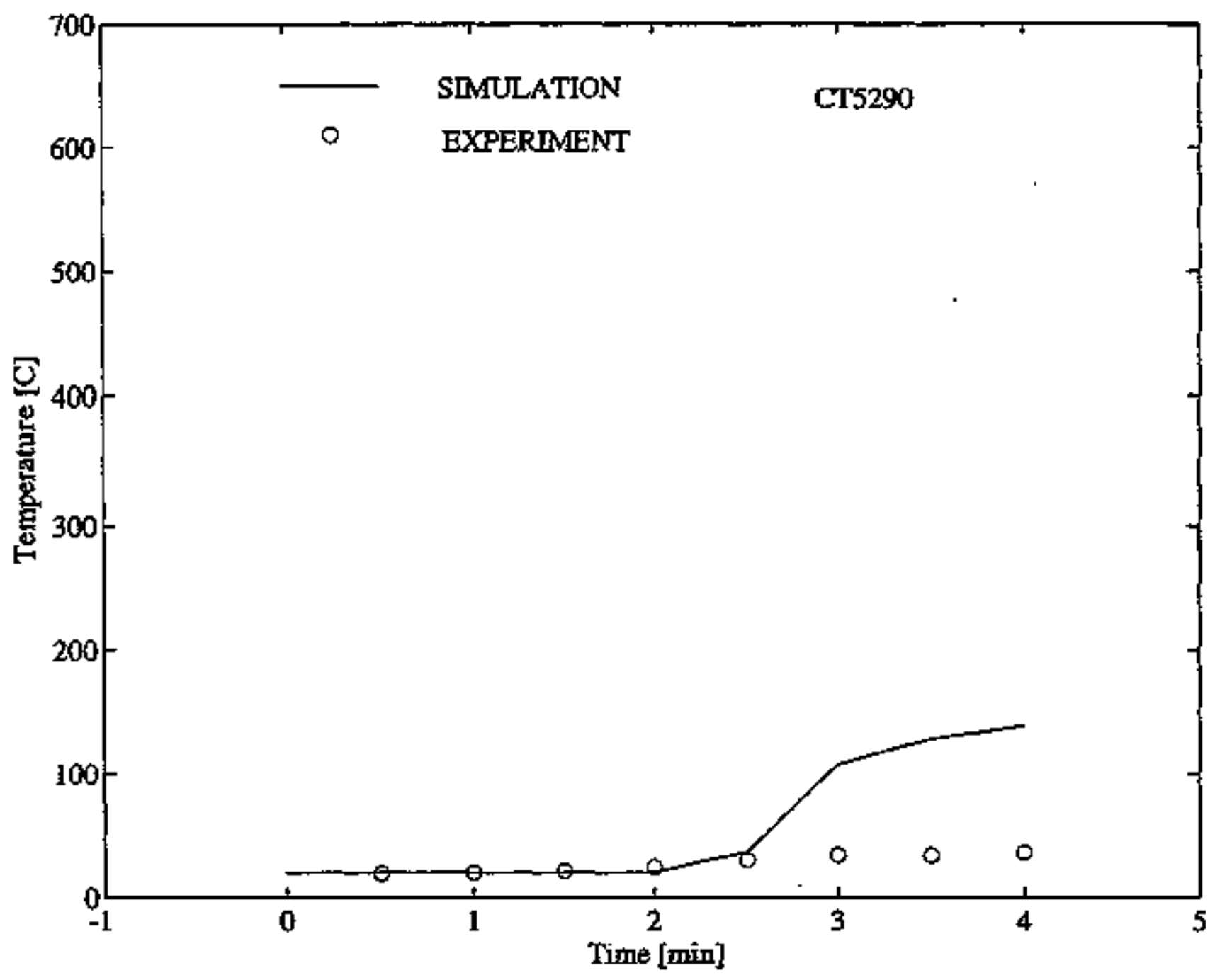

Flgure $\mathrm{E}-12$

Comparison of Temperature Data ar Location of Themocouple CT 5290 


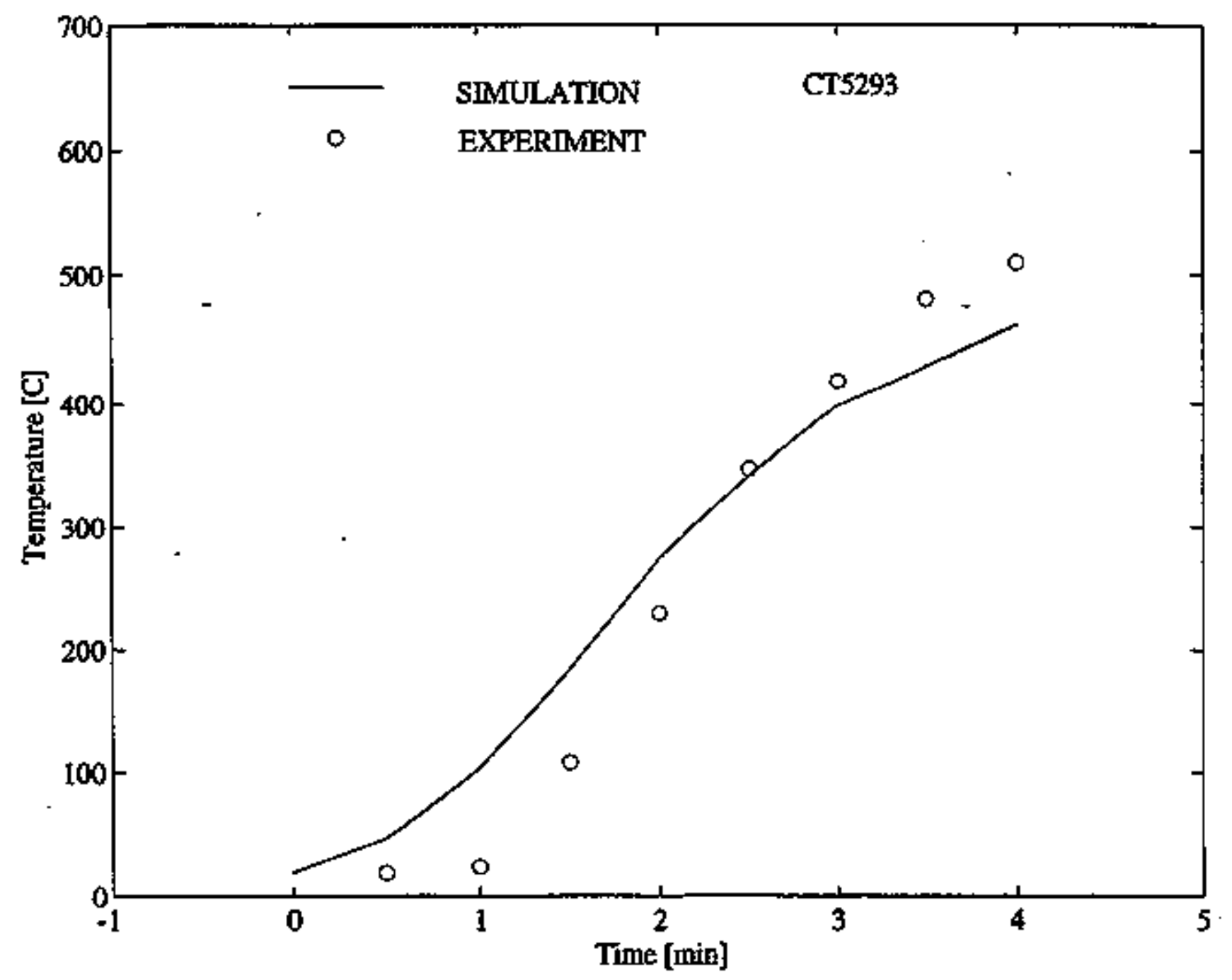

Figure E-13

Comparison of Temperature Data at Location of Thermocouple CT 5293 


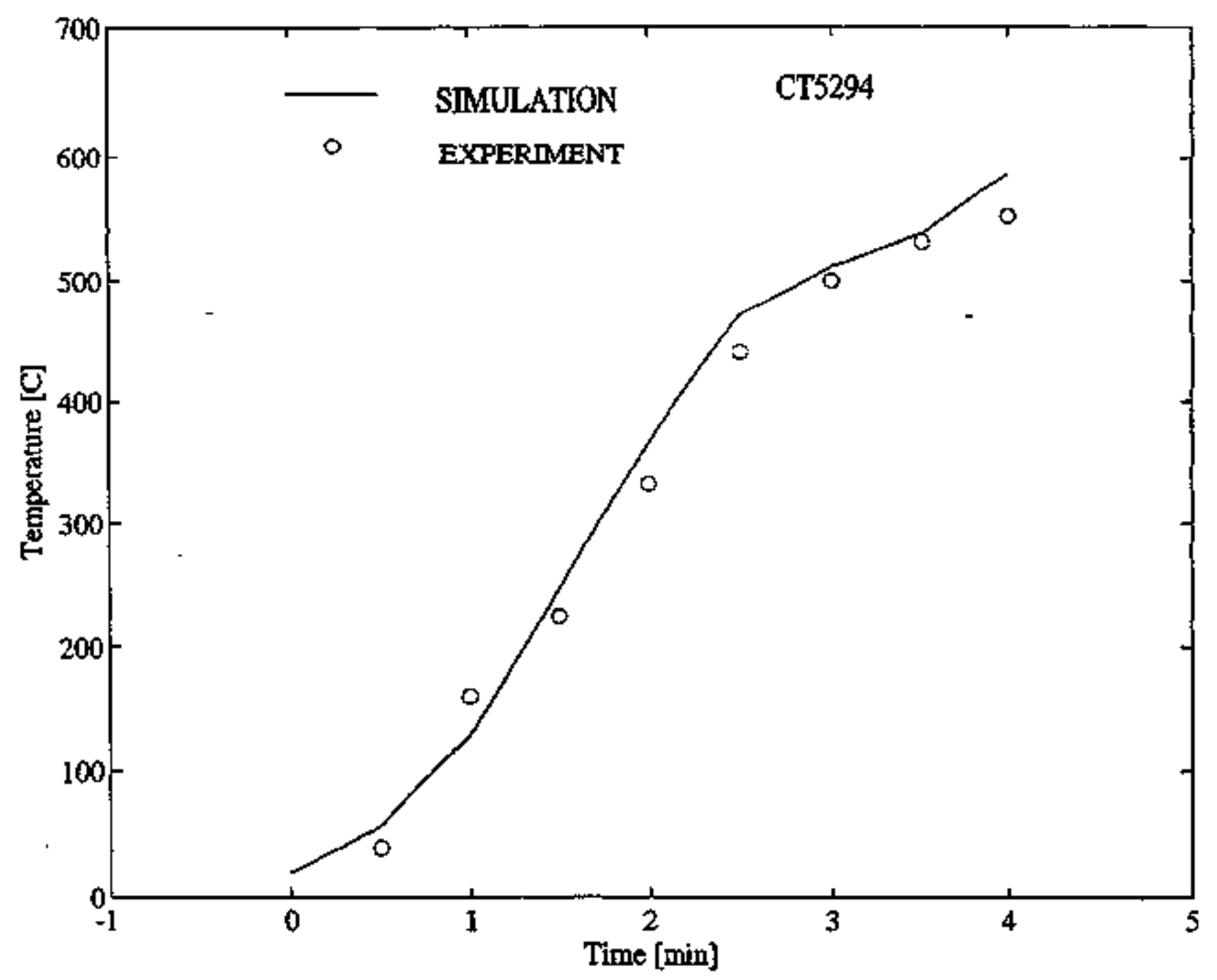

Figure B-14

Comparison of Temperature Data at Location of Thermocouple CT 5294 


\section{Appendix C: University of Notre Dame Field Nodel Calculationg for HDR Test $\mathbf{F 4 1 . 5}$}

The following report on the Notfe Dame Field Model Calculations for foR Test E41.S is encluded as a stand-alone report. It has been published in Heat Transfer in Bixe and coppustion Systems, Askis HTD vol. 272, eds. W.W. Yuen and K.S. Ball, pp. $13-20,1994$. 


\title{
SIMULATION OF STRONG TURBULENT BUOYANT FLOW IN A VENTED COMPLEX ENCLOSURE
}

\author{
K. T. Yang* and Q. Xia \\ Department of Aerospace and Mechanical Engineering \\ University of Notre Dame \\ Notre Dame, IN 46556, USA \\ and \\ V. F. Nicolette \\ Thermal and Fiuid Engineering \\ Sandia National Laboratories \\ Albuquerque, NM 87185, USA
}

\begin{abstract}
A three-dimensional field model for torbulent flow in an arbitrary compartment, taking into account strong buoyancy, full compressibility, turbulence, surface-sarface radiation exchange, and wall heat losses is ntilized to simulate a full-scale fire test in a fire room with open doorways located in a decommissioned nuclear reactor containment vessel in Gernany. Results show that reasonable agreement in the numerical and test data in the unsteady temperature field at three locations inside the fire room was obtained, even though the numerical simulation underestimated the doorway instantaneous exit velocities by as mach as $40 \%$. The discrepancies are discussed in terms of both test uncertainties and adequacy of the physical submodels utilized in the field model.
\end{abstract}

*Corresponding Author 


\section{INTRODUCTION}

It is now generalty recognized that despite the great complexity of the real fire phenomenon it is still critical that their quantitative descriptions should be developed for the parpose to help to mitigate the losses of lives and properties. Such descriptions basically can be obtained by means of fire models which are the mathematical models for the physical and chemical processes involved in the spread of fire in a space as functions of the ignition source, space geometry, and materials content. Once validated by test data, such fire models, for instance, can be utilized to significantly reduce the need for full scale fire tests which are extremely expensive and requires a great deal of effort to study the consequences of various fire scenarios for fire hazard mitigation, and also in post-fire investigations.

Fire models can be classified in terms of zone models and field models with relative advantages and disadvantages which are now well recognized. Despite such advantages for the field models as the capability to provide seamless cetails of the velocity, temperatore, and species concentration fields and interaction effects among various regions in the fire spread space such as stratification and thermal radiation, these field models and their development have not received the proper attention they rightly deserve in the past. The primary reasons are that they are very computing intensive and access to high-power compling resources was rather limited, and also that there were uncertainties in modeling such phenomena as turbulent conbustion and thermal radiation. However, with increasing accessibility to supercomputers, minisupercomputers, and high power workstations and personal computers, field models are increasingly being used to deal with the simulation of real fire scenarios. For instance, the use of the Harwell-Flow 3D code, a field model, to simulate the air flow in the King's Cross underground station fire in Londion in 1987 (Simcox, Wilkes, and Jones, 1988) is a good example, and several others have also been discussed at the 1990 Eurotherm Seminar on Fire Modeling (Jones, 1990). Despite such increased attention to the application of field models, there is still a great deal of uncertainty as to the generality of such models and the achievable accuracy of applying such models to real fire sitaations. This uncertainty is the result of the difficulty in modeling turbulent combustion of real fuels in fires and themal radiation effects of participating media, as well as of the general lack of pertinent test data base, especially for follscale fire tests. Such test data are infeed critically needed to provide a means for validating the field models and also to provide fundamental information on the deficiency of the models so that they can be properly improved in tine.

In the past several years, an intenational cooperative effort bas been established to assess the viabilitity of the latest fire models, both zone and field models, on the basis of full-scale fire tests carried out in a decorsmissioned nuclear reactor contaimment building at the Heiss Dampf 
Reaktor (HDR) facility in Germany. The objectives of this assessment is to determine the current state of development of fire models with the view toward their eventual use in the mitigation of fire hazards in nuclear reactors. It is noted that these are the only tests ever conducted inside an actual nuclear reactor containment building. The University of Notre Darne UNDSAFE three-dimensional fire model (Nies, 1986; Raycraft, Kelleher, Yang, and Yang, 1990) was one of the field models chosen for the assessment. Two series of foll-scale fire tests were conducted in the same designated fire rom inside the HDR building for the purpose of model validation. One series, designated as the $\mathrm{E} 41.5 \mathrm{Test}$, deals with a naturally-ventilated fire (Mueller and Volk, 1990), while the second series known as the E41.7 Test deals with a forcedventilation fire (Mueller and Max, 1991). The purpose of this paper is to show some of the numerical simulation results for the E41.5 Test as compared to the test data, while results of similar comparisons for the E41.7 Test are given in a separate paper ( $Y_{\text {ang, Huang, and }}$ Nicolette, 1994). It should be noted that these comparisons provide an excellent opportunity to assess the accuracies of the current available fire models as well as to point out critical shortcomings of such fire models.

\section{DESCRIPTION OF NATURALLY-VENTHLATED FULL-SCALE FIRE TEST}

Details of the geometries of the HDR containment building and the fire room, and descriptions of the materials of the fire-room walls, ceiling, and floor and the fuel oil characteristics can be found in the report of Mueller and Volk, (1990). Briefly, the containment building is in the shape of a vertical pressure vessel, about $60 \mathrm{~m}$ in height and $20 \mathrm{~m}$ in diameter, and the bottom of the building is about 11m below grade. A schematic of this building is shown in Figure 1. The fire room floor is located at the $4.5 \mathrm{~m}$ level above ground, and the fire room is shown in Figure 2. The main fire roors has a height of $5 \mathrm{~m}$ and that of the doorway area is about $3 \mathrm{~m}$. The fuel pan is located on the floor in the main fire room, as can also be seen in Figure 2. The combined room has a total volume of about $100 \mathrm{~m}^{3}$, and the total floor or ceiling area is about $23 \mathrm{~m}^{2}$. All side walls are riade op of largely $10 \mathrm{~cm}$ and $15 \mathrm{~cm}$ thick $Y$ tong, while the floor consists of $25 \mathrm{~cm}$ thick Ytong. The ceiling is covered with insulations made $\mathrm{pp}$ of $3 \mathrm{~cm}$ Promalane and $2.5 \mathrm{~cm}$ of Alsiflex. Most of the walls and floor are also covered with $2 \mathrm{~cm}$ of Alsiffex mats. All thermophysical properties sach as density, specific heat and thermal condactivity of these materials are known and tabulated in the reports by Mueller and Volk (1990) and Mueller and Max (1991). The fuel oil is SOL-T made by the Shell Conpany and produces only non-greasy dry soot. It has a density of $0.756 \mathrm{~kg}^{3} \mathrm{~m}^{3}$ at $20^{\circ} \mathrm{C}$, and a heating value of $42,500 \mathrm{~kJ} / \mathrm{kg}$. The side fire room is equipped with two fire protection doors with variable openings and controlled remotely. 
In the E41.5 Test with natural ventilation (buoyancy induced flow only with the doors open), the major portion of the test lasts 18 minutes, during which the burn rate of the fuel oil was measured, along wilh extensive measurements of gas and flame temperatures, temperatures at selected locations, gas concentrations, pressures, and doorway velocities. Some of these measured data will later be used to compare with simulation results from the field model, which will also be discussed on the basis of the shortcomings in the field model. It is pertinent to mention here that the heat release rate of the fite was not measured, but must be inferred from the fuel-loss data. This anavoidable deficiency in the measurements, as will be discussed later, does impact on the simulation results.

\section{THE FLLD MODEL}

The field model utilized in the present study, under the code name of UNDSAFE (University of Notre Dame $\mathbf{S}$ moke and Eire in Enclosures), has been under continuous development in recent years. Early efforts were concentrated on two-dimensional room fire problems and could account for strong buoyancy, full compressibility, simple rectangular room geometry, one-dimensional ceiling-floor radiation exchange, but not including effects of turbulent cornoustion and wall losses. The model was applied to a variety of room and extemal fire scenarios with some reasonable validation by experimental data (Satoh, Lloyd, Yang, and Kanury, 1983; Yang, Lloyd, Kanury, and Satoh, 1984; Yang and Lloyd, 1985; Kou, Yang and Lloyd, 1986). More recently, this field model has been extended to three-dimensional enclosures including wall losses, pressurization and surface-surface radiation exchange (Nies, 1986), complex geometries (Raycraft, Kelleher, Yang and Yang, 1990), internal ventilation (Houck, 1988), and effects of sprinklers (Chow and Fong, 1993). Limited experimental validation has also been given by Raycraft, Kelleher, Yang, and Yang (1990) and by Delaney (1992). However, despite the versatility of this field model, as noted above, it is still not complete and in addition lacks sufficient validation to ascertain its general validity, as is the case for all existing field models. The glaring shortcoming in the present model resides with the lack of a viable turbulent combustion model, and a lesser shortcoming in accounting for the effects of species concentration in multidimensional cadiative transfer. The former is particularly difficult because of the general lack of combustion kinetics for real complex fuels such as that employed in the HDR fire test. In essence, this difficulty is inherent in all field models.

Since no combustion model is used in the present field model, the heat release rate must necessarily be prescribed. As the combustion process takes place in the region above the fuel pan, the prescribed heat release rate is utilized as volumetric heat sources with a postulated flame region. As will be mentioned later, the flame surface is taken to be black, and surface-surface and surface-flame radiation exchanges are accounted for in the field model. Due to the neglect 
of combustion and gas radiation, the species equations need not be considered, and the dimensionless goveming field equations for turbulent buoyant compressible flow can be written in dimensionless tensor forms as (Nies, 1986; Raycraft, Kelleher, Yang, and Yang. 1990):

$$
\begin{aligned}
& \rho_{t}+\left(\rho u_{i}\right)_{, i}=0 \\
& \left(\rho u_{i}\right)_{, t}+\left(\rho u_{j} u_{j}\right)_{, j}=-p_{i}-\rho G+\left(\sigma_{i t}\right)_{,} \\
& \left(\rho c_{p-m} T\right)_{, t}+\left(\rho u_{j} c_{\rho \mathrm{pm}} T\right)_{, i}=\left(k T_{i}\right)_{i}
\end{aligned}
$$

where the dimensionless shear stress tensor $\sigma_{\mathrm{ij}}$ and mean specific heat $\mathrm{c}_{\mathrm{pm}}$ are given by

$$
\begin{aligned}
& \sigma_{\tilde{0}}=\mu\left(u_{i, j}+u_{j, 1}-\frac{2}{3} \delta_{i} u_{k, 2}\right) \\
& c_{p m}=\frac{1}{T-1} \int_{1}^{T} c_{p} d T
\end{aligned}
$$

where $\delta_{\mathrm{ij}}$ is the Kronecker delta function. It is noted here that both viscous dissipation and pressure work can be neglected in the fire phenomena The above dimensionless quantities are normalized as follows: The coordinates $\bar{x}_{i}$ with the height of the fire soom $H$; the time variable $\mathfrak{t}$ with $H / a_{R}$ where ${ }_{R}$ is a constant reference velocity; all velocity components $\bar{u}_{i}$ with $U_{R}$; absolute temperature $\bar{T}$ with $T_{R}$ where $T_{R}$ is again a reference temperature normally taken to be the air inlet temperature; the pressure difference $\overline{\mathrm{D}}-\overline{\mathrm{p}}$ ), where $\overline{\mathrm{p}}_{e}$ is the hydrostatic equilibrium pressure, with $\rho_{R} /{ }^{\prime}{ }_{R}{ }^{2}$ where $\rho_{R}$ is a constant reference air density based on $p$ and $T_{R}$; the gravitational acceleration $G=(0,0, g)$ with $u_{R}{ }^{2 / H}$; and the thermophysical properties $\bar{\rho}$ (density), $\bar{c}_{p}$ (specific heat), $\bar{\mu}$ (viscosity) and $\overline{\mathbf{k}}$ (thermal conductivity with, respectively, $\rho_{R},{ }_{p R}, \rho_{R}{ }^{a} R^{H}$, and $\rho_{R} c_{p R}{ }^{{ }^{a}} R^{H}{ }^{f}$ where $c_{p R}$ is a constant reference specific heat evaluated at $\mathrm{T}_{\mathrm{R}}$. All $\mathrm{t}_{\mathrm{i}}$ and $\overline{\mathrm{T}}$ are Reynolds averaged quantities, and $\mu$ and $k$ consist of both laminar and turbulent quantities. Also, for convenience, the origin of the coordinate system is fixed at the left front comer of the fire room. Thus, the i-coordinate is in the direction from the fire roor to the entry room; the j-coordinate is in the direction of the 
depth, from the front to the rear, and the k-cootdinate is from the floor to the ceiling (see Figure 1).

The boundary conditions can be easily witten. All velocity components vanish on a solid surface. At the doorway, the boundary conditions are written as follows: (Yang, 1987); where the velocity normal to the doorways, which were open during the E41.5 Test, is outward from the fire room, all velocity components and temperature have zero gradients at the doorway. For doorway locations where the normal velocity is directed inward, the temperature is that of the ambient temperature $T_{R}$ and all velocity components again have zero normal gradients. These conditions obviously allow for hoth in- and ont-flows at the doorways. Except that for the doorways, the temperatute boundary conditions at the walls, ceiling and flow are in accordance with a heat balance and coupled to the conduction through the thicknesses and convection at the outer surfaces. The heat balance involves sufface radiation fluxes from all the other surfaces including those of the flame, except those that are shaded, the convection fluxes from the flow, and conduction fluxes into the solid.

The formulation of the field model is not complete without several submodels for compressibility, buoyancy, wall losses, turbulence, radiation and combustion. These are now described. Compressibility is already accounted for in the governing differential equations, and density is determined in accordance with the perfect gas law. It is noted here that due to the open doorway with ample ventilation, the pressure is nearly constant throughout the fire room. Strong buoyancy is accommodated in Equation (2) without invoking the Boussinesq approximation. Heat Transfer through the walls and ceiling is taken to be that of unsteady one-dimensional conduction through the thicknesses, coupled with convection at the exterior sarfaces with a prescribed surface coefficient of heat transfer. The floor, in view of its large thickness, is treated as insulated.

In addition to affecting the flow field in general, turbulence plays two other roles in the fire phenomena. One is that turbulerce stretches the flames, thus pronoting the combustion process, and the other is that it provides a mixing mechanism for the gas species and soots, thus affecting the species and soot concentration distributions which in tan affect the radiation heat exchange from these radiation participating media. While these latter effects can be tather significant, especially in large fires such as the one considered here, they cannot be properly modeled without a turbulent combustion modiel, as is the case in the present field model. Conseguently, the turbulence model utilized here does not need to be complex, but only requines simple descriptions relative to production and dissipation of turbulence. This is in fact another justification for simple nurbulence models. While several field models such as, for instance, Harwell-Flow 3D (Simcox, Wilkes, and Jones, 1988) and KAMELEON (Holen, Brostrom, and Magnussen, 1990) have utilized the standard k- $\varepsilon$ model of turbulence, the Notre Dame field 
model has, on the other hand, always advocated that a much simpler mixing-length type of algebraic model, which accounts for stratification effects, is of sufficient accuracy for the fire phenomena as validated by experiments (Yang and Lloyd, 1985; Raycraft, Kelleher, Yang and Yang, 1990). Such an algebraic model is retained in the current sirulation stady, and is given as follows:

$$
\frac{\mu}{\mu_{R}}=1+\frac{\left(\frac{l}{H}\right)^{2} \sqrt{\frac{\sum\left(\frac{\partial u_{i}}{\partial x_{j}}\right)\left(1-\delta_{i}\right)}{2+\frac{R i}{\mathrm{Pr}_{i}}}}}{2}
$$

where

$$
\begin{aligned}
& \frac{l}{H}=K\left\{\frac{\sqrt{u_{i} u_{i}}}{\sqrt{\sum\left(\frac{\partial u_{i}}{\partial x_{i}}\right)^{2}}}+\frac{\sqrt{\sum\left(\frac{\partial u_{i}}{\partial x_{j}}\right)^{2}}}{\sqrt{\sum\left(\frac{\partial^{2} u_{i}}{\partial x_{i} \partial x_{j}}\right)^{2}}}\right\} \\
& R i=\frac{H}{u_{R}^{2}} \frac{\left(\frac{\partial T}{\partial n}\right) \bar{n} \cdot \bar{g}}{\sum_{i}\left[\left(\frac{\partial u_{i}}{\partial n}\right) \tilde{n} \cdot \tilde{g}\right]^{2}}
\end{aligned}
$$

where $\mathrm{Ri}$ is the gradient Richardson nunzber, 1 is a mixing length, and $\mathrm{II}$ is a unit vector in the direction opposite to gravity. The quantity $\mathrm{P}_{\mathrm{i}_{\mathrm{t}}}$ is a turbulent Prandl namber, which is also used to provide a model for the effective thermal conductivity $\mathbf{k}$ (molecular plus turbulent):

$$
\frac{k}{\mu_{\mathrm{R}}}=\frac{1}{\operatorname{Pr}}+\frac{1}{\mathrm{Pr}_{\mathrm{t}}}\left(\frac{\mu}{\mu_{R}}-1\right)
$$

where Pr is the molecular Prandtl number, also taken as a function of temperature $\bar{T}$. In this algebraic model, $\mathrm{Pr}_{\mathrm{t}}$ is assigned a numerical value of unity, for simplicity. Equation (6) clearly shows the stratification effect as represented through the ase of the Richardson number. It 
should be mentioned here that the $\mathrm{k}-\varepsilon$ model of turbulence does produce a more accurate estimate of the strain rates in the turbulent flow which could be useful in relating turbulence to the combustion process (Candel, Veynante, Lacas, Maistret, Darabiha, and Poinsot, 1990).

As indicated previously, the hot gas in the rooms is taken to be transparent and only surface to surface radiation exchange is included in the present field model. Conseguently, the radiation tlux only comes into play in the themnal boundary conditions at the walls, ceiling and floor. Furthermore, the flame surfaces are taken to be opaque and are treated the same as any other solid surface. Each surface, which, for convenience, coincides with the compatational call, is taken to be gray and diffuse, and the radiation flux there is calculated by the standard radiosity method (Siegal and Howell, 1992) in terms of the surface enissivity and view factors. The view factors are determined once for all, taking into account shading due to obstructions along the line of sight. Partial blockages are accommodated by modifying the surface areas involved. In general, nonzero view factors are calculated by using the view factor definition, treating each surface as a sufficiently small area. This determination is not accurate for two strfaces in close proximity, in which case the exact view factors based on finite areas are otilized (Howell, 1982). Even though this specific field model does not consider a participating medium, it can be included without any fundamental difficulty, despite the fact that this would create much additional complexity in the radiative transfer calculations (Yang, 1986).

From a fundamental point of view, a turbulent combustion model is needed in a complete fire field model, and together with approptiate turbulence and gas radiation models, will provide information about fuel and combustion product speciss concentration distributions, flame zones, and time-dependent heat release rates and their spatial variations in the fire. Since, as already mentioned previously, a combustion model is not utilized in the corrent field model, information must be provided on the flame size and shape, and the volumetric heat release rate and its distribution. This is another reason that the effect of participating medium is not considered here because it does not have any meaning without a combustion model. In the present numerical simulation, the following provisions are made. The flame or fire plume envelope is taken, for convenience, the same as that of the fuel par, and extends from the pan all the way to the ceiling. These are obviously not correct strictly. The fire envelope does not have a constant cross section vertically because of the entrainment, while the assumption of fire plume extending to the ceiling is probably reasonable in view of the fact that a very large fire is being considered over a period of about 18 minutes into the fire and the door openings do provide a strong ventilation. The overall heat release rate in the fire, without a turbulent combustion model, is very difficult to estimate, even from the fuel loss rate data from the test because of the lack of combustion efficiency information. On the other hand, the heat release rate data were not measured in the test. As a result, the application of the present field model dictates the use of a calibration 
scheme based on the test data to detemine the heat release rate, and as will be described later, a single calibration point is utilized in the present simulation study. As it turns out, as will also be shown, this scheme is responsible for at least a part of the disagreement between the simulation results and the test data In addition, in the present study, the heat release rate is also taken to be distributed uniformly over the volume enclosed within the flame envelope. This assumption is also incorrect for obvious reasons. Normally for a large fire, the maximum heat release tate occurs at about one third of the height from the fuel pan because of fuel gasification effects. On the other hand, since the total heat release is preserved in the simulation, temperatures in the hot ceiling layer stould not be overly affected by this assumption of uniform spatial distribution of the heat release rates.

The numerical algorithm in the Notre Dame field model is based on a finite-volume finite-difference staggered-cell formulation (Raycraft, Kelleher, Yang and Yang, 1990; McCarthy, 1991), which is a direct extension of the 2-D formulation in our earlier room fire studies (Yang, Lloyd, Kanury, and Satoh, 1984; Yang and Lloyd, 1985) with several improvements. One is that in the local pressore correction algorithn to satisfy fiow continuity, the temperature and density fields are recalculated in each iseration. A second inprovement is that the convective terms in the governing equations (2) and (3) are discretized on the basis of the QUICK scheme (Leonard, 1983) to minimize nomerical diffusion effects. Also, a global pressure correction routine is included to accommodate possible global pressure build-up due to insafficient ventilation (Nicoleste, Yang, and Lloyd, 1985). In addition, as mentioned previously, the numerical algorithn incoxporates the heat loss calculations at any solid boundary. The radiation fluxes artiving at the boundary cells are updated once every several time steps to conserve calculations and the view factors are calculated only once and are stored in the form of a table lookop for subsequent radiation flux calculations.

\section{NUMERICAL VALIDATION STUDIES}

Before the field model described above was applied to simulate the E41.5 Test in the present study, two sets of numerical validations were carried out to assure that the computer code based on the field model is self-consistent and does lead to plausible results. Both numerical validation exercises deal with the E41.5 Test fire-room geometry, but with different arbitrarily chosen heat release rates. The geometry of the fire room was simplified somewhat to eliminate the curvature in the rear wall, as shown by the computational domain given in Figure 3. A uniform cell gtid was adopted, and each cell had a side of $273 \mathrm{~mm}$. Altogether there were 12,768 calculation cells which are designated in indices $I, J, K$, as also shown in Figure 3 . This cell structure is the same as that later used in the E41.5 Test simulations. The coefficient of heat transfer on the exterior surfaces of the walls and ceiling was taken to be $85 w / \mathrm{m}^{2} \mathrm{~K}$, 
corresponding to that of a mixed convection condition. This value was also the same as that utilized in the full simulation of the test data. All computations in the present study were carried out on an IBM mainframe computer and an IBM RISC 6000 computer.

In the first numerical validation, a ramped heat release rate was utilized. A linear heat release rate was first prescribed from ignition to a level of $250 \mathrm{KW}$ at 60 seconds into the fire, and was then maintained at that level until a little over 260 seconds, which represented the end of this validation study. The purpose of this exercise was to determine the suitability of chosen time steps for numerical stability considerations, to check both heat and mass balances at the doorways, and also to see if steady-state conditions were achievable. For these reasons the calculation of radiation fluxes was not included in the calculations in this first exercise. The calculations showed that numerical stability was achieved with an initial time step of $0.005 \mathrm{sec}$ until $\bar{t}=115 \mathrm{sec}$ and then a second time step of $0.002 \mathrm{sec}$ until the end of the calculations. The time step change was done antomatically in the code at time instants where the numerical residual mass exceeded prescribed tolerances. The numerical results are shown in Figures 4 . The solid curve in Figure 4(b) is evidently the ramped heat release rate described previously, and represents the rate of energy gained by the fire room. During this hypothetical fire, the doorways remained in the opened position, and hot gases would leave the upper part of the doorways, while cool air would in turn come into the fire room in the lower part of the same doorways. This scenario is typical of compartment fires with only one doorway (or one window) in ventilated fires. In general, it is expected that the total mass-flow rate of the incoming cool air would essentially follow that of the outgoing hot gases. This is shown in Figure 4(a), where the solid line represents the mass flow rate of cool air, while the dashed line is that of the outgoing hot gasses. The dotted curve close to the zero mass-flow rate level represents the residual masses in the calculated results as time proceeds, giving an indication of the degree of inaccuracies involved. The heavily dotted region close to $\bar{i}=115 \mathrm{sec}$ was dne to the transients as the time step was changed. The residual mass level could very well be redeced in the early times if the initial time step was chosen to be smaller, and it is also seen that the time step utilized beyond $\bar{t}$ $=115 \mathrm{sec}$ was completely satisfactory. Also, it is interesting to note that even when the residual mass error is taken into account, the in-flow mass flow rate was somewhat higher than that of the outflow at early tines into the fire. The primary reason for this is that the density of the hot gases is lower and there is a slight pressurization in the fire room. Also, there is a strong indication that a steady-state condition was achieved beyond $i=100 \mathrm{sec}$. This can also be discemed in Figure 4(b) for the heat rates, where the dashed curve gives the total instantaneous heat rate that leaves the fire room, i.e., the sum total of heat exiting through the doorway and wall losses. It is clearly seen that this heat balance is essentially maintained throughout the hypothetical fire. It is also worthy to note the large-scale oscillations in the responses to the fire 
load. These ascillations have also been observed in both the observed and numerically simulated data in another full-scale fire test carried out at the Naval Research Laboratory (Raycraft, Kelleher, Yang, and Yang, 1990), and are believed to be due to flow separations and other large flow instabilities occurring in the fire roors.

The second numerical validation study included every feature in the final E41.5 Test simulation except that the heat release rate is based on $25 \%$ of that corresponding to the experimental fuel-loss jata and the heating value of the fuel. Physically, this represents a combustion efficiency of $25 \%$, which is obviously too low. The purpose of this exercise was to carry out a simulation run which includes every part of the computer code based on the field model described previously including radiation, but at a lower level of heat release rate (a maximum of about $2 \mathrm{MW}$ ) to insure that numerical instability was not a probjem, so that the entire simulation up to $18 \mathrm{~min}$ from the commencement of the fire, similar to the E41.5 Test, could be completed expeditiously. The results again in terms of the mass in-flow and out-flow rates and the corresponding heat rate are shown in Figures 5. It is noted here that all curves shown are time averaged to facilitate discussion of general trends. The mass out-flow rates, as shown by the dashed curve in Figure 5(a), also include the residnat mass, and the very slight differences in the two cerves represent numerical emors. The numerical errors in the heat rates in Figure S(b) are also very slight, as evidenced by the heat rate doe to the residual mass shown as the dotted curve. These errors are not included in any of the two curves above. It is seen here that at the-earlier times, the heat rate that leaves the fire room, which includes the wall losses, lags behind that provided by the fire. This obviously is responsible for the increase of temperatures inside the fire room. At a later time, the trend is reversed and the overall temperature rise becomes more subdued.

From the above two numerical experiments, it can be concluded that the computer code based on the field model is capable of producing numerically accurate results, and any shortcomings in the result must be attributed to deficiencies in the formulation of the field model in terms of the many submodels used.

\section{NUMERICAL SIMULATION OF THE E41.5 TEST}

As mentioned previously, in the E41.5 Test the fuel burn rate was measured by a weighing scale located under the fuel pan. This data can be converted into the theoretical heat release rates by introducing the heating value of the fuel oil which is $42,500 \mathrm{~kJ} / \mathrm{kg}$, and these theoretical values are shown in Figure 6. The actual heat release rates are necessarily much lower due to incomplete combustion, and anfortunately the combustion efficiencies are not known, but must be somehow estimated. In the present study, the combustion efficiency was estimated by a single calibration based on temperatures and velocities in the hot-gas layer at the 
doorways; the resulting efficiency was then taken as constant and utilized throughout the entire fire duration of $18 \mathrm{~min}$. At the outset, it was realized that such a calibration scheme was full of hazards, largely due to the choice of the calibration data point. Even though it was basically possible to utilize several data points for calibration purposes, the overwhelming extent of the needed computing resources would have been impractical. Several sets of computations at combustion efficiencies of $50 \%, 55 \%, 60 \%$ and $100 \%$ were carried out up to $4 \mathrm{~min}$, and the restlting ceiling hot-gas temperatures at a thermocouple location designated as 5216 at the $4 \mathrm{~min}$ instant and the hot-gas exit velocities at the doorway close to the ceiling at the 2 min instant were compared with the comesponding test data in the B41.5 Test. The therroocouple 5216 is located close to the ceiling in the small entry room right next to the main fire room. These comparisons are stown in Table 1 . It is clearly seen that the best comparisons of the temperature and velocity occur at a combustion efficiency of $60 \%$, which was somewhat lower than expected. This value of efficiency was then used in the simulations throughout the fire period of 18 min. It should be noted that this combustion efficiency, even if it is correct, is not the true value, but a value representing the combined effects of incomplete combustion, gas and soot radiation effects, and other effects which are not accounted for in the field sodel.

In the full numerical simulations, the initial time step was again taken to be $0.005 \mathrm{sec}$, which was changed to $0.002 \mathrm{sec}$ at about $1.2 \mathrm{~min}$ into the fire. It was reduced again to 0.0005 $\sec$ at about $70 \mathrm{~min}$ time instant, which was then maintained until the end of computationis at 28 min. This time step schedule followed closely the heat release rates as showa in Figure 6, as expected. In the E41.5 Test, several temperatures at specific locations in the fine room were measured, along with the exit velocities at the doorway. Comparisons of the measured ternperatures and the nemerically sinulated temperatures at three thermocouple locations 5216 . 5236 and 5230, and that of the exit velocities betow the location 5236 are shown respectively in Figures 7 and 8. The location 5216 is at the $7.4 \mathrm{~m}$ level above grade and close to the ceiling in the smaller entry room, but right next to the main fire room. This is a critical location, since all the hot gases from the fire would exit the fire room by this location. The location $\$ 236$ is at the same level as that of 5216, but right above the middle of the two doorways, and this is the same location where single calibration on the temperatures were made. Location 5230 is vertically below the location 5236, but at $0.35 \mathrm{~m}$ above the floor in the cool-air stream coming in from outside the fire room. The velocity comparisons in Figure 8 are made in the hot-gas layer at a location below 5236 in the doorway, and this is the sane velocity that was used in the calibration for the combustion efficiency.

With the single calibration on the combustion efficiency at the 3 min and $4 \mathrm{~min}$ time instants (see Table 1) in the temperatores at the 5236 location, it is seen from Figure 7 that the numerical simulations at all three therruocouple locations based on time-averaged ternperature, 
the solid lines, compare reasonably well with the test data up to a time instant of $8 \mathrm{~min}$. Beyond that time, the computed hot gas layer temperatures are considerably higher than that from the measurements, even though the general trends in this time period are still similar. This comparison is obviously affected by the combustion efficiency calibration utilized in this study. However, the very fact that the test data show only moderate variations in the temperatures in this period may very well be caused by gas and soot radiation effects which are not accounted for in the field model. As it is generally known, such effects will tend to smear out the temperature field. Also, it is reslized that in the early tirne period into the fire, the gas and soot radiation effects are not as critical because of the lower temperatures involved. As for the temperature at thermocouple location 5230, the nield model underpredicts the test results again in the latter part of the fire phenomenon. This is surely the effect of gas and soot radiation. Incidentally, in such a large fire over a prolonged period of time, the losses through the wall and ceiling are quite significant, up to $30 \%$ according to the simulation results. Consequently, the choice of a single exterior wall coefficient of heat transfer in the present study may also have influenced the comparisons shown in Figure 7.

Figure 8 shows the comparison of exit velocities in the hot ceiling layer at the doorway. The solid curve represents the time-averaged velocities of the numerical simulations, while the open circles give the corresponding test data. At the outset, it should be realized that measuring velocities in an intense fire environment is difficult, and that in the E41.5 Test, there was a degree of uncertainty as to how close the probe was placed close to the wall. Nevertheless, while the simulation provides the correct trend, it overpredicted the exit velocities by a significant margin, and this overprediction signals deficiencies in the field model. However, since in buoyancy-driven flows the velocities are very sensitive to the varying temperature field, it is not surprising to see this overprediction in view of the fact that the temperatures are also overpredicted (Figure 7).

From the above comparisons it can be concladed that while the field model utilized in the present study does provide reasonably good trends in the temperature and velocity fields, its inability in modeling the combustion efficiency or the heat retease rates in full-scale fires represents a significant shortcoming in its application to deal with such large fires. In this tegard, it is pertinent to mention that a subsequent numerical simalation study dealing with a foll-scale forced-ventitation fire in the same HOR facility fire room (E41.7 Test) has been completed recently (Yang, Huang, and Nicolette, 1994), in which the heat release rates were determined by the application of a zone model. Consequently, the resslts were completely independent of the test data. Very good agrement between the simulation data and the test data was found. Consequently, it can be said that at this stage of the development of the field model, a 
combination of the field model and a zone model, which is used to provide a good estimate of the heat release rates, is a viable means to study real-world full-scale fires at the present time.

\section{CONCLUDING REMARKS}

In the present numerical study a three-dimensional field model is described to simulate a full-scale fire test carried out in a decommissioned nuclear reactor containment building. The fire room has a very complex geometry and the fire was fully naturally ventilated with open doorways. The field model is not complete in that it lacks a tortulent combustion submodel and also does not account for gas and soot radiation. Because of this deficiency, the combustion efficiency was estimated by a single calibration based on the experimental data on the temperature and velocity at specific locations and time instants. The field model with the fireroom geometry was numerically tested in terms of prescribed heat release rates with heat and mass flow balances before it was used to simulate the full-scale fire test. Results of the comparisons of temperatures at three specific thermocouple locations and velocities at the exiting hot ceiling layer at the doorway showed that the simulation results were good up to about 8 min into the fire, but overestimated both temperatures and velocities thereafter until the end of the fire at 18 min. Part of the discrepancy between the results in the latter time period is attributed to the fact that the field model did not account for gas and soot radiation.

The lack of a turbulent combustion submodel was considered a significant shortconing of the field model utilized in the present study, and it is suggested that this shortcoming could be for the short term remedied by incorporating a zone model to provide the needed heat release rate data to the field madel.

\section{ACKNOWLEDGMENT}

The support of NRC Grant FN L130 is gratefully acknowledged. The authors are also gtateful for help of technical personntel of the University of Notre Dame Computer Center.

\section{NOMENCLATURE}

cp Dimensionless specific heat

G Dimensionless generalized gravitation vector

g Dimensionless gravity

G Gravitational vector 
Height of fire room, $m$

I,J,K Coodinate indices

K Constant in turbulence mode, $\mathrm{K}=0.4$

k Turbulent kinetic energy, $\mathrm{m}^{2} / \mathrm{s}^{2}$

k Dimensionless effective thermal conductivity

I Mixing length in turbulence madel, in

n. Unit vector in direction opposite of gravity

Pr Molecular Prandtl number

$\mathrm{Pr}_{\mathrm{t}} \quad$ Turbulent Prandtl number

pi . Dimensionless pressure difference

Ri Gradient Richardson number

T Dimensionless temperature

t

Dimensionless tima

$\mathrm{u}_{\mathrm{i}} \quad$ Dimensionless velocity components

$\mathbf{x}_{\mathrm{i}} \quad$ Dimensionless coordinates

E Dissipation rate of turbulent kinetic energy, $\mathrm{m}^{2} / \mathrm{s}^{3}$

1 Dimensionless effective viscosity

p Dimensionless density 
$\sigma_{\text {ij }}$ Dimensionless shear stress tensor

SUPERSCRIPT

Dimensional quantities

\section{SUBSCRIPYS}

e

Equilibrium conditions

it

Derivatives with respect to $x_{i}$

m

- Mean conditions

$\mathbf{R}$

Refenence conditions

\section{REFERENCES}

Candel, S., Veynante, D., Lacas, F., Maistret, E., Darabiha, N., and Poinsot, T. (1990): Flamelet Description of Turbulent Combustion, Proceedings of the 9th International Heat Transfer Conference, Vol 1, Hernisphere Publishing Co., New York, pp. 113-128.

Chow, W.K. and Fong, N.K. (1993): Application of Field Modeling Technique to Simulate Interaction of Sprinkler and Fire-Induced Smoke Layer, Combustion Science and Technology Vol. 89, pp. 101-151.

Delaney, M.A. (1992): Numerical Field Model Simulation of Full Scale Fire Tests in a Closed and an Open Compartment, MS. Thesis, Naval Postgraduate School, Monterey, CA.

Holen, J., Brostrom, M. and Maguussen, B.P. (1990): Finite Difference Calculation of Pool Fires, Third Symposinm _Internationall on Combustion, The Combustion Institute, pp. 16771683.

Houck, R.R (1988): Numerical Field Model Simulation of Full-Scale Fire Tests in a Closed Spherical/Cylindrical Vessel with Internal Ventilation, M.S. Thesis, Naval Postgraduate School, Montery, CA.

Howell, J.R. (1982): A_Catalog of Radiation_Configaration_Factors_McGraw-Hill Book Co., New York

Jones, I.P. (1990): Fire Modelling, Eurothrm Seminar No. 13, Abstract of Papers, Harwell Laboratory, England. 
Kou, H.S., Yang, K.T, and Lloyd, J.R. (1986): Turbulent Buoyant Flow and Pressure Variations around an Aircraft Fuselage in a Cross Wind Near the Ground, Eire Safey Science in Proc. Eirst International Symposium pp. 173-184.

Leonard, S.P. (1983): A Convectively Stable, Third-Order Accurate Finite Difference Method for Steady Two-Dimensional Flow and Heat Transfer, Numerical Properties_and Methodologies in Heat Transfect ed. T.M. Shih, Hemisphere Pablishing Corp, Washington, D.C. pp. 211-226.

MoCarthy, T.G. (1991): Numerical Field Model Simnlation of Full Scale Firs Tests in a Closed Spherical/Cylindrical Vessel Using Advanced Compater Graphics Technigpe, M.S. Thesis, Naval Postgraduate School, Monterey, CA.

Malter, K, and Max, U. (1991): Inpot Data Set for E41.7 Blind Postcalculations of an Oil Fire in a Closed System, Kernforschungszentrum Karlswhe GmbH.

Muelier, K, and Volk, R. (1990): Characteristics of an Oil Fire in a Closed Subsystem with the Ventitation System Connected and Variable Degrees of Door Opening, Design Basis Report. Kernforschungszentrum Karlsnuhe GmbFl.

Nicolette, V.F., Yang, K.T., and Lloyd, J.R. (1985): Transient Cooling by Natural Convection in a Two-Dimensional Square Enclosure, International Jonmal of Heat and Mass Transfer ${ }_{2}$ Vol. 28 , No. 9. pp. 1721-1732.

Nies, G.F. (1986): Numetical Fijeld Model Simulation of Full Scale Tests in a Closed Vessel, M.S. and M.E. Thesis, Naval Postgraduate School, Monterey, CA.

Raycraft, J., Kelleher, M.D., Yang, H.Q., and Yang, K.T. (1990): Fire Spread in a ThreeDimensional Pressure Vessel with Radiation Exchange and Wall Heat Losses, Mathematicaland Computer Modeiling. Vol. 14. pp. 795-800.

Satoh, K., Lloyd, J.R. Yang, K.T., and Kanury, A.M. (1983): A Numerical Finite-Difference Study of the Oscillating Behavior of Vertically Vented Compartments, in Nomerical Properties and Methodologies in Heat Transfer.Ed. T.M. Shih, Hemisphere Publishing Corp., Washington, D.C., pp. 517-528.

Siegel, R, and Howell, J.R. (1992): Thermal Badiation_Heat.Transfer,3rd Ed., Heroisphere Publishing Co., Washington, D.C.

Simcox, S., Wilkes, N.S., and Jones, L.P. (1988): Compater Simulation of the Flows of Hot Gases from the Fire at King's Cross Underground Station, AERE-G4782.

Yang, K.T. (1986): Numerical Modeling of Natural Convection-Radiation Interactions in Enclosures, Keynote Address, in Proceedings of the 8th Intemational Heat Transfer Conference. Vol. 1, Hemisphere Publishing Co., Washington, D.C., Pp. 131-140.

Yang, K.T. (1987): Natural Convection in Enclosures, Chapter 13 in Harribook of Single-Phase Convective Heat Transfer, Wiley-Interscience Publishers, New York, pp. 13-1 io 13-51.

Yang, K.T., Hpang, H.J., and Nicolette, V.F. (1994): Field Model Simulation of Full-Scale Forced-Ventilation Room-Fine Test in the HDR Facility in Gentiny, paper submitted for presentation at the 1994 AIANASME Thermophysics and Heat Transfer Conference, Colorado Springs, CO. 
Yang, K.T, and Lloyd, J.R. (1985): Turbulent Buoyant Flow in a Vened Simple and Complex Enclosure, in Natural Convection-Fundamentals and Applications.Eds. S. Kakac, W. Aung and R. Viskanta, Hemisphere Publishing Co., Washington, D.C., pp. 303-329.

Yang, K.T., Lloyd, J.R., Kanury, A.M., and Satok, K. (1984): Modeling of Turbulent Baoyant Flows in Aircraft Cabins, Combastion Science and Technology. Vol. 39, pp. 107-118. 
Table 1. Single Calibration for Estimating Combustion Efficiency

\begin{tabular}{|c|c|c|c|}
\hline \multirow{3}{*}{$\begin{array}{l}\text { Combustion Efficiency } \\
\qquad(\%)\end{array}$} & \multirow{2}{*}{\multicolumn{2}{|c|}{$\begin{array}{l}\text { Hot Gas Temperature at Exit } \\
\text { (T) }\end{array}$}} & \multirow{3}{*}{$\begin{array}{l}\text { Hot Gas Exit Velocity } \\
\text { at } 2 \mathrm{~min} \\
(\mathrm{~m} / \mathrm{s})\end{array}$} \\
\hline & & & \\
\hline & $3 \mathrm{~min}$ & $4 \min$ & \\
\hline 50 & 2.4 & 2.9 & 3.25 \\
\hline 55 & 3.7 & 4.2 & 3.74 \\
\hline 60 & 3.9 & 4.4 & 4.02 \\
\hline 100 & $\cdots$ & -- & 12.04 \\
\hline E41.5 Test & 3.8 & 4.2 & 3.96 \\
\hline
\end{tabular}




\section{LIST OF FIGURES FOR APPENDIX C}

Figure 1

Figure 2

Figure 3

Figure 4

Figure 6

Figure 7

Figure 8
HDR Reactor Containment Building

Geometry of Fire Room

Computational Domain

Ramped Heat Input, $250 \mathrm{kw}$

(a) Mass Balance (b) Heat Balance
Figure 5

$-$

Heat Release Rate at 25\% Combustion Engineering

(a) Mass Balance

(b) Heat Balance

E41.5 Test Heat Release Rates (100\% Corabustion Efficiericy)

Comparison of Temperatures (Simukation Temperatares Time Averaged)

Comparison of Hot Gas Exit Velocity (Simalation Velocities Time Averaged) 


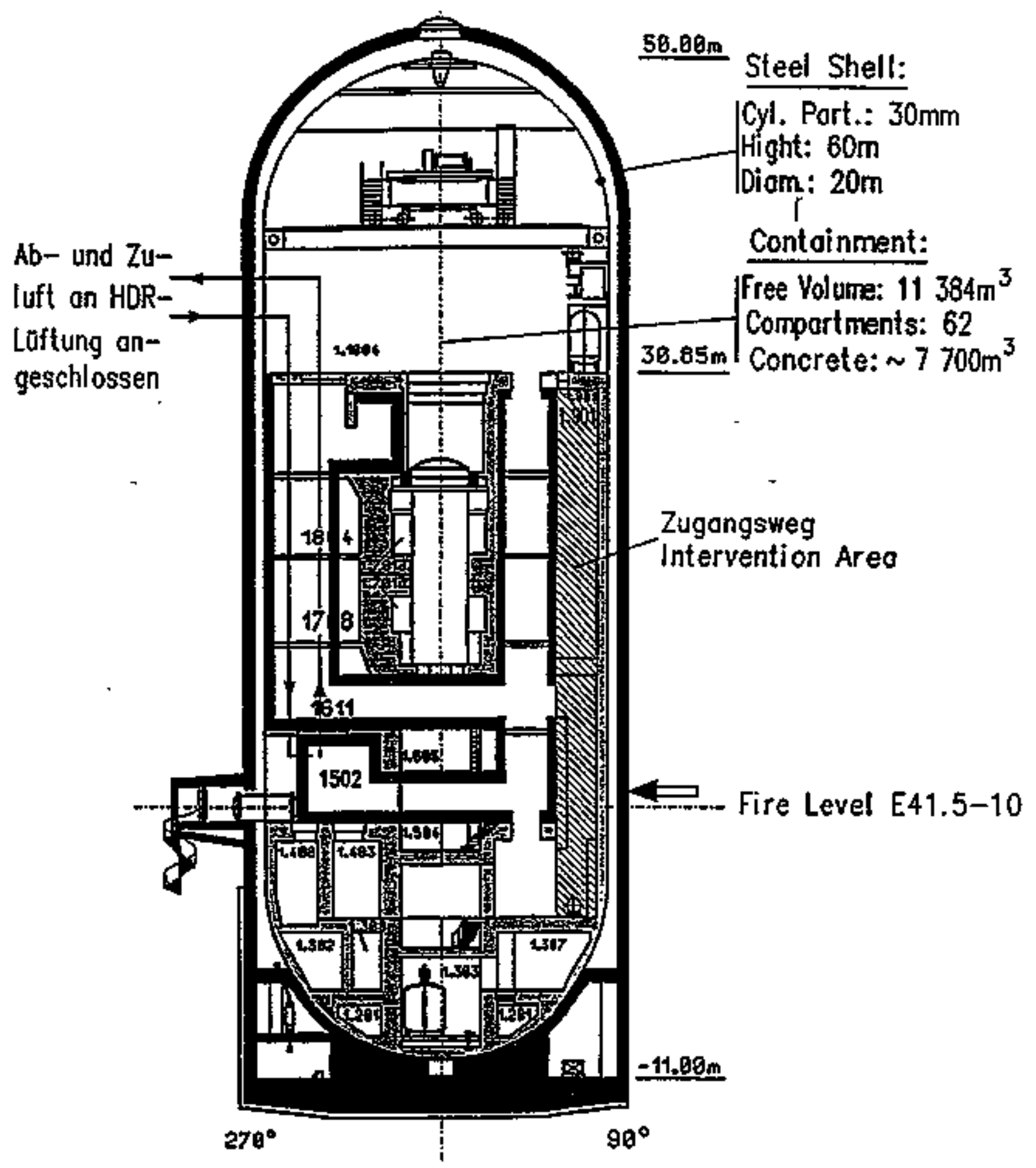

Figure c-1

HDR Reactor Containment Building 


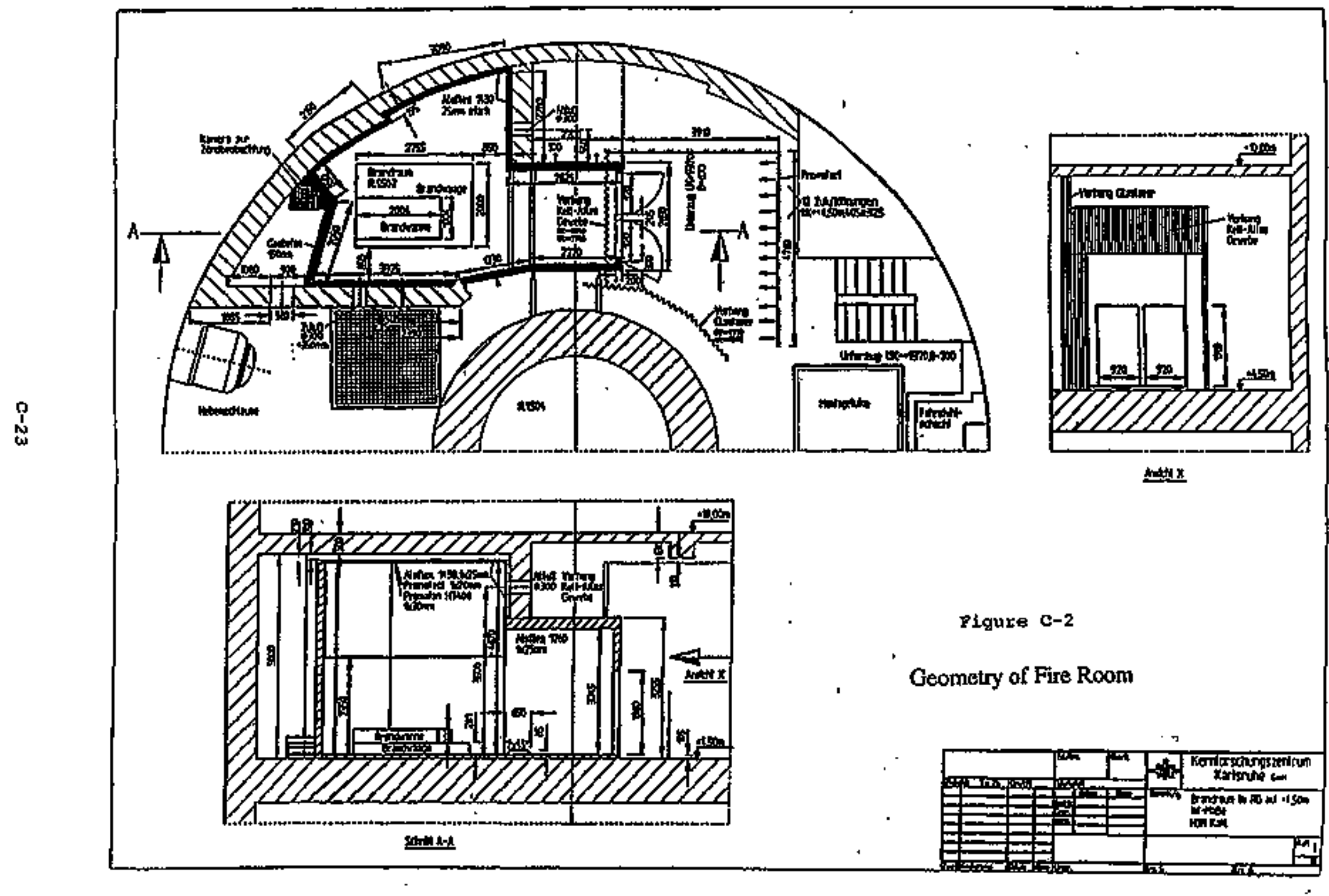




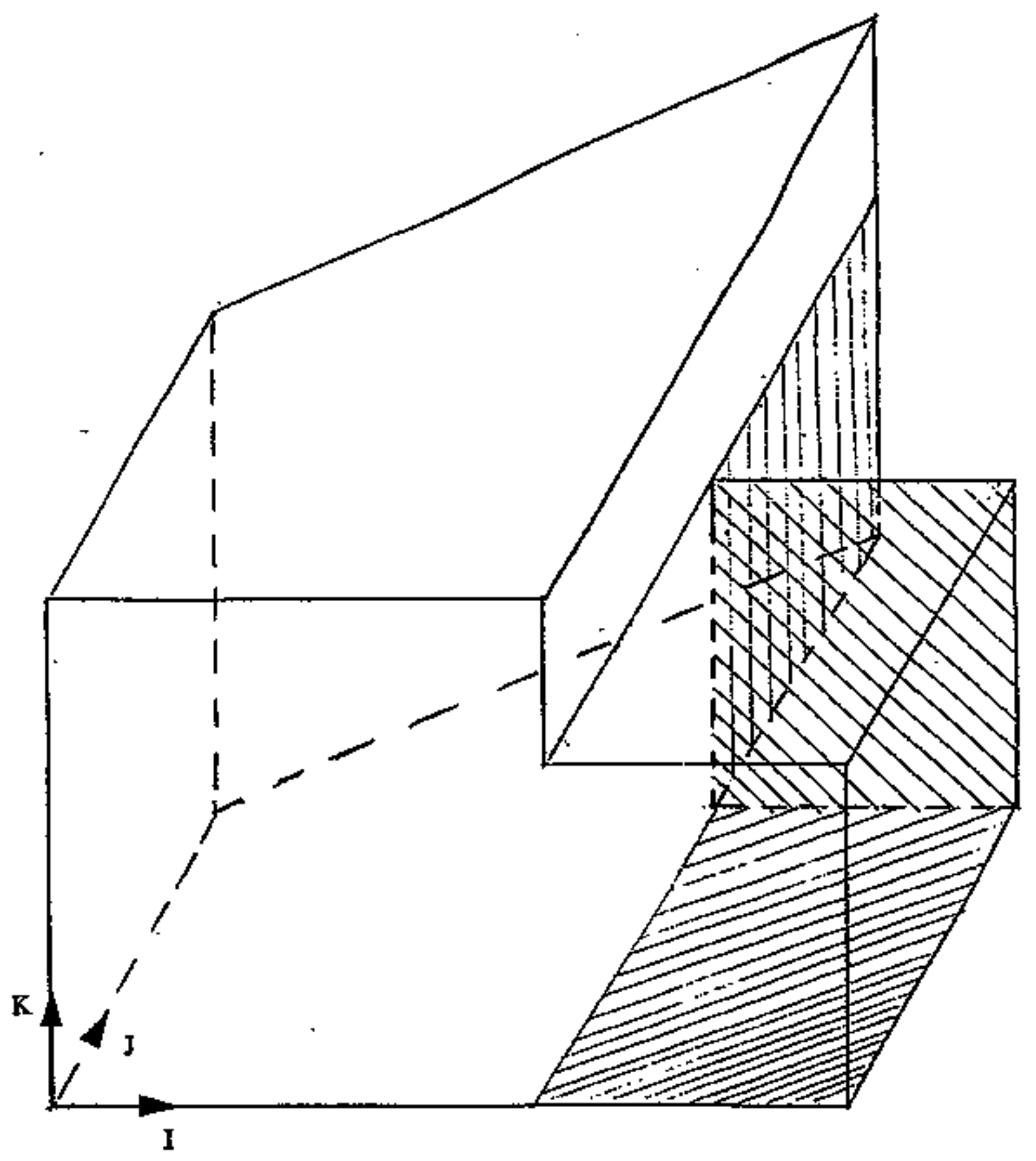

Figure c-3

Computational Domain 


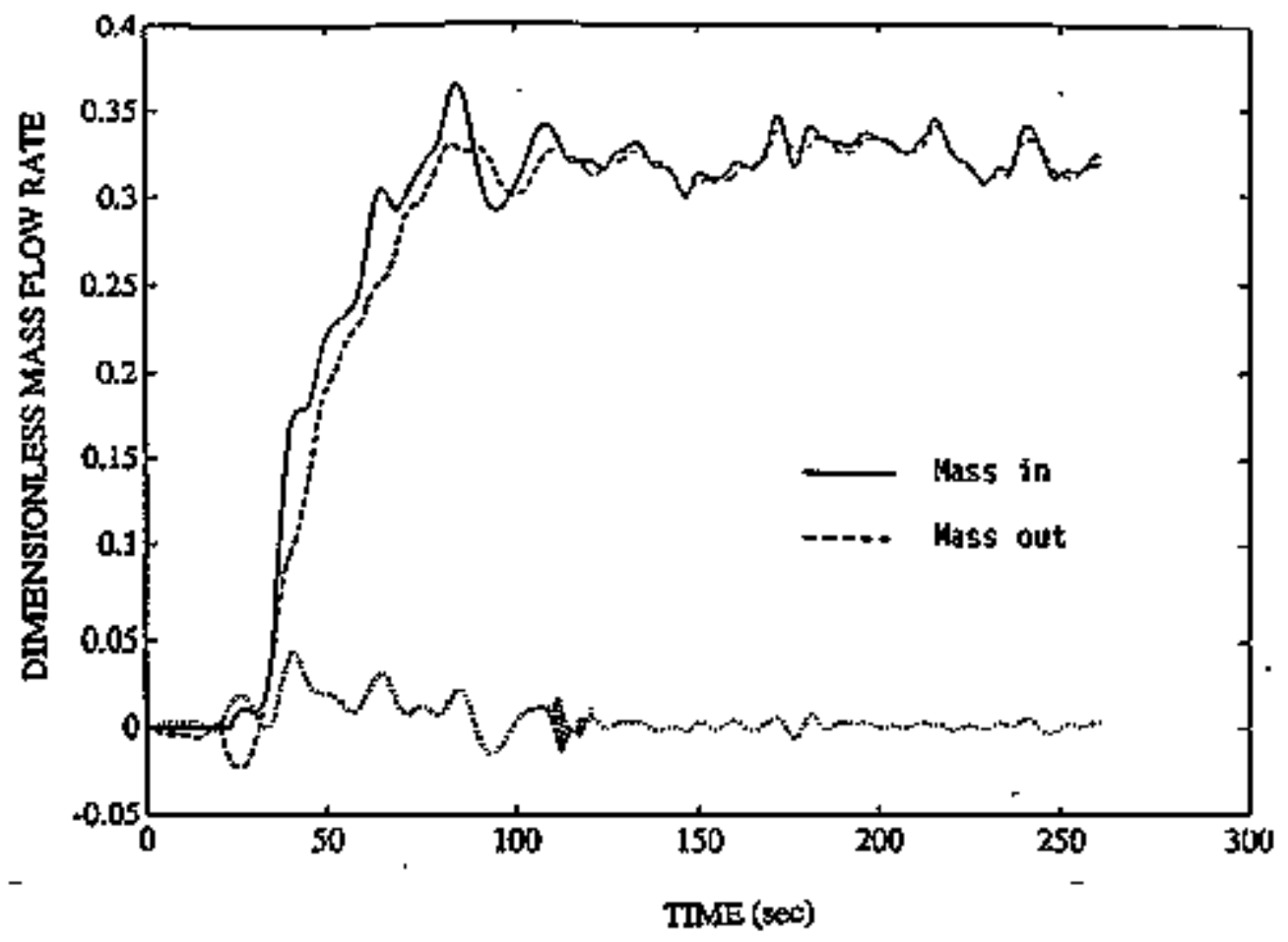

(a)

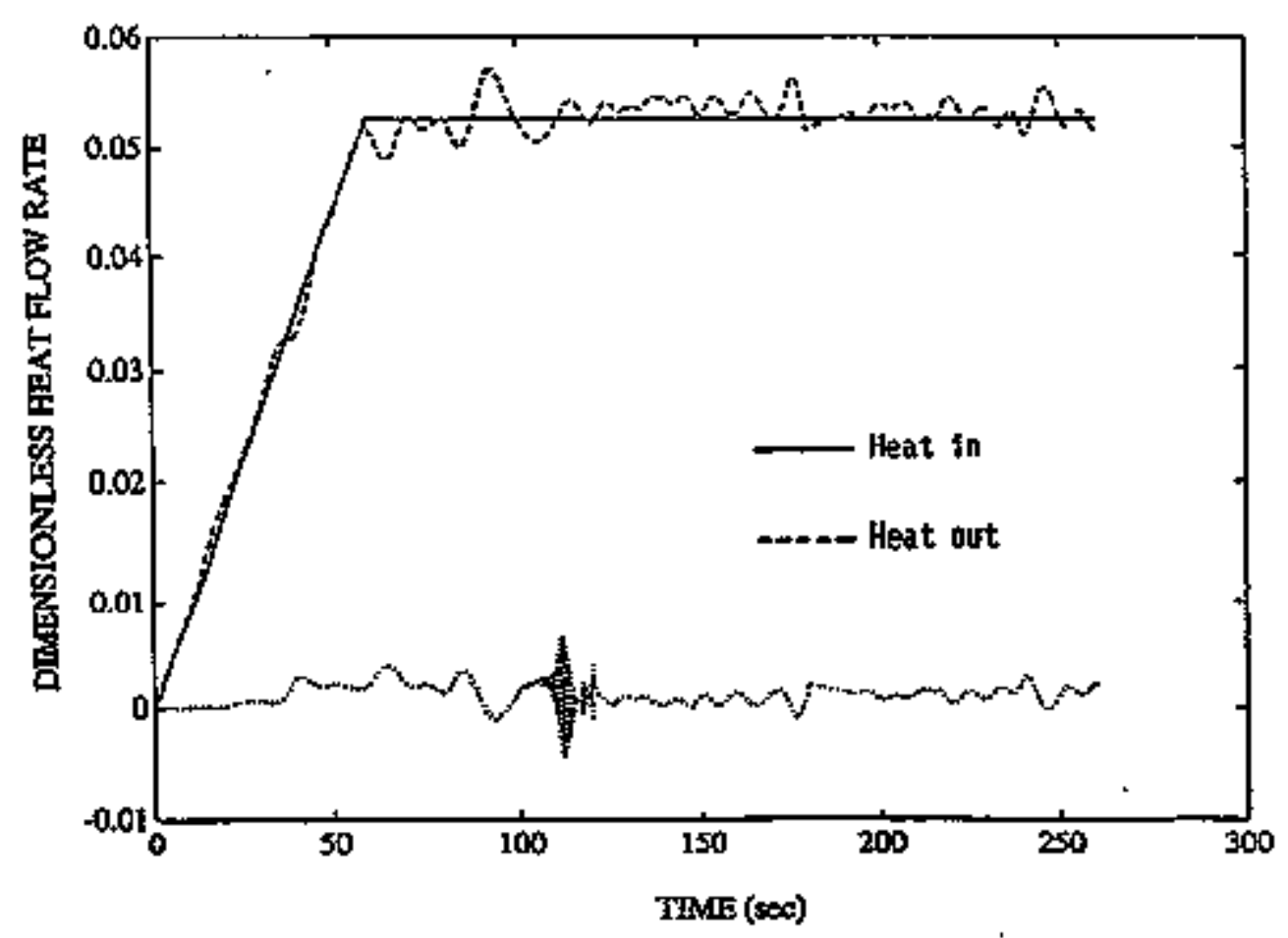

(b)

Fignure C-4

Ramped Heat Input, $250 \mathrm{kw}$ (a) Mass Balance (b) Heat Batance 


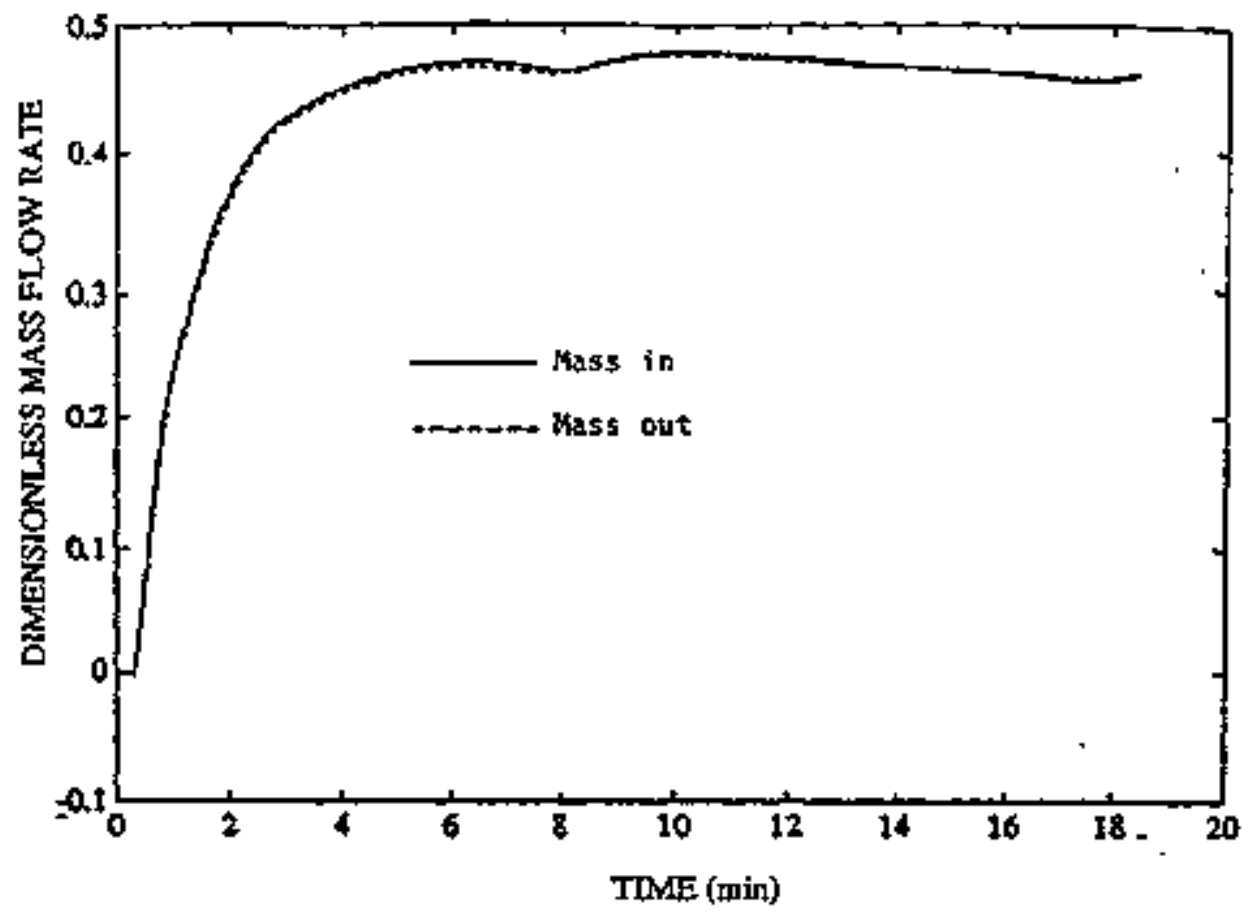

(a) Mass Baiance

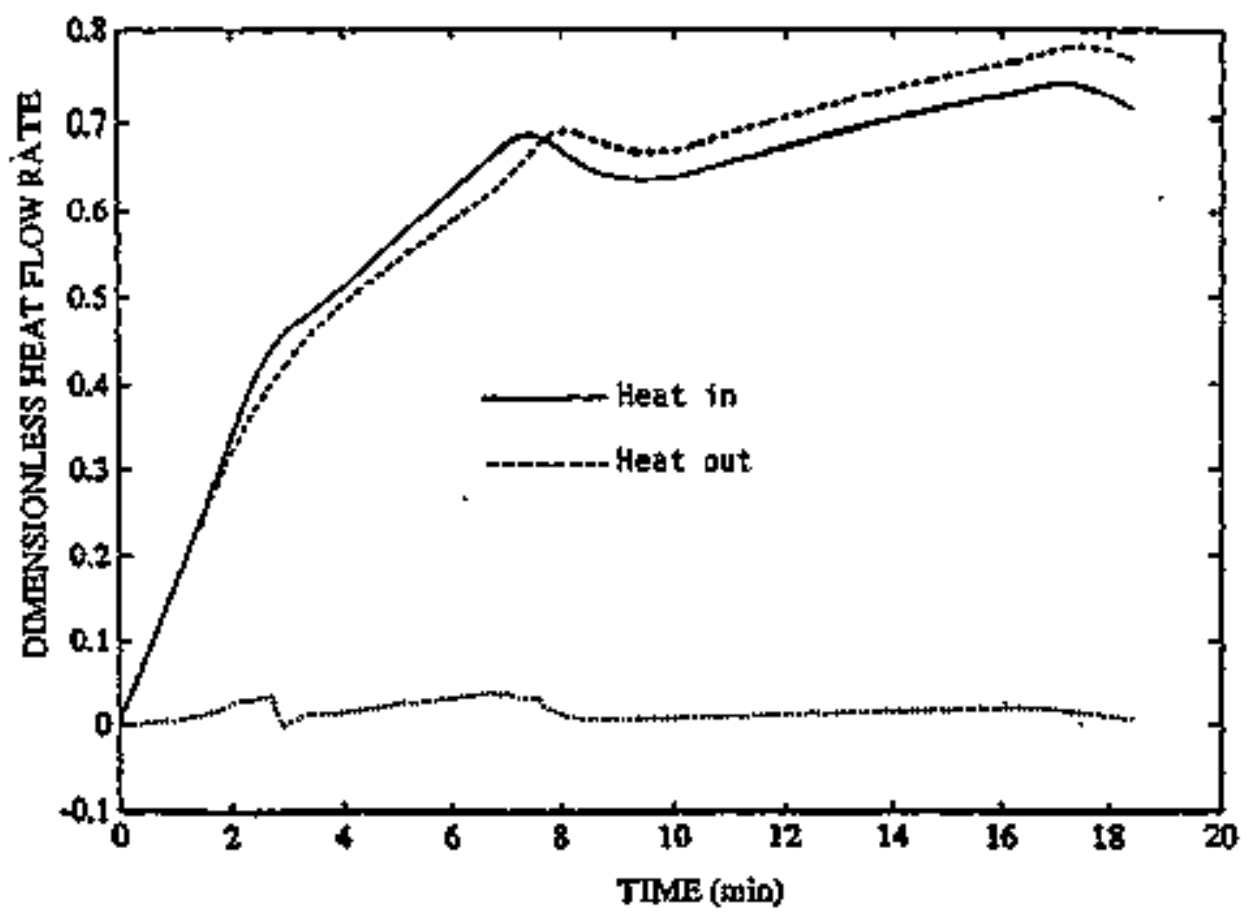

(b) Heat Balance

Figure c-5

Heat Release Rate at $25 \%$ Combustion Engineering 


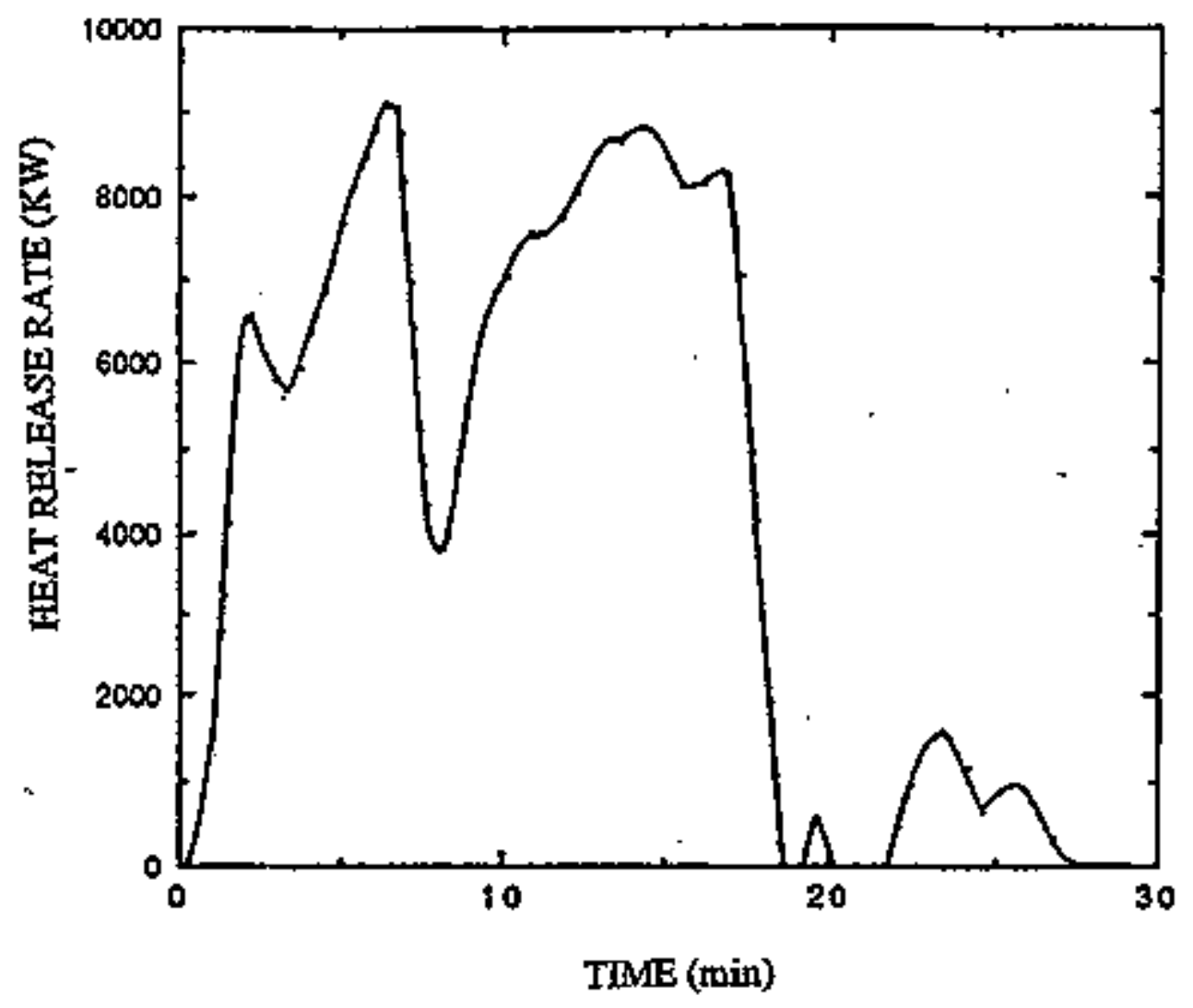

Pigure C-6

E41.5 Test Heat Release Rates (100\% Combustion Efficiericy) 


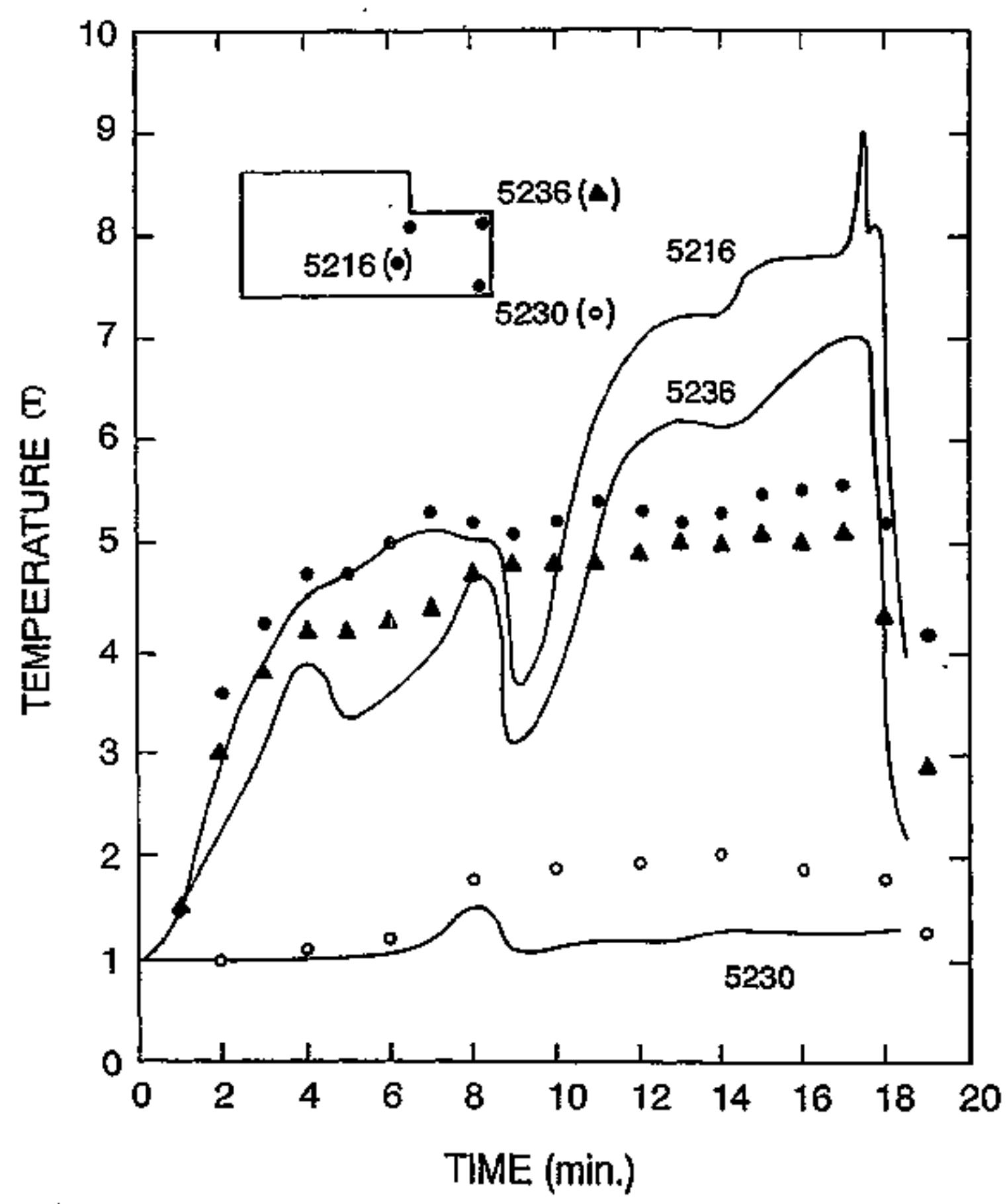

Figure C-7

Comparison of Temperatures (Simulation Temperatures Time Averaged) 


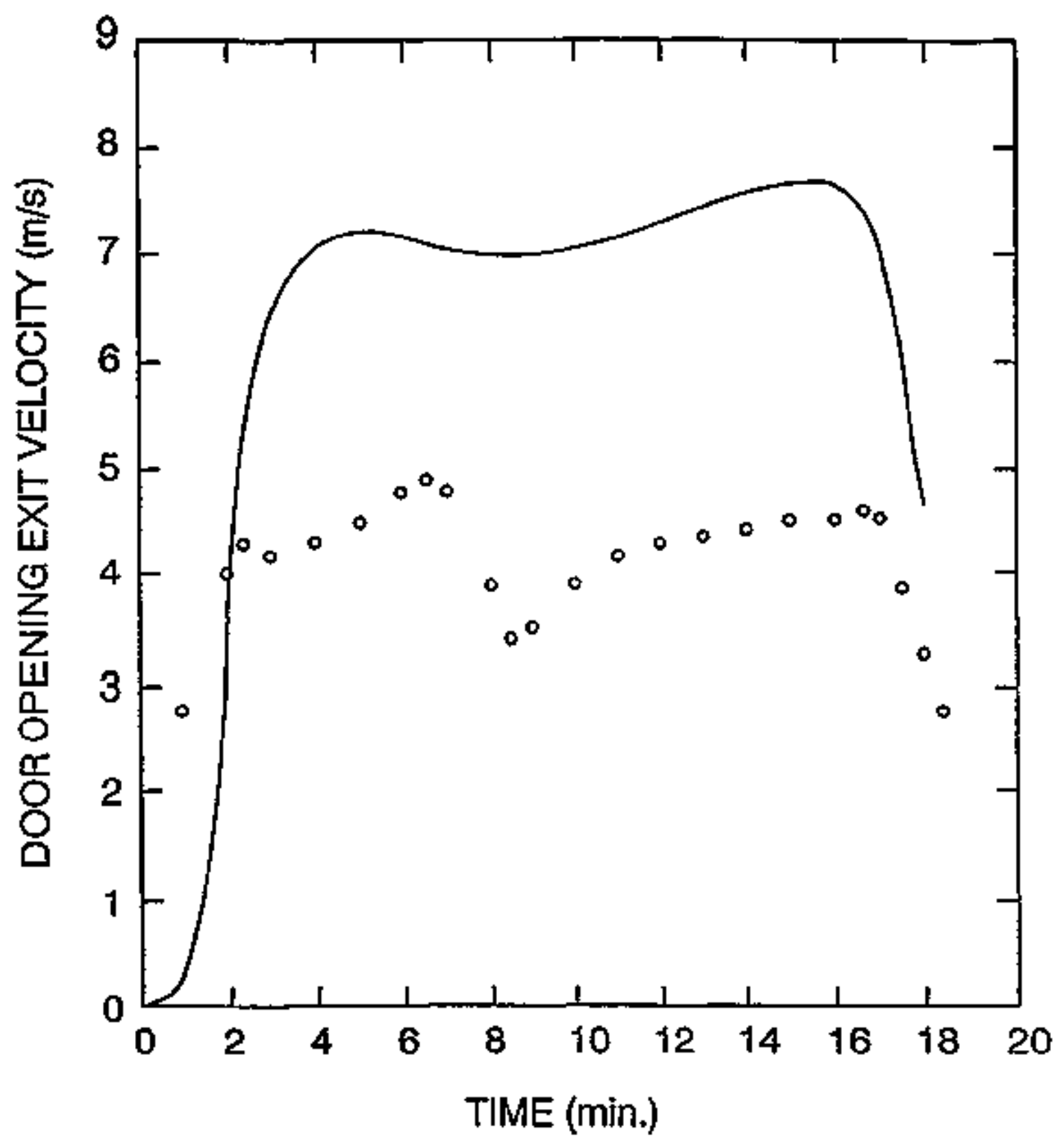

Figure c-8

Comparison of Hot Gas Exit Velocity (Simulation Velocities Time

Averaged) 


\section{DIETRIEDTION:}

U. S. Huclear Regulatory Comission Attn: Willian Glenves (10)

office of Nuclear Regulatory Research

Weshington, DC 20555

t. S. Department of Energy

Attn: Andrew $J$. Pryor

Albtiquercue Operations office

PO Box 5400

Albuquexcye, int 87115

Professor K.T. Yang

Dept. of rechanical Engtneering

Univetsity of Notxe Dame

Notre Dame, IN 46556

Electric Power Research Institute

Attin: Bob Kassawara

Wuclear Power Division

3412 H1llview Ave,

Palo Alto, CA 94303

National Institute of Standards and Technolgy

Attn: Walter Jones

Building 224, Room A249

Geithersburg, 洁 20899

T. Eklund

Fire Safety Research Branch

$\mathrm{ACD}-250$, Bìd $\mathrm{eg} .204$

Atlantic city Int'l Almport, NJ

08405

Pravin Gandhi

Underwriter's Iaboratory

333 Pfingaten Road

Northbrook, II 60062

George Apostolakis

Dept. of Mechanical Engtneering

Jniv, of Calif, at Los Angeles

Los Angeles, cA 90024

Factory Mutual Research Corp.

Attn: Soonil Nank

1151 Boston-Providence Turnpike

PO Bax 9102

\orwood, 녈 02062

Doug Bellex

Azure Dragon Enterpri,ses, Inc.

22 George Hil1 RA.

Grafton, HA 01519
Professor J. R. Barnett

Worcester Polytechnic Institute

Pire Protection Enginaring

100 Institute Road

Worcester, MA 01609-2280

Professor Matt Kelleher

Chairanan, Bechanical Enc. Dept.

Naval PostGraduate School

Monterrey, cA 93943

Fire science and Technology, Inc.

Attn: Vyto Babrauskas

10900 Bethesda Church Ra.

Demascus, MD 20872

Professor A.F. thoniem

Mechanical Engineering Dept.

Massachusetts Institute of Technology

Room 3-342

77 Massachusetts averuoe

Cambridge, MA 02139

Firerech

Attn: Thomas capaul

- Brian Meachain

P. O. Box 199

CH-8706 FELDMEITEW, SAITZERIAND

Gesellschaft fur Anlagen una Reaktors icherheit (GRS), mbR

Attn: H. Liemersdort

i. Rowekamp

T. Riekert

B. Schwinges

Operational Behaviour Division

schwertnergasse 1

50667 COLOGNE, FEDERAL REPUBLIC OF GEFIANY

Gesellschaft fur Anlagen und

Reaktorsicherhest (GRS), mbH

Attn: Hermann Jahn

Bereich systemanalyse

Forschungsgelande

85748 GARCHING b. MUTCHEM

FEDERAL RETUBLIC OF GERMANY

Battelle-Institut e.V.

Attn: Rarsten Fischer

Lothar Holf

Am RomerhoE 35

D-6000 Prankfurt an Mein 90

FRANRFURT, FEDERAL REPUBEIC OF GERMANY 
Distribution (Concinued) :

CEA IPSN/DRS/SEA

Attr: Roger Rzekiecki

Chef du Groupe Physigue des Feux

DRS/SEA CEN CADARACHE

13108 Saint-Paul-Eez-Durarce

FRANCE

Brandforsk

Aten: Tomeny Arvidsson

S-11587 STOCKHOLF, SWEDEN

Winfrith AEA Technolocy

Atta: Chrís Fry

Heat Transfer Group, Bldg. B30

DORCHESTER, DORSET DT2 \&DH UNITED KIISGDOM

O. Koski-Rahkonen

VTT

Fire Technology Laboratory

Kivimithentie 4

SF-02150 ESPOO, FINEAND

O. Sugawa

center for Fire science \& Technology

Science University of Tokyo

2641 Yambaki

NODA-SHI , 278

JAPAW

\section{A. Strong}

University of thaterloo

Dept. of Mechanical Engineering

Wacerloo, ONTARIO CANADA N2L-3GI

K. Muller

Kernforschungszentrum Karl sruhe

HDR Sicherheitsprogxanmu

PO BOX 3640

76021 KARLSRUHE, GERHANY

Petra Buccner

IGTS, $\mathrm{mbH}$

thaldowallee 117

10318 BERLIN, GERMBRY

Artn: C. Lebeda

u. Sehneider

Tech. Universite Wien

Inst. fur Baustofflehre und Bauphysik

Karlsplacz $13 / 206$

1040 WIEN, AUSTRIA
Bjorn Hekkelstrand

SINTEF/NTH

Division Thermodymamics

N-7034 TRONDHEIM, NORWAY

Lopez Marie-claude

Institut de Protection et de surete Nucleaire

Centre d'Etudes Mucieaires (CEN/G)

GRENOBLE. FRAHCE

Internal SNL:

no, $\mathrm{HS}$ NAmge

10841 P.J. Homert, 1500

10828 P.J. Hommert (actg.). 1502 (route to 1511)

I $0441 \mathrm{~J}, \mathrm{f}, \mathrm{Biff1e}, 1503$ iroute to 1517,1518 )

10828 E.D. Gorham, 1504 iroute co 1514, 1515;

10834 A.C. Raczel, 1512 prouce to 1516)

10835 R.D. Skocypec, 1513

1 O835 E.A. Boucheron, 1513

$1 \quad 1513$ L.A. Gritzo, 1513

2 0835 V.F. Nicolette, 1313

10835 S.R. THeszen, 1513

10025 A.R. Lopez, 1515

$10825 \mathrm{C} . \mathrm{C}$. Wong, 1515

$1 \quad 1135 \mathrm{~J} . \mathrm{E}$. MoYa, 2735

$10739 \mathrm{~J} . \mathrm{T} 311 \mathrm{~s}, 6429$

10737 M.P. Bohn, 6449

is 0737 S.P. Notwlen, 6449

19018 central Technical Files, 8523-2

50899 Technical Library, 13414

l 0619 Print Medit. 12615 


\begin{tabular}{|c|c|}
\hline 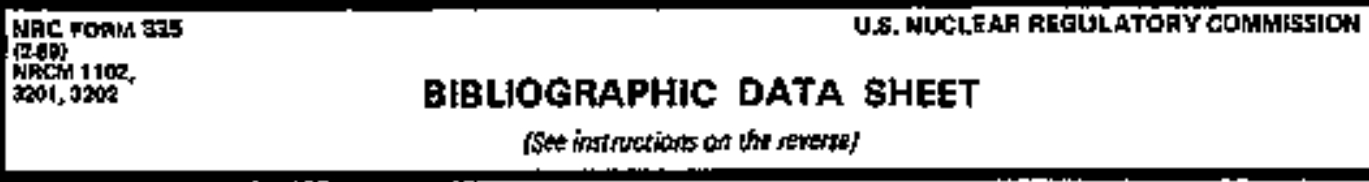 & $\begin{array}{l}\text { 1. REPDT ACMEER } \\
\text { RUREG/CR-6017 } \\
\text { SAHD93-0528 }\end{array}$ \\
\hline \multirow{4}{*}{$\begin{array}{l}\text { 2. TITLE AND StBTITLE } \\
\text { Pice Modeling of the Heiss Dampf Reaktor Contaimment }\end{array}$} & \multirow{2}{*}{$\begin{array}{l}\text { SAHD93-0S28 } \\
\text { DATE REPORT PUGUSHED }\end{array}$} \\
\hline & \\
\hline & \begin{tabular}{|c|c|c|} 
HONTH & reAR \\
Septenber & 1995 \\
\end{tabular} \\
\hline & $\begin{array}{l}\text { 4. FIN OA GRANT MUMBER } \\
\text { L13.30 }\end{array}$ \\
\hline V. F. Nicolette, Sandia National Laboratories & $\begin{array}{l}\text { Q.TYPE OF ALPORT } \\
\text { Techäic\&l }\end{array}$ \\
\hline K. T. Yang, Jniversity of Rotre Dame & 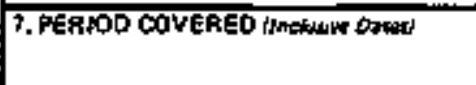 \\
\hline 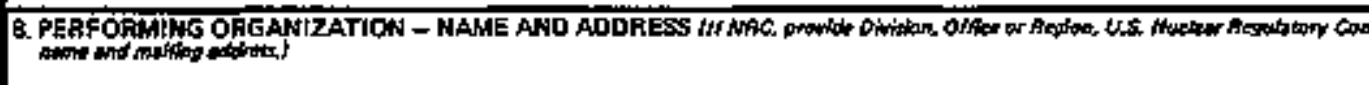 & 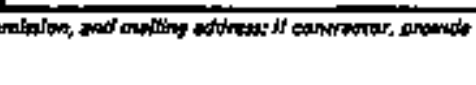 \\
\hline $\begin{array}{ll}\text { Sandia National Labozatories } & \text { Hotre Dame University } \\
\text { Albuquerque, NM } 87185-0835 & \text { Notre Dame, IN } 46556\end{array}$ & 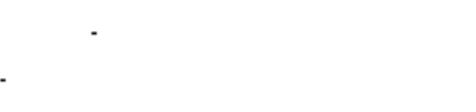 \\
\hline 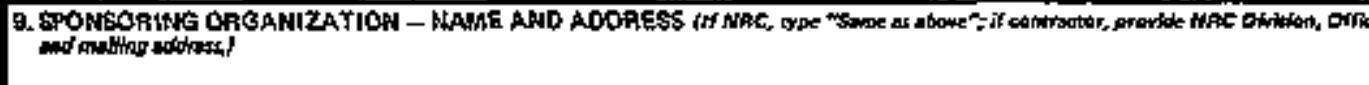 & 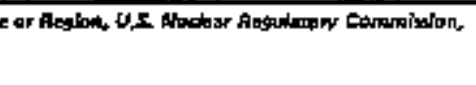 \\
\hline $\begin{array}{l}\text { Division of Engineering Technology } \\
\text { office of Muclear Regulatary Research } \\
\text { U.s. Nuclear Reguletory Comission } \\
\text { Washington, DC } 20555-0001\end{array}$ & 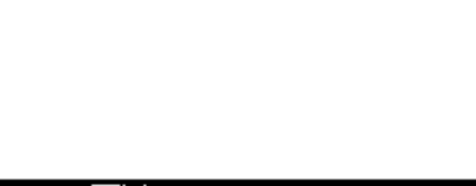 \\
\hline $\begin{array}{l}\text { 10. SUPPLENENTARY NOTES } \\
\text { N. Gleaves, NRC Project Hanager }\end{array}$ & \\
\hline 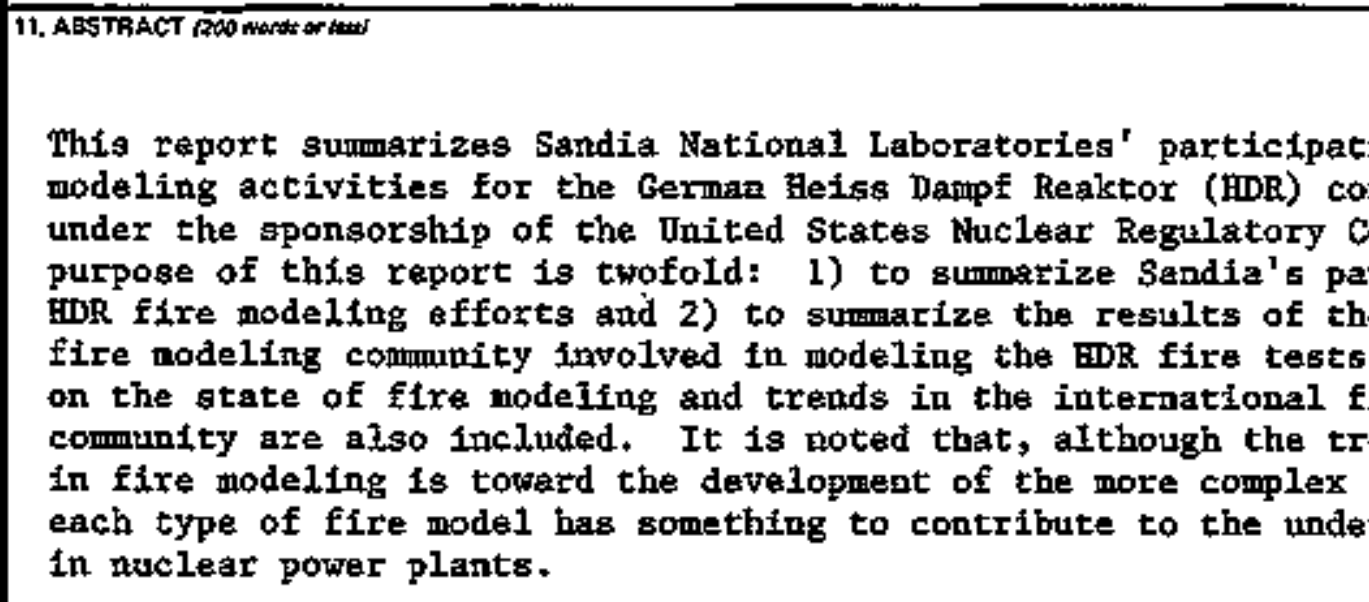 & $\begin{array}{l}\text { Ion in the fire } \\
\text { atainment building, } \\
\text { onntssion. The } \\
\text { rticipation in the } \\
\text { international } \\
\text { Additional copments } \\
\text { ire modeling } \\
\text { end internationa,lly } \\
\text { fire fleld models, } \\
\text { rstanding of fires }\end{array}$ \\
\hline 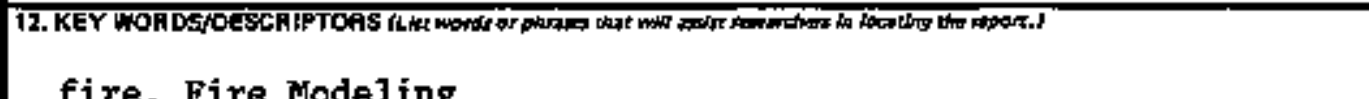 & 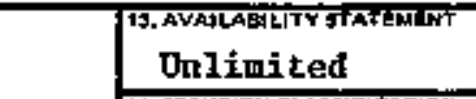 \\
\hline fire, Fire Modeling & 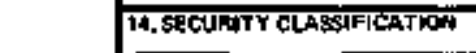 \\
\hline & 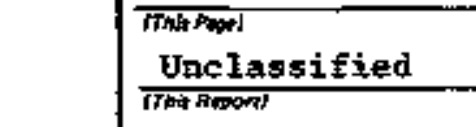 \\
\hline & Unclassified \\
\hline & 1B. PRICE \\
\hline
\end{tabular}




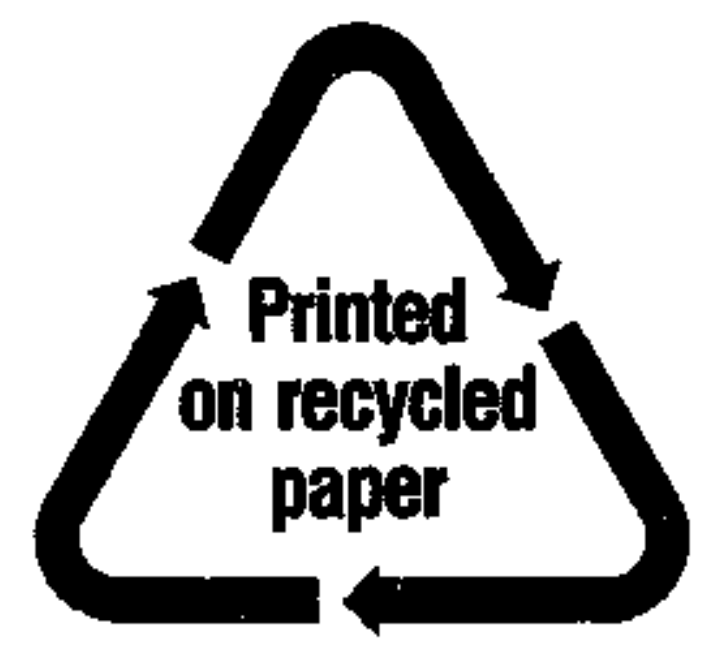

Federal Recycling Program 